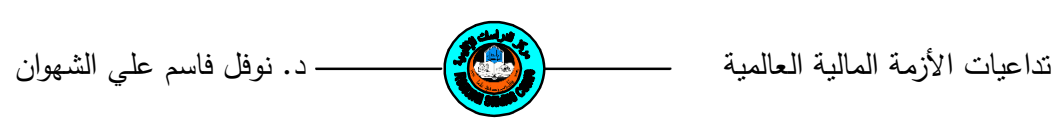

$$
\text { تداعيات الأزمة المالية العالمية ^ . . . ع على الاقتصادات العربية }
$$

$$
\text { الاكتور نوفل قاسم علي الثهوان }
$$

مدرس، قسم الدراسات الاقتصادية/ مركز الدراسات الإقليمية/ جامعة الموصل - العراق

$$
\text { مستخلص البحث }
$$

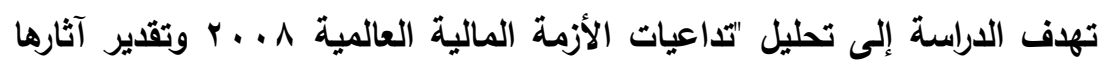

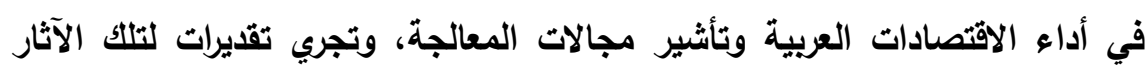

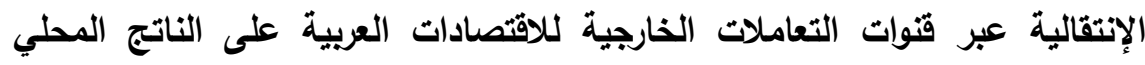

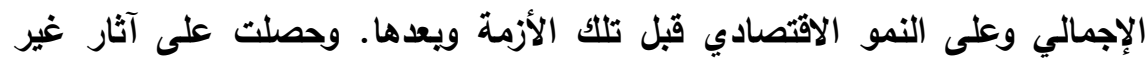

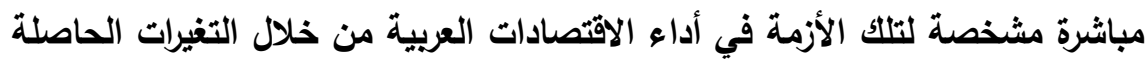

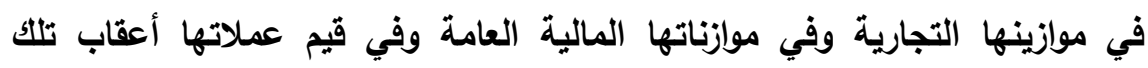

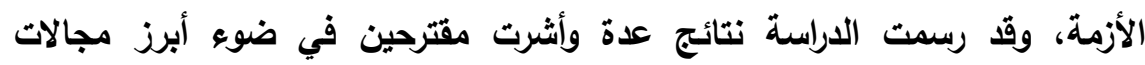

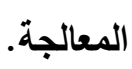
كلمات مفتاحية: الأزمة المالية العالمية، الأداء الاقتصادي، الإقتصادات العربية، العلاقات النجارية الخارجية مقدمة

هناك مدى منطقي لقيم أسعار الفائدة ينبغي أن تعمل بـه أسواق الإتنمان

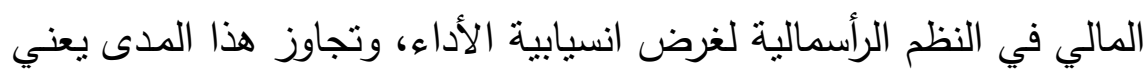

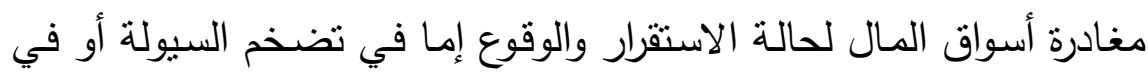

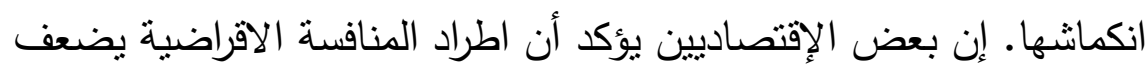

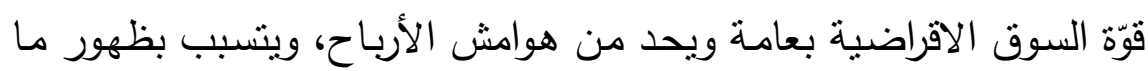

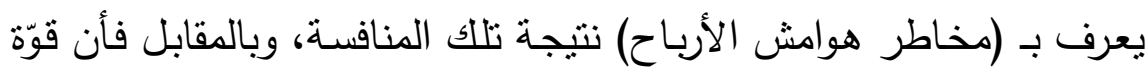


السوق الاقراضية الأكبر تفضي إلى مخاطر إئتمان أعظم لأن أسعار الفائدة

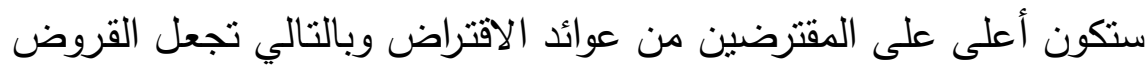

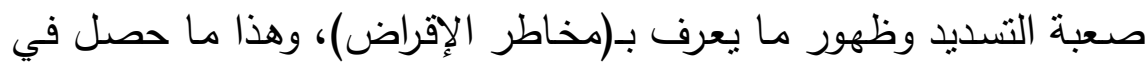

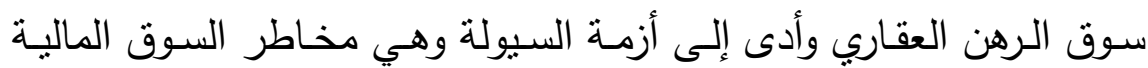
بكاملها (').

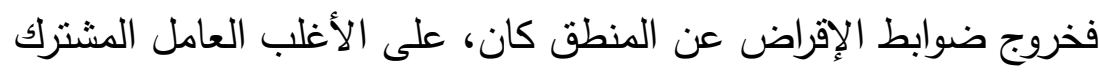

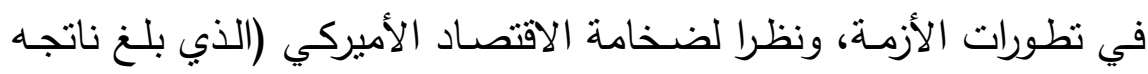

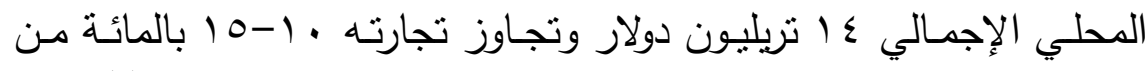

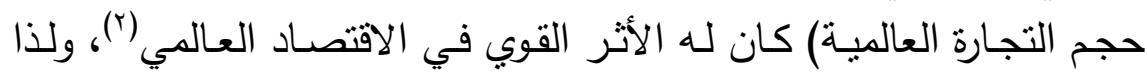

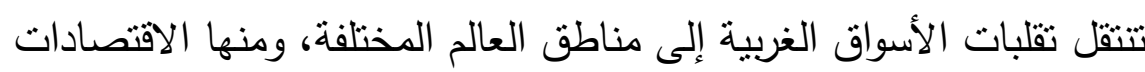
العربية وتمتن لنوئث في أدائها وفي التتمية الاقتصادية التانية.

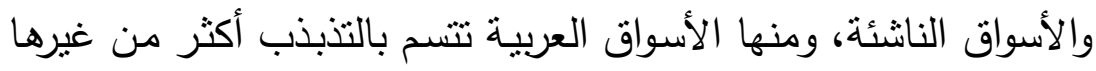

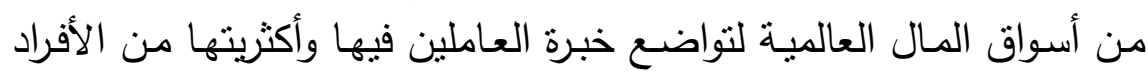

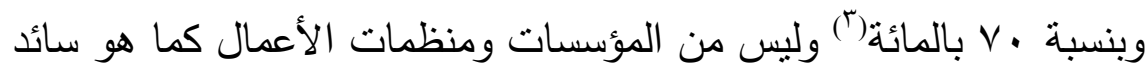

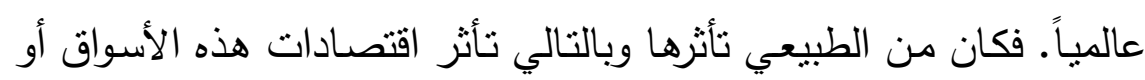

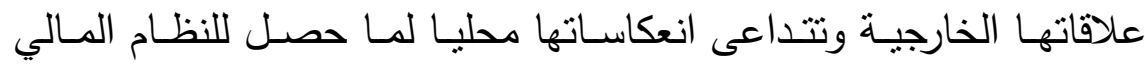

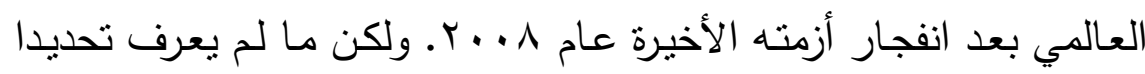

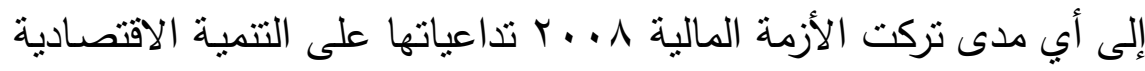

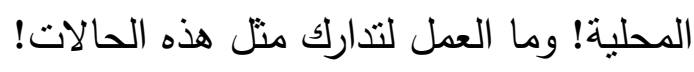

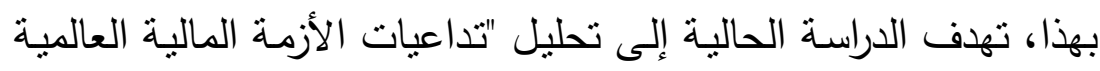

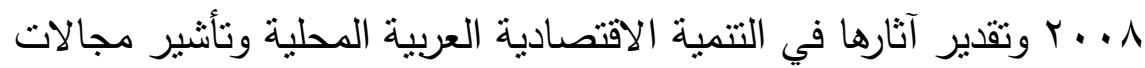

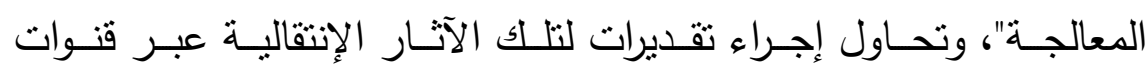

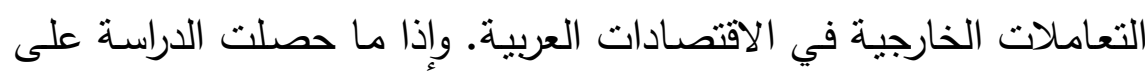

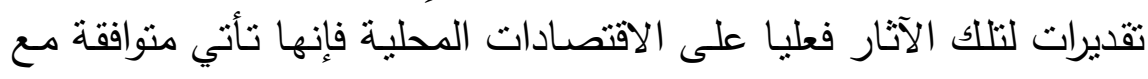




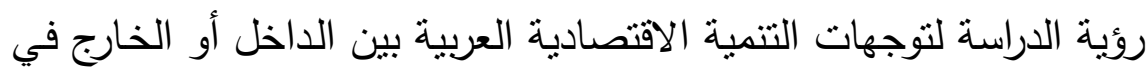
ظل التغيرات الدولية في السنوات الحالية من الألفية الجديدة.

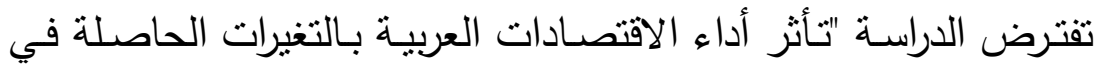

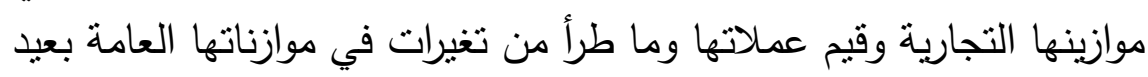

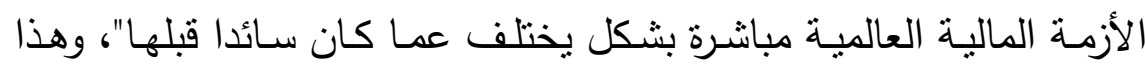

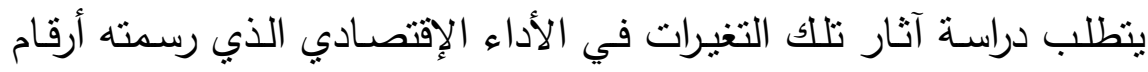

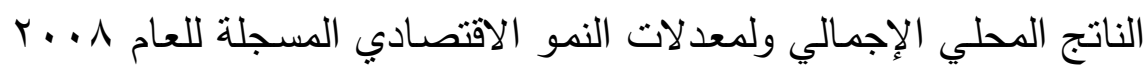

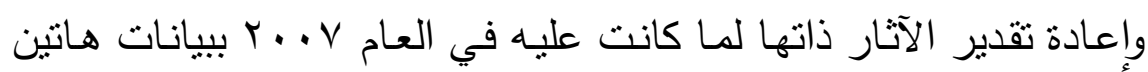
السنتين.

وعلـى افتـراض أن مـا حاصـل لـتخيـرات العلاقـات التجاريـة الخارجيـة

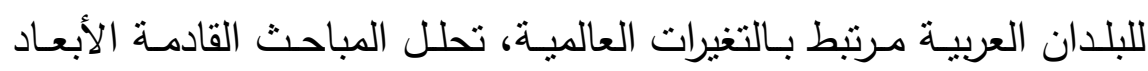

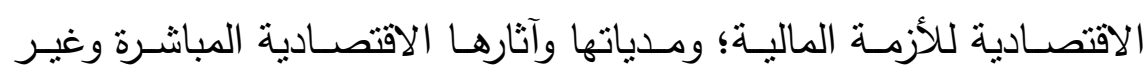

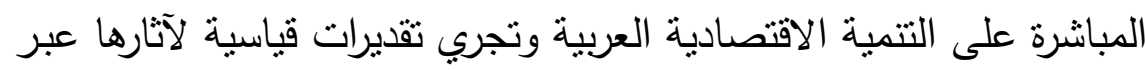

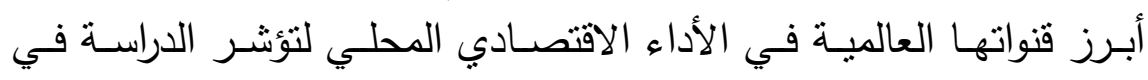

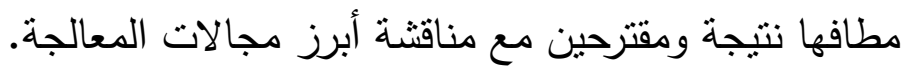

\section{1 الأبعاد الاقتصادية للأزمة المالية العالمية}

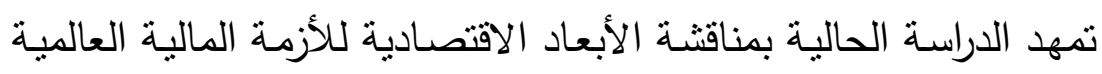

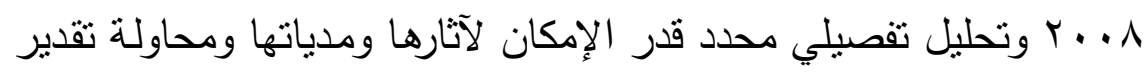

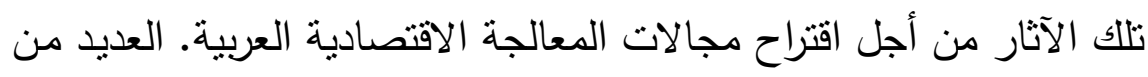

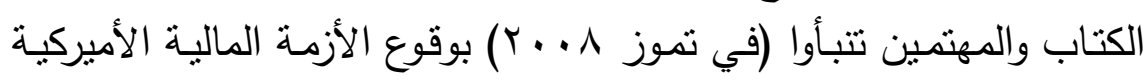

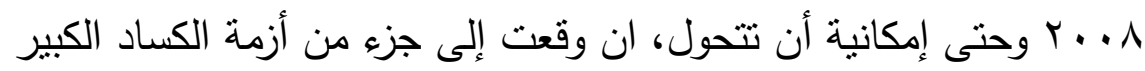

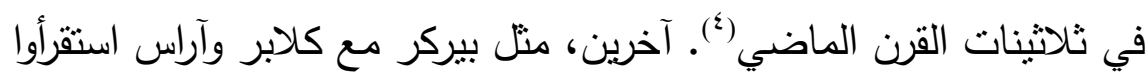

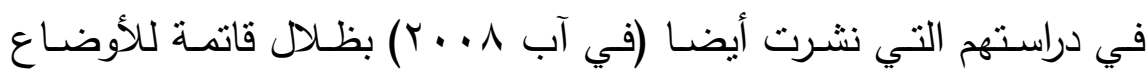




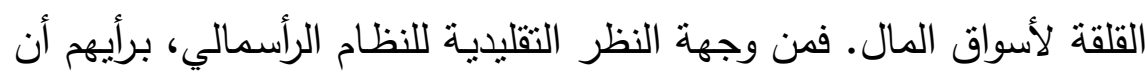

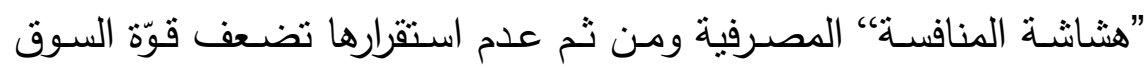

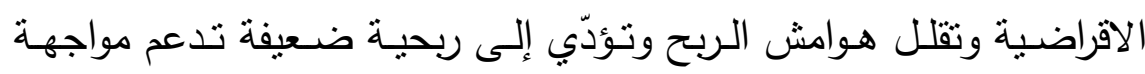

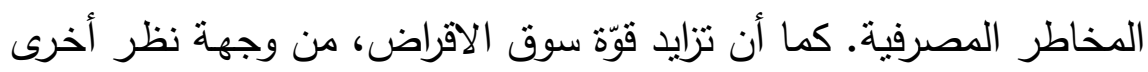

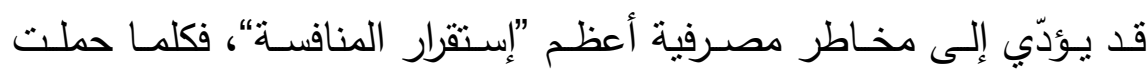
أسعار الفائدة أكثر على المقترضين جعلت تسديد القروض صعبد الفيا وهذا يثير مخاطر أخلاقية ومشاكل إختيار مضادّة(1).

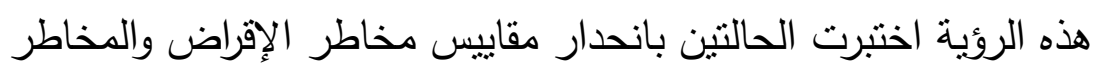

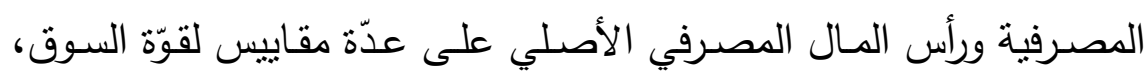

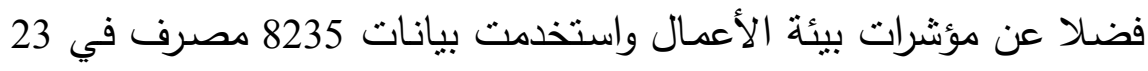

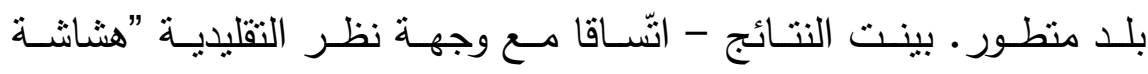

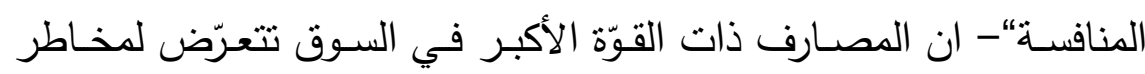

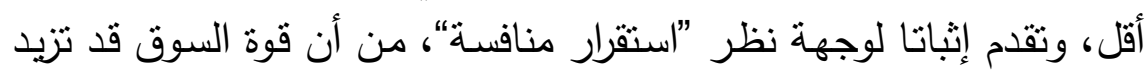

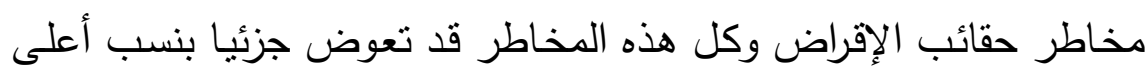

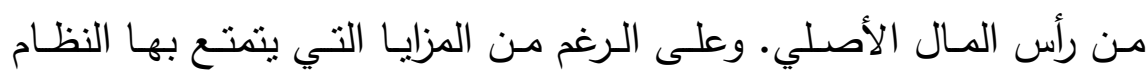

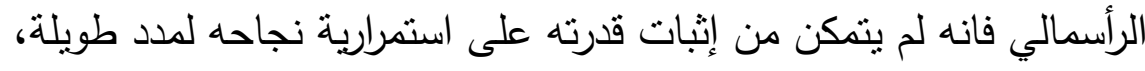

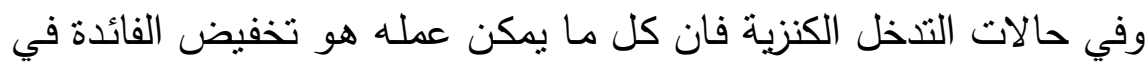

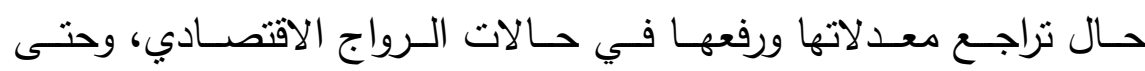

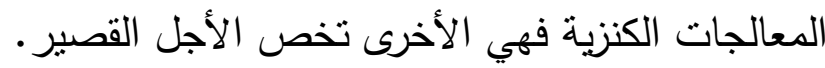

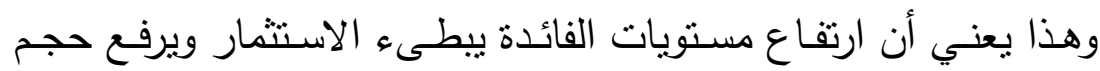

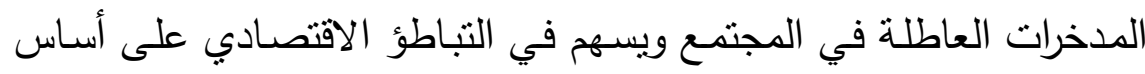

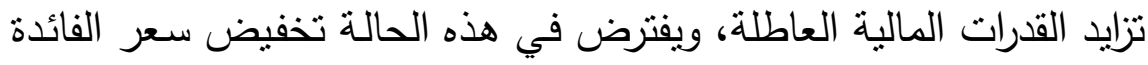

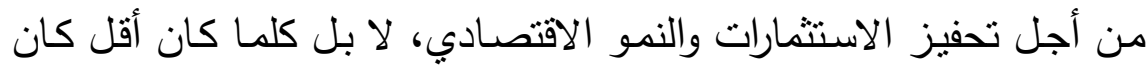




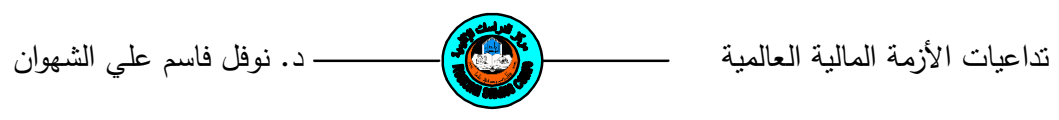

أكثر تحفيزا للنمو (*). ولكن تخفيض سعر الفائدة بصب في تخفيض الأسعار

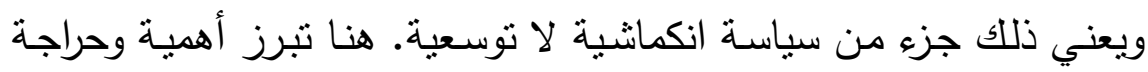

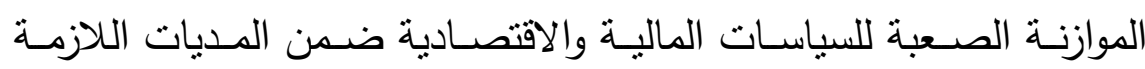
لاستمرار النمو الاقتصادي للنظام الرأسمالي. للانيان.

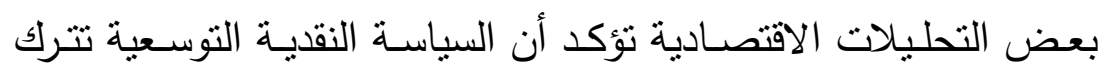

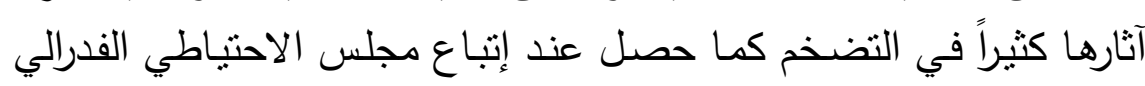

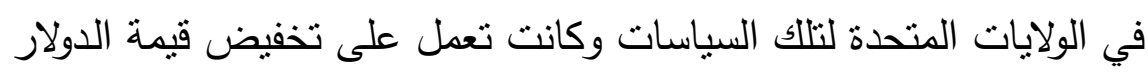

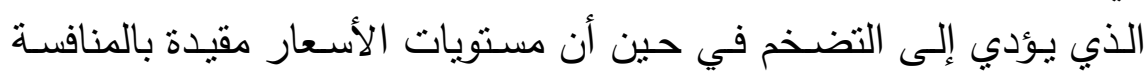
الخارجية(؟). ومنذ عقد النسعينات الماضي تكررت الأزمات المالية لأسواق المضاربة

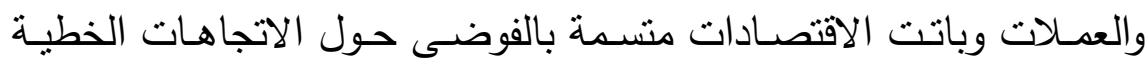

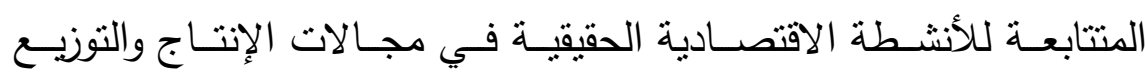

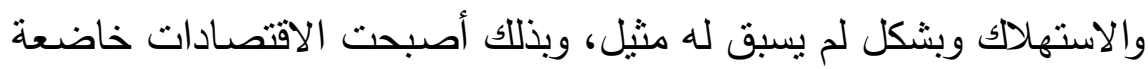

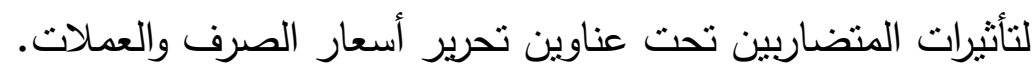

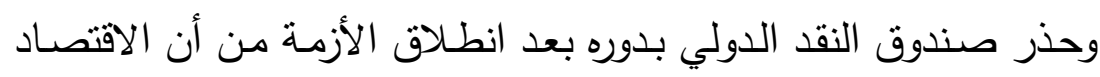

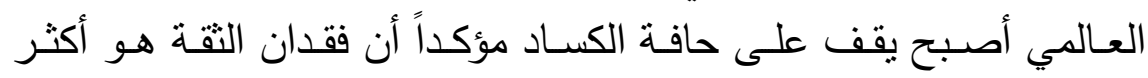

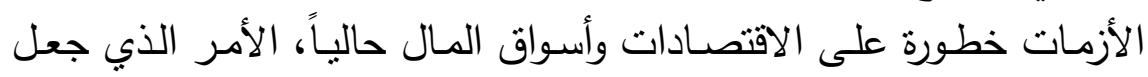

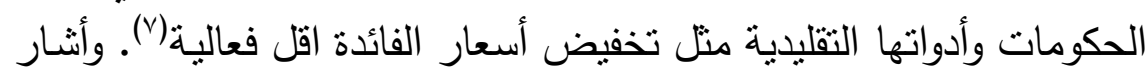

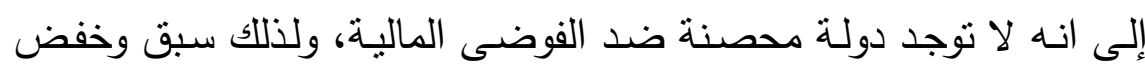

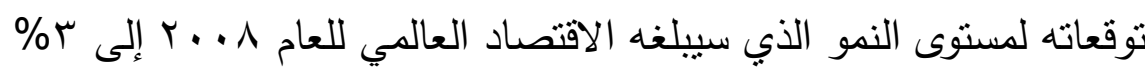

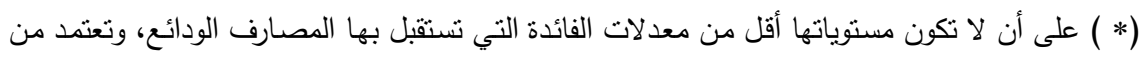

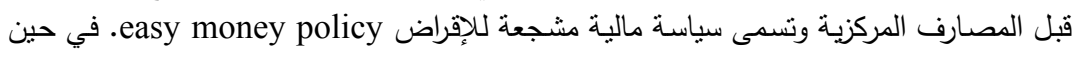

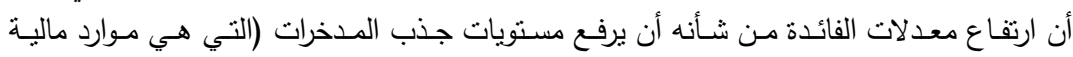




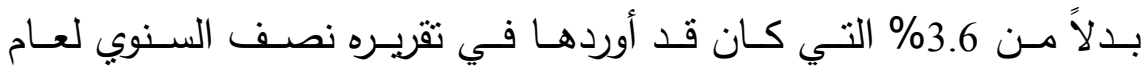
(^) r...

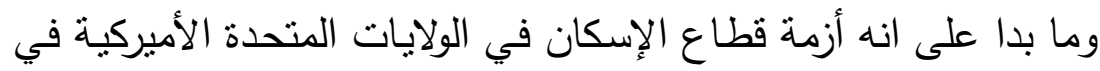

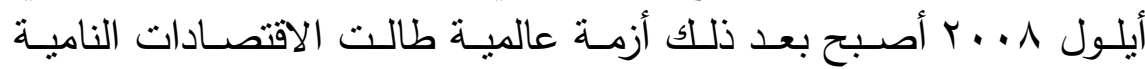

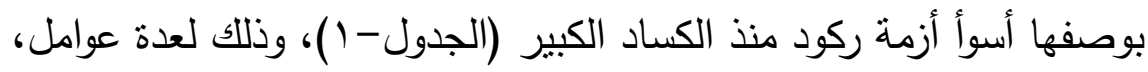

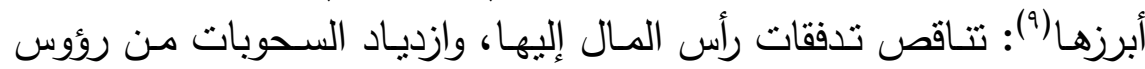

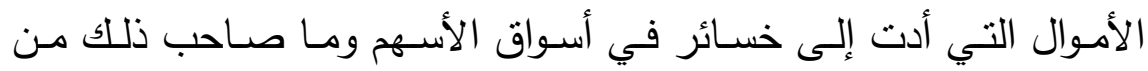

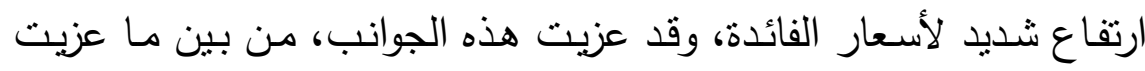

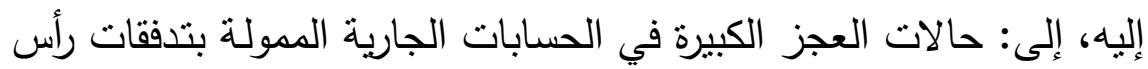

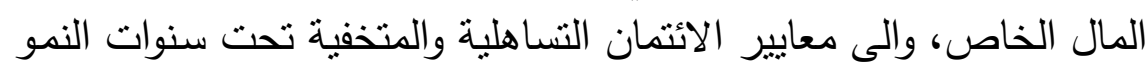

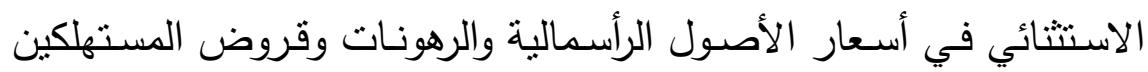

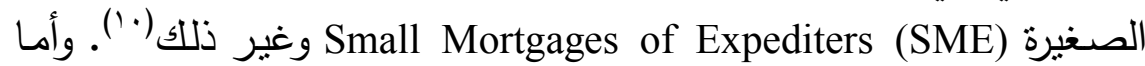
آثارها فتشير إلى ضعف معدلات النمو واقترانها بالأزمة المالية وهنا بعني انخفاض المبالغ المالية التي ستتوافر للحكومات لاستشمارها في التعليم وفي لاتي

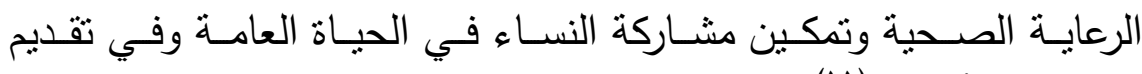

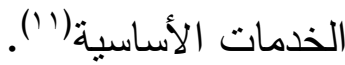

الجدول - 1: معدلات النمو في الناتج المحلي الإجمالي الحقيقي في مناطق العالم النامية

(تغيرات بشكل نسبة مئوية عن السنة السابقة)

\begin{tabular}{|c|c|c|c|}
\hline$\%$ & 2009 & 2008 & المناطق النامية \\
\hline 114 & 2.1 & 4.5 & أمريكا اللاتينية والبحر الكاريبي \\
\hline 71 & 3.5 & 6.0 & أوروبا وآسيا الوسطى \\
\hline 63 & 3.5 & 5.7 & جنوب آسيا \\
\hline 31 & 6.7 & 8.8 & شرق آسيا والمحيط الهادي \\
\hline 17 & 4.6 & 5.4 & الثرق الأوسط وشمال أفريقيا \\
\hline
\end{tabular}

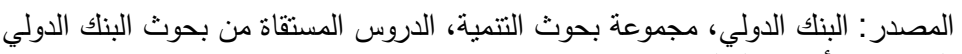

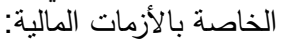

http://econ.worldbang.org/external/default/main?pagepk=6H/65259 


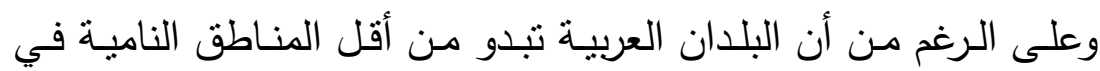

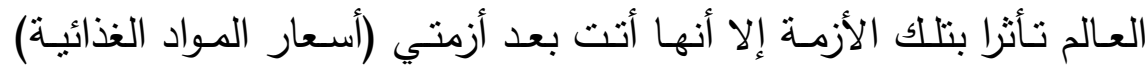
والمحروقات ومن شانها إلحاق الضرر الكبير بالفقراء في المنطقة العربية.

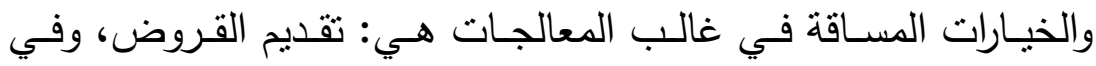

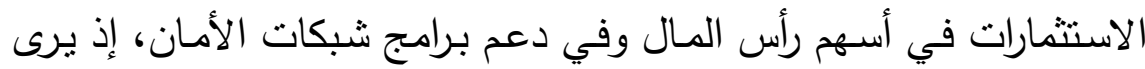

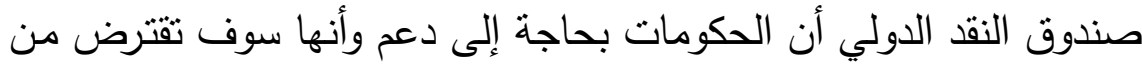

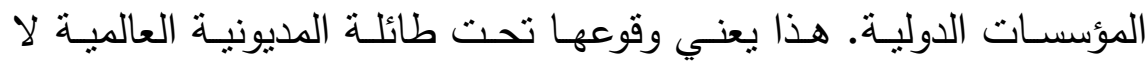

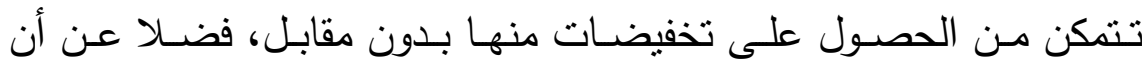
الإقراض لا يخلو من برامج مكلفة بحد ذاتها. ولكن ما تتبناه الدراسة الحالية

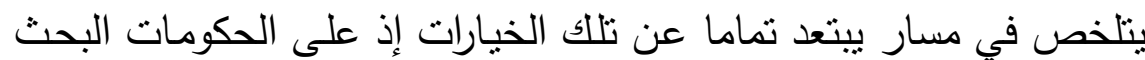

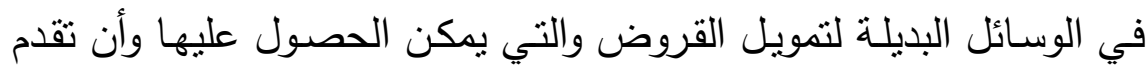
بدون فوائد (أسعار فائدة صفرية \%) الأكثر إنعاشـا للنمو ويثوافق في الوقت التئ

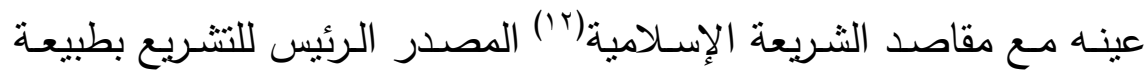

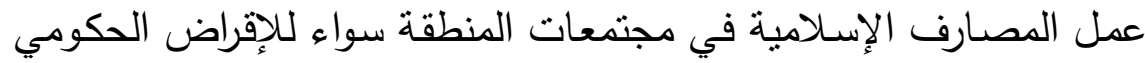

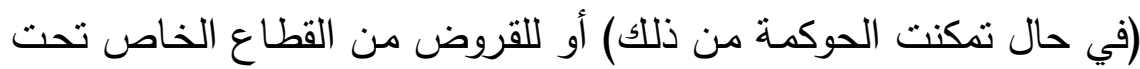

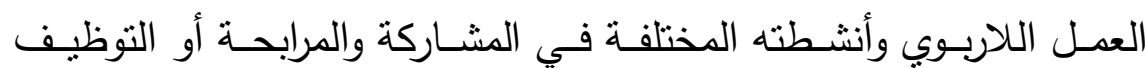
والاستثمار أو غير ذلك.

\section{r. مديات الآثار الاقتصادية للأزمة المالية}

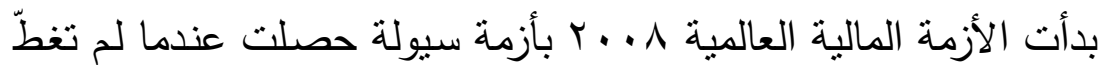

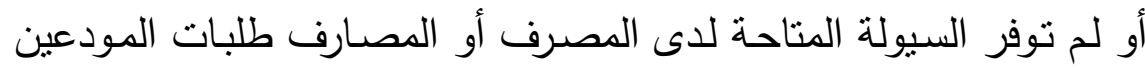

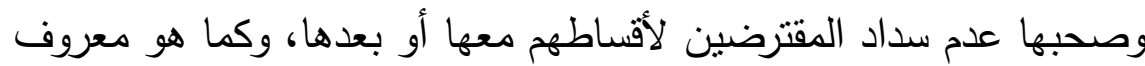

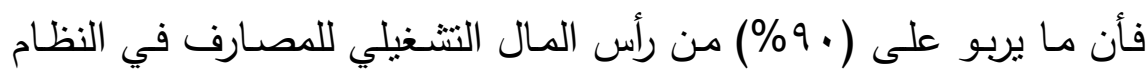


الرأسمالي هي أموال وأمانات للناس المودعين، بينما قد لا يزيد رأس المال

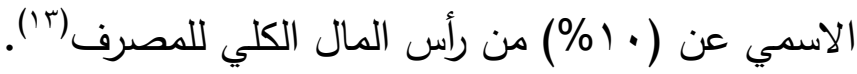

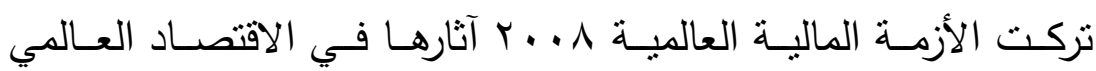

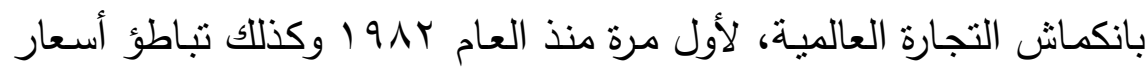

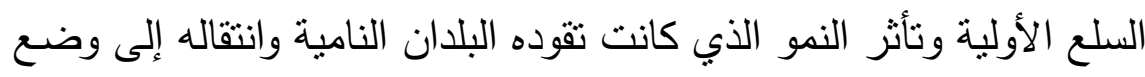

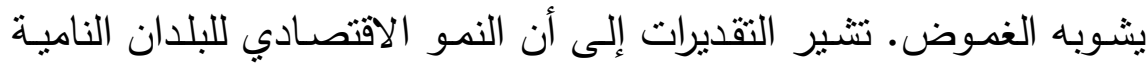

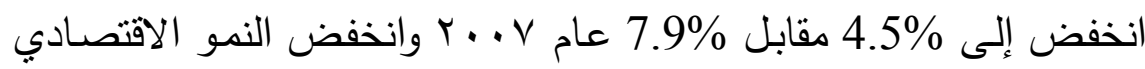

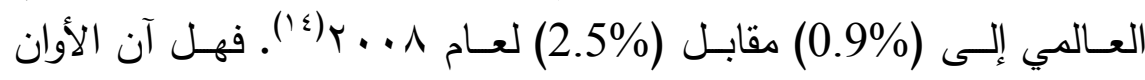

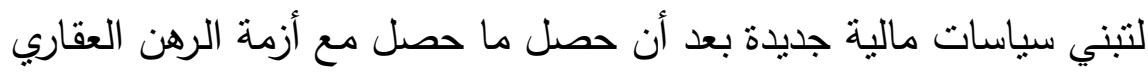

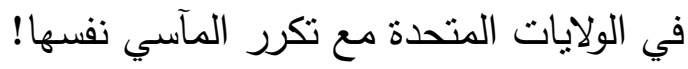

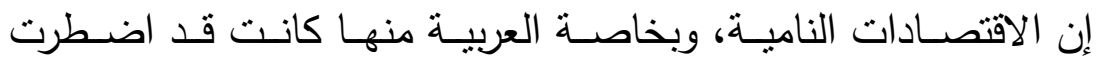

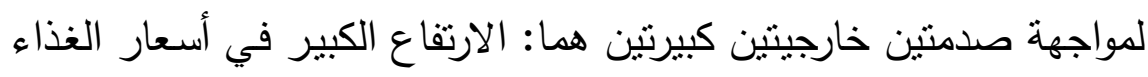

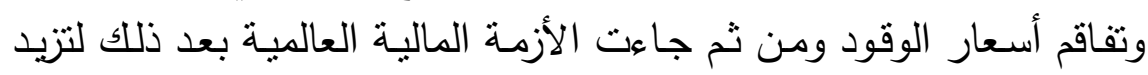

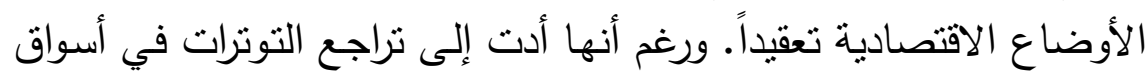

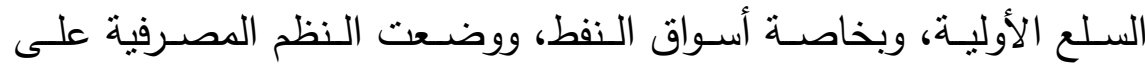

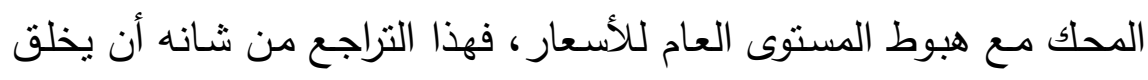

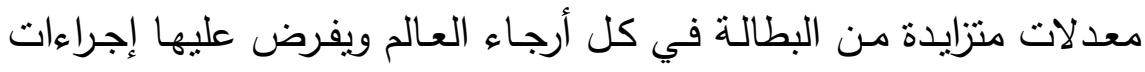

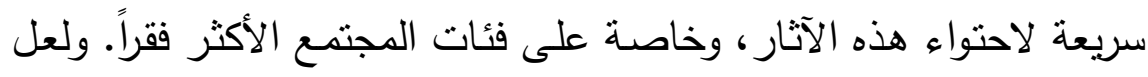

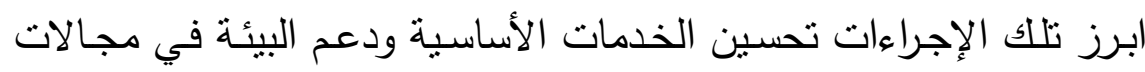

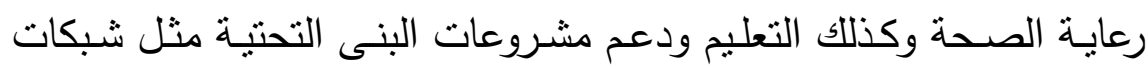

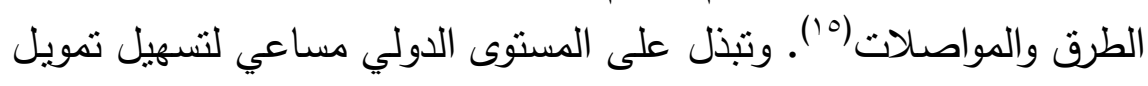

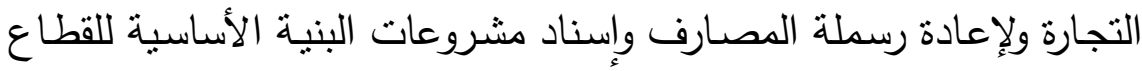
الخاص التي تواجه صعوبات مالية(' آن. 


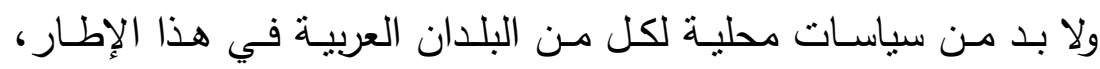

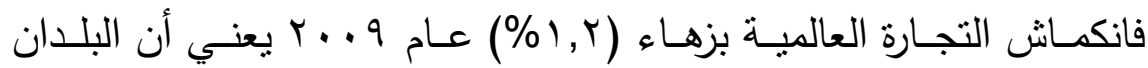

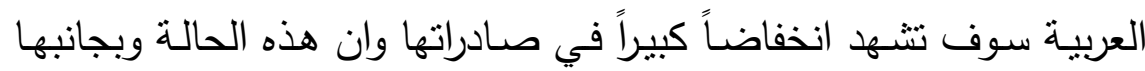

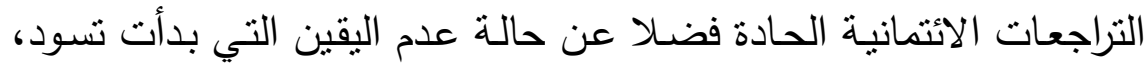

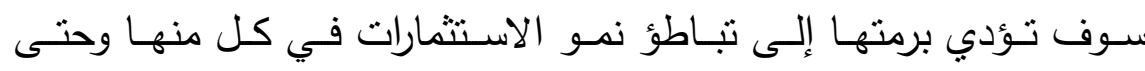

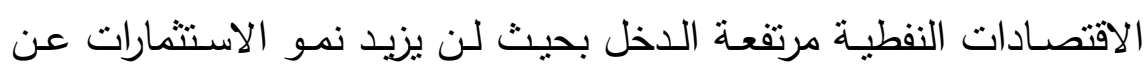

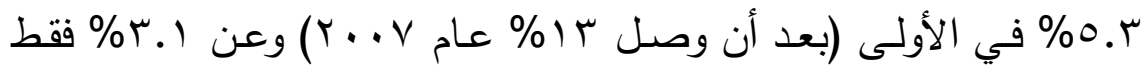
في الثانية.

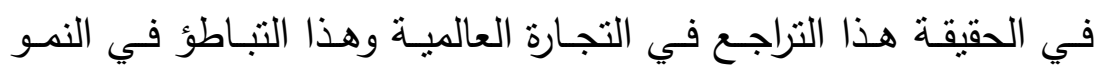

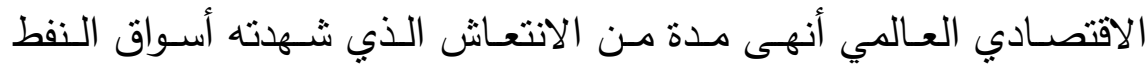

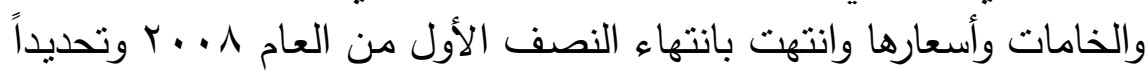

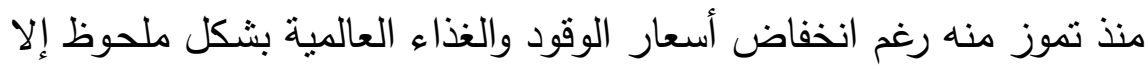

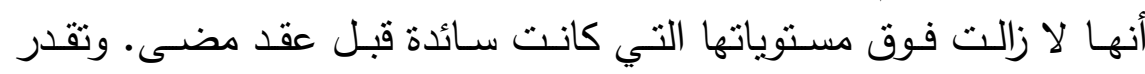

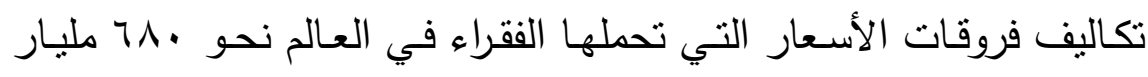

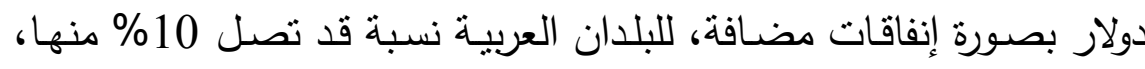

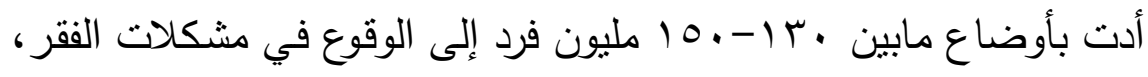

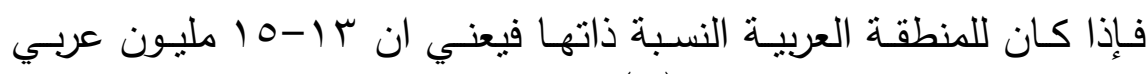

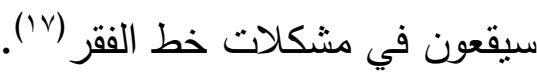
وكان من المتوقع في بداية العام 9 . . ب أن يرتفع سعر النفط في نهايته

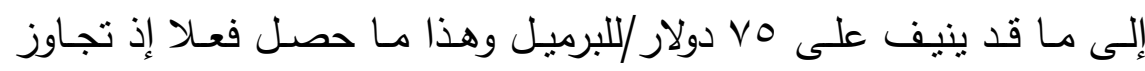

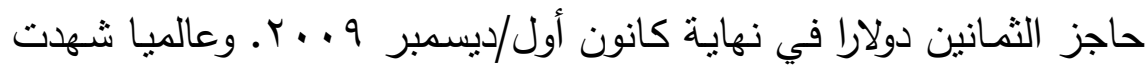

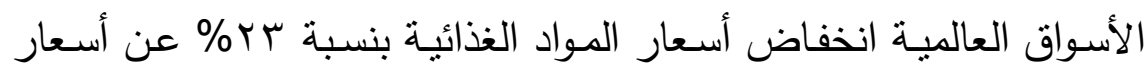

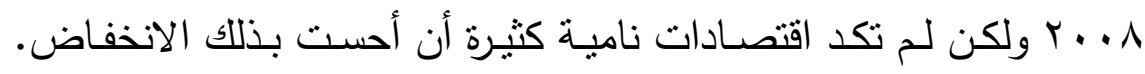

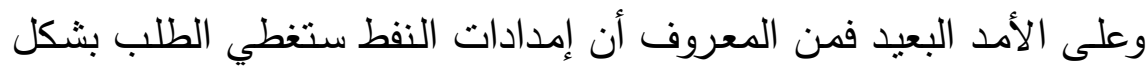

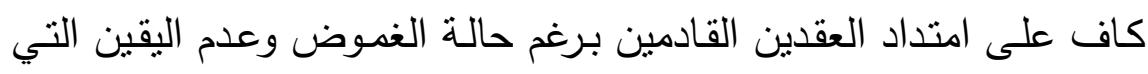




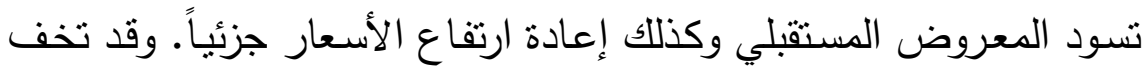

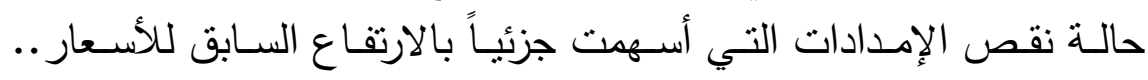

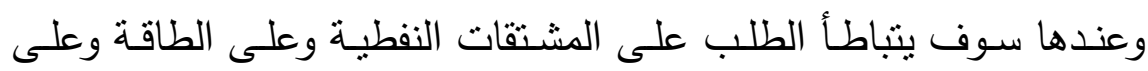

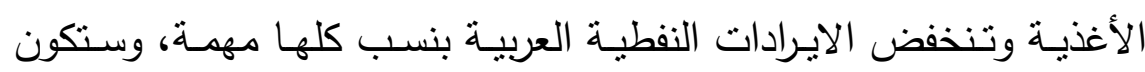
متفاوتة في ظل التراجع المرتقب في نمو الاستثمارات.

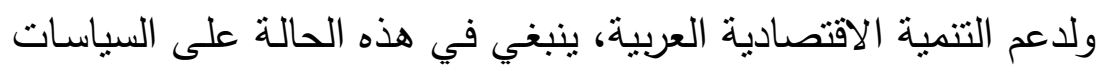

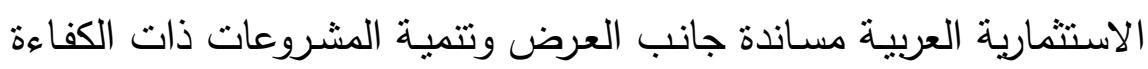

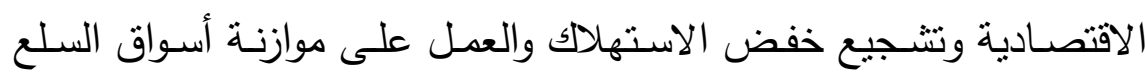

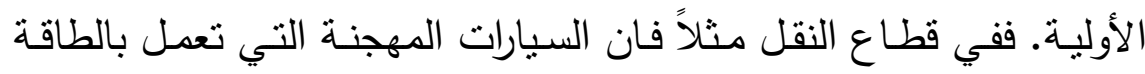

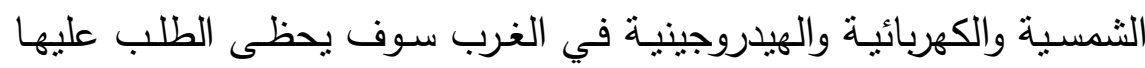

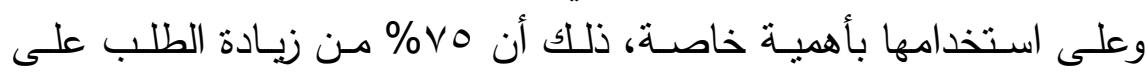

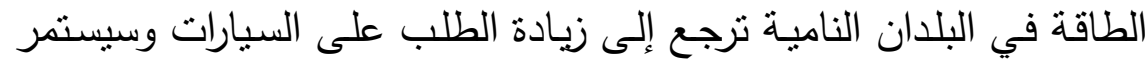

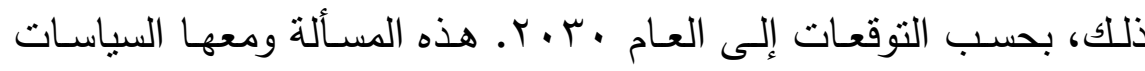

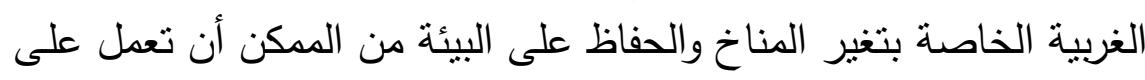
الحد من الطلب على المشتقات النفطية.

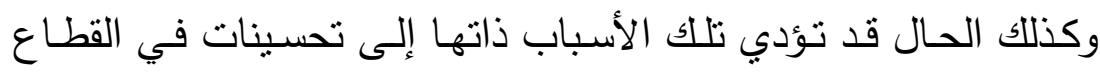

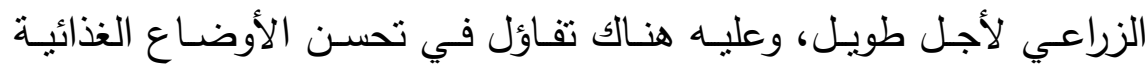

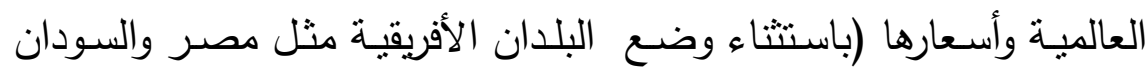

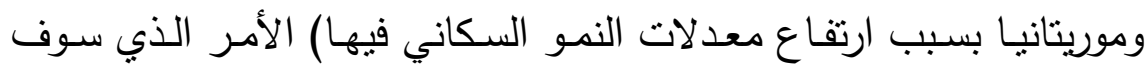

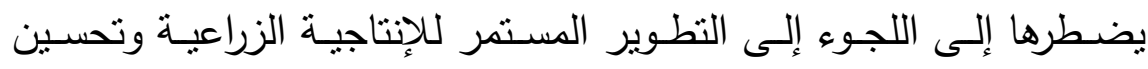

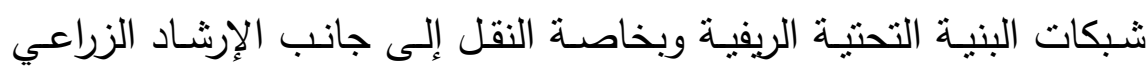

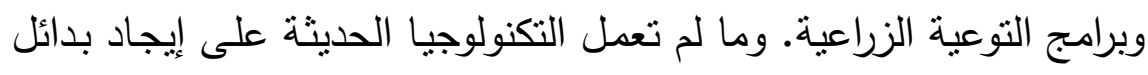

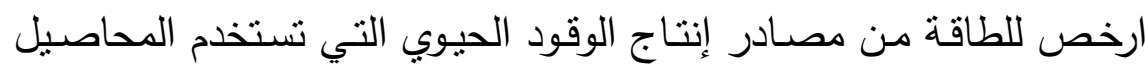

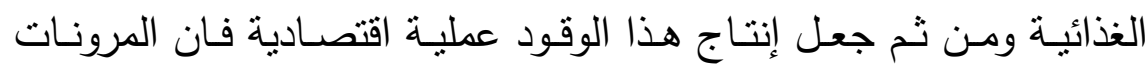


المرتفعـة لأسـعار الأغذيـة بالنسـبة لأسـعار الـفط يتوقـع لهـا أن تشـتر

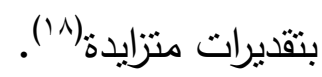

وصادرات النفط والسلع الأولية من شانها أن تشجع النمو الاقتصادي إذا إلـا

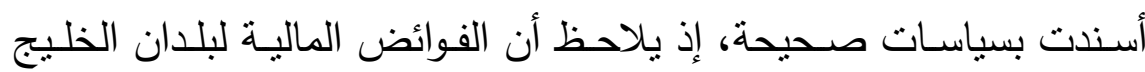

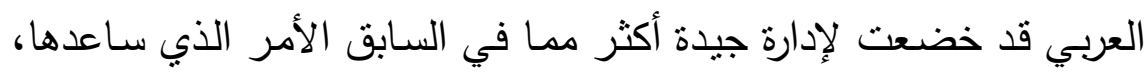

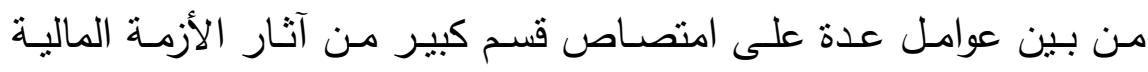

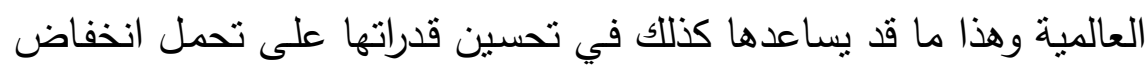

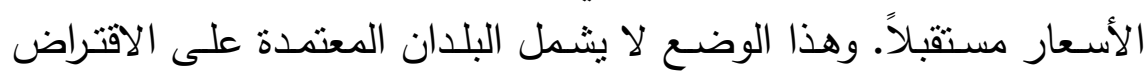

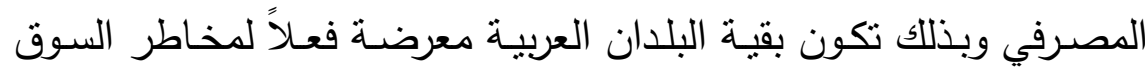

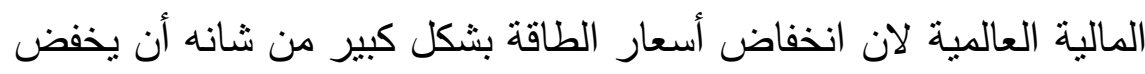

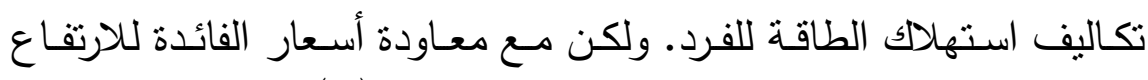

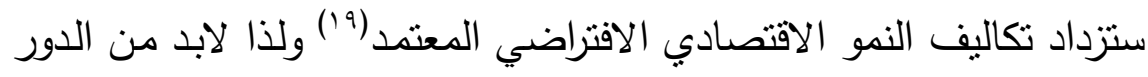

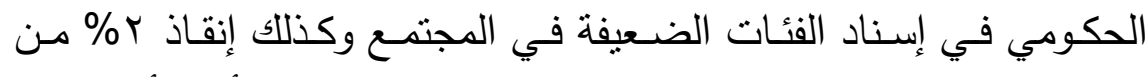

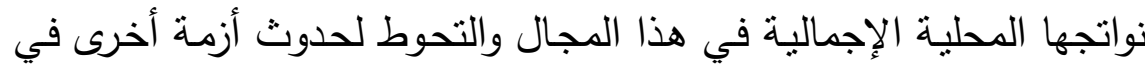

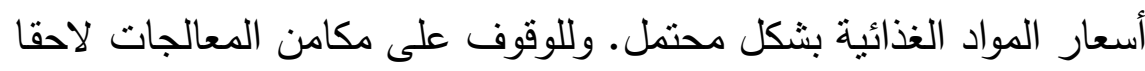

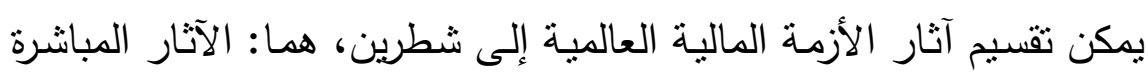

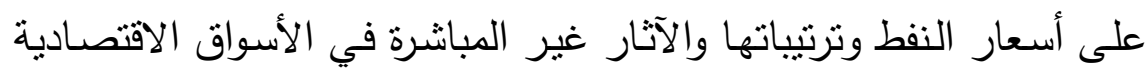

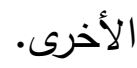

أولاً: الآثار المباشرة للازمة:

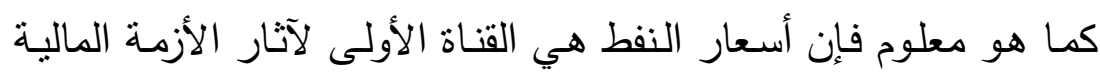

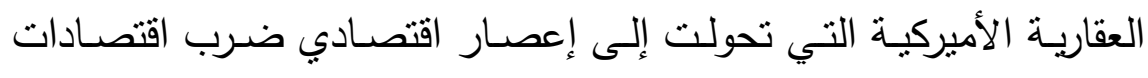

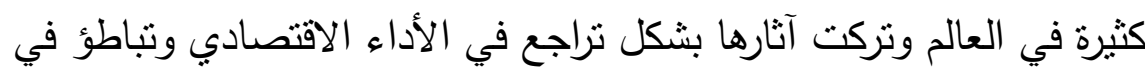

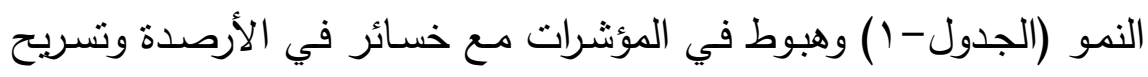


لآلاف العاملين وهبوط في الدخل الحقيقي الإجمالي والفردي. نتزايد تلك

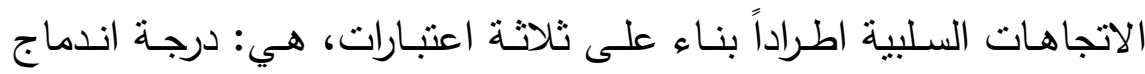

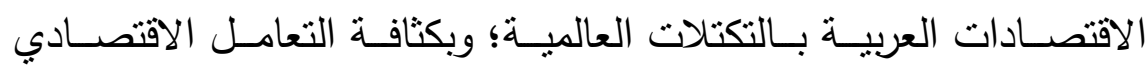

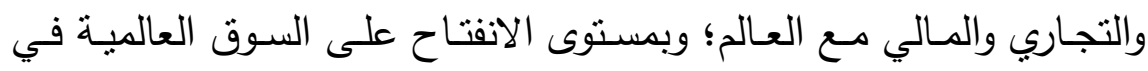

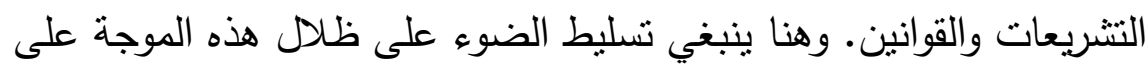
اقتصادات المنطقة العربية وكيفية تباين تأثثراتها المحتملة.

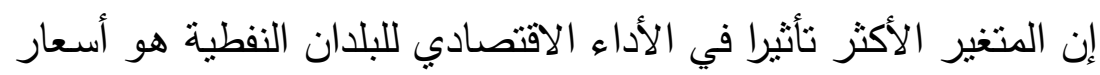

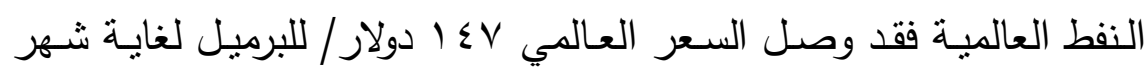

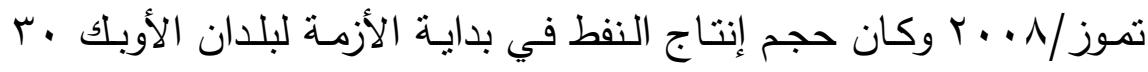
مليون برميـل/بـاليوم منهـا بr مليـون برميـل عربـي تـدر أكثر مـن ثلاتثة

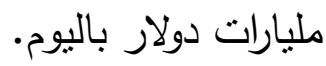
يستدل من ذللك أن هذه الأرقام كانت تسجل متوسط نصبي للفرد العربي

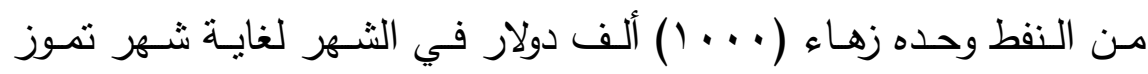

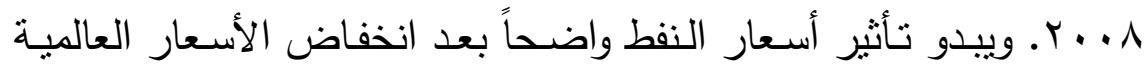

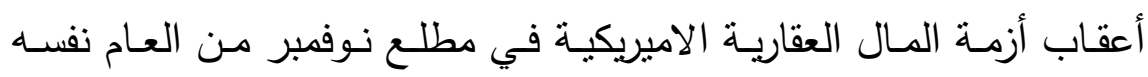

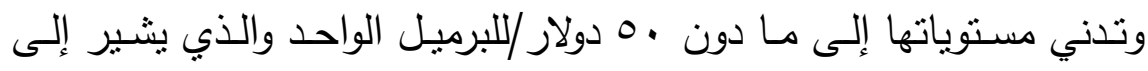
انخفاض متوسط نصيب الفرد الواحد من سكان أوبك من النفط ثلث مستواه السابق.

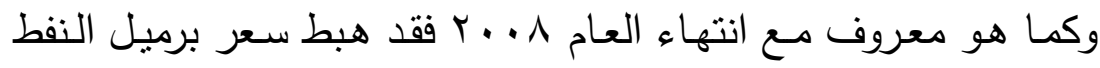

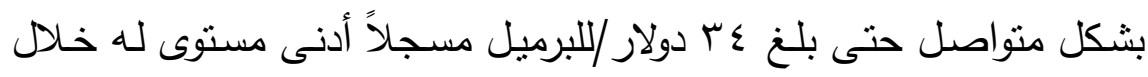

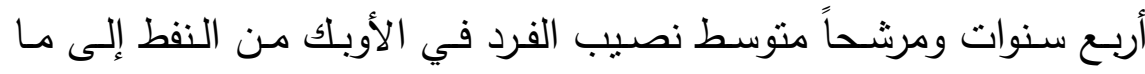

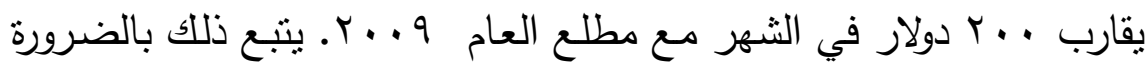
تخفيض الإنفـاق الحكـومي بجانبيـهـ الاسـتهلاكي والاسـتشماري، المحركـان الرئيسان للإنفاق الكلي (ومعهما إنفاق القطاع الخاص المتدني والاستثمار 
الأجنبي المحدود) وما يترتب على ذلك من إعادة النظر بالميزانية المالية إجمالاً.

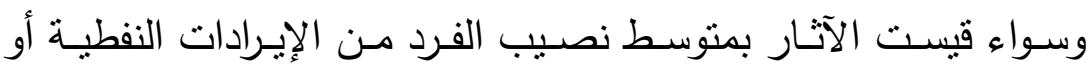

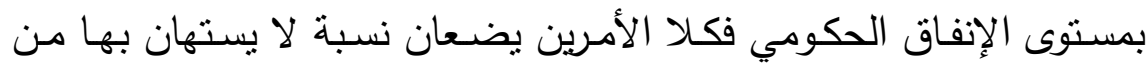

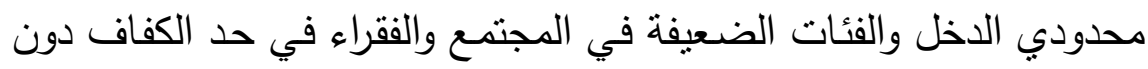

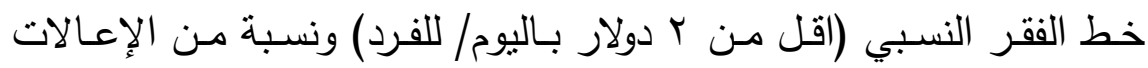

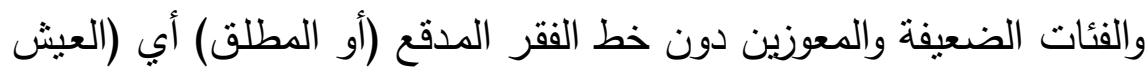

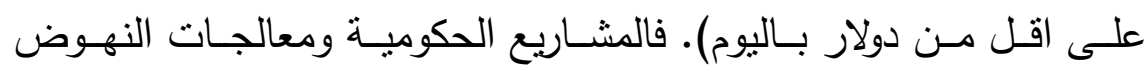

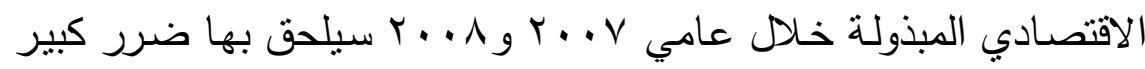

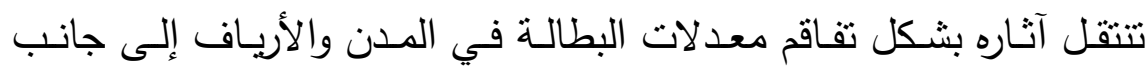
تخفيض محتمل للنفقات التثغيلية الجارية للاولة.

ثانياً: الآثار غير المباثرة: بعض الاتجاهات والمتغيرات المصاحبة

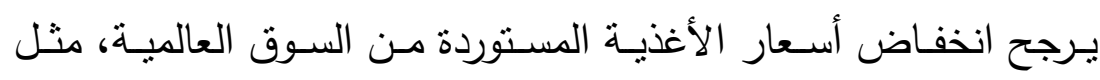

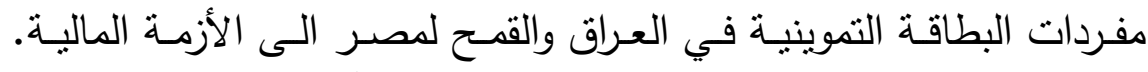

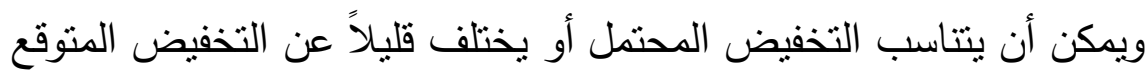

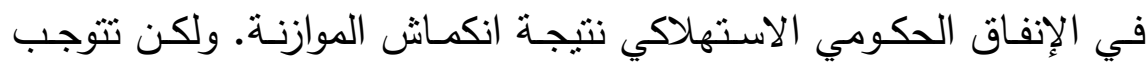

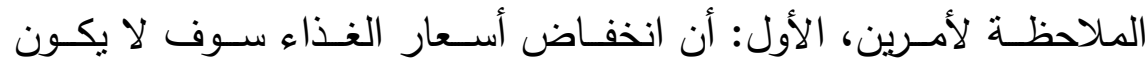

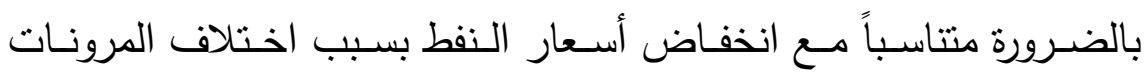

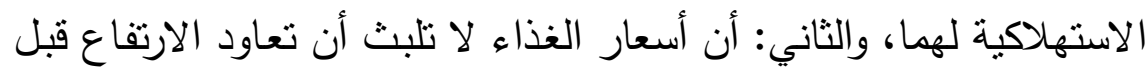

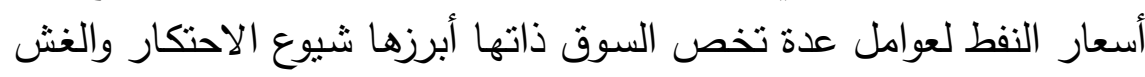
فيها بشكل كبير .

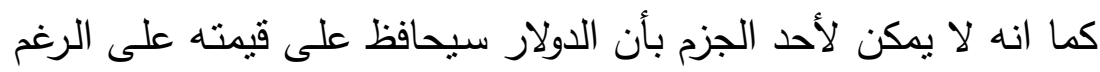

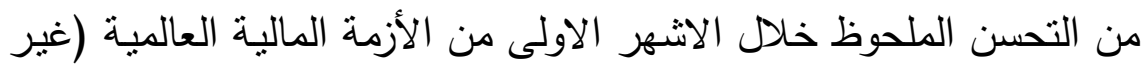


المصاحب لها بالضرورة) ويمكن أن يترك آثارا ايجابية على الاقتصادات

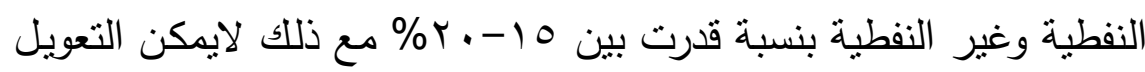

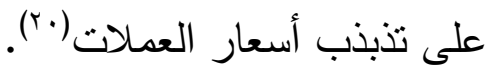

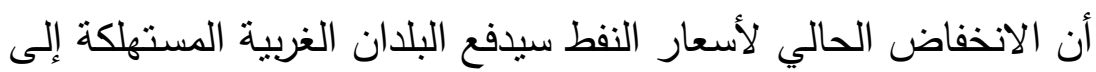

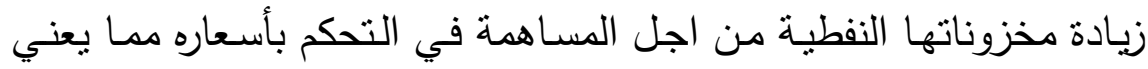

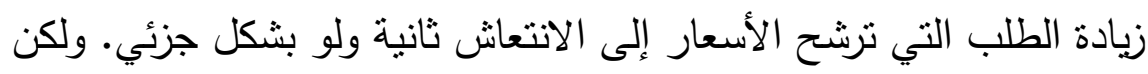

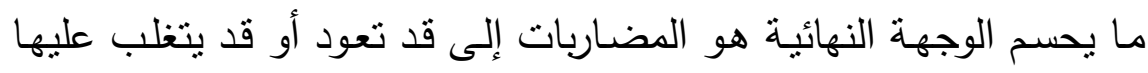
هاجس عجز الإمدادات عن تغطية احتباجات السوق العالمية.

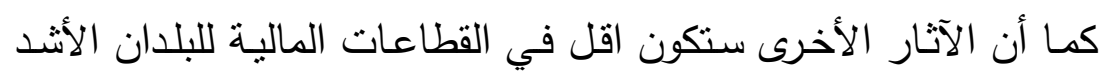

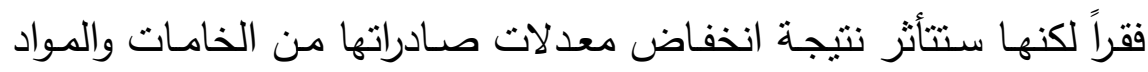

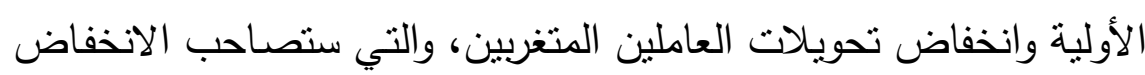

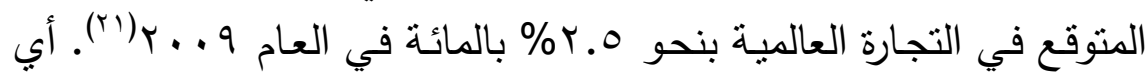

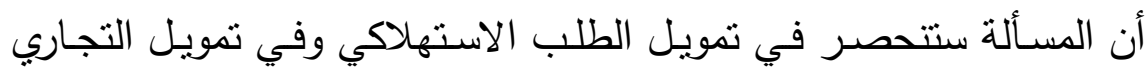

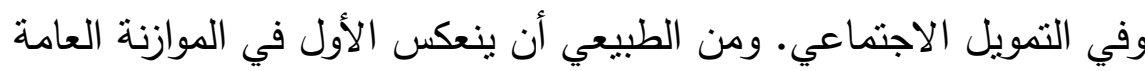

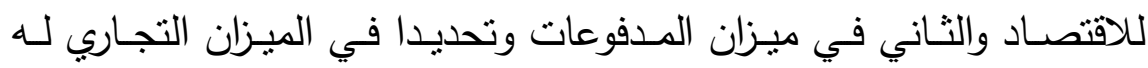

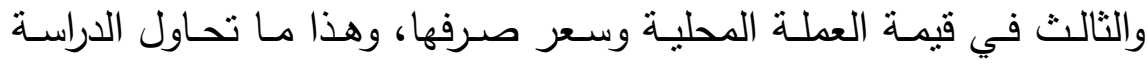

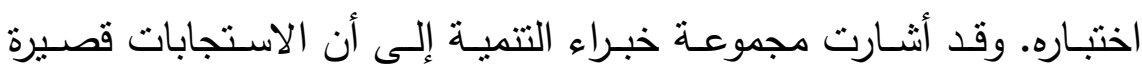

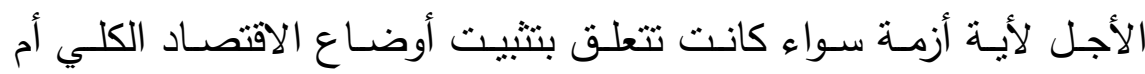

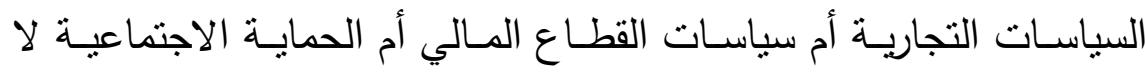

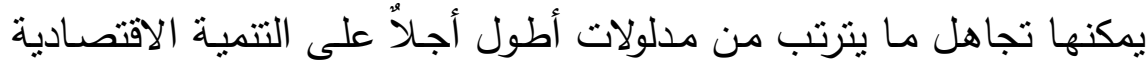
وإمكانية التعرض لأزمات في المستقبل (rr). 
إلى جانب الآثار المباثرة وغير المباشرة للأزمة المالية العالمية ^ . . ب

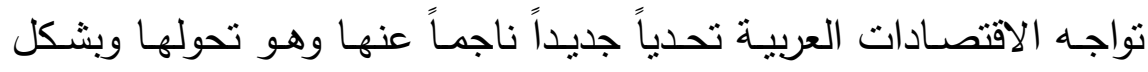

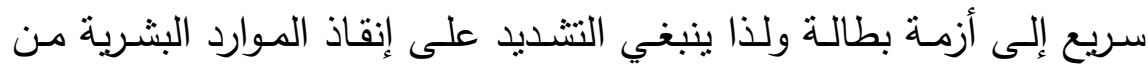

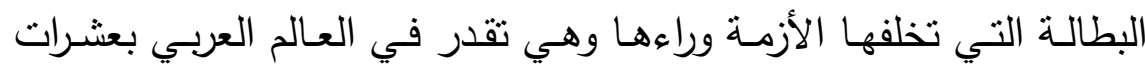
ومئات آلاف وكذلك إنقاذ الموارد المالية من التركز لاى أقليات مستفيدة من ونداءهي الأزمة في مجال العقارات ومن الهرب عن طريق الخامات الهيدروكاربونية

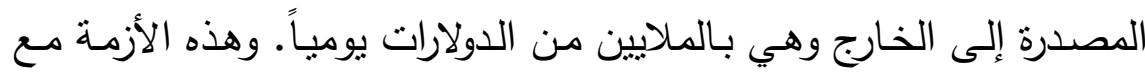

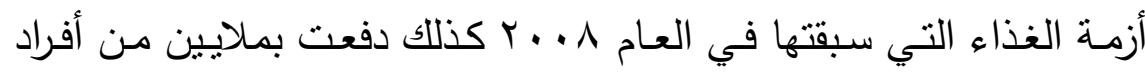
المجتمع إلى الفقر والجوع. وظروف الائتمان المنتددة جداً، وإلى جانبها النمو الاقتصادي المتواضع

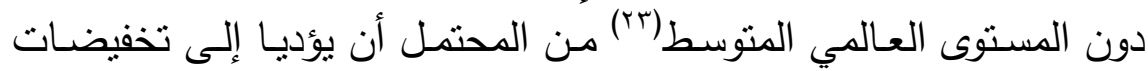
كبيرة في الإيرادات الحكومية ومن ثم في القدرات اللازمة لمجابهة احتياجات

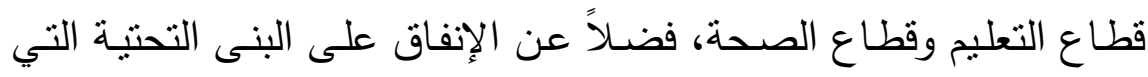

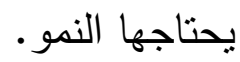

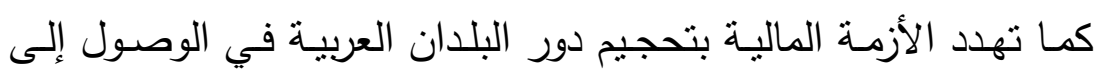
الأسواق التجاريـة والاستثمارات العالميـة، فكل تباطؤ في النمو الاقتصـادي

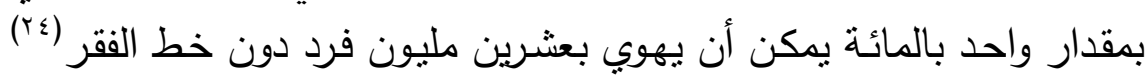
في الوقت الذي يتوجب على الحكومات الإبقاء على التزاماتها في التتمية ومساعدة أفراد المجتمع الأكثر تعرضاً لضغوط لألوفي الأزمة. تتفاوت تداعيات الأزمة المالية العالمية من بلد عربي لآخر بحرة بحسب درجة

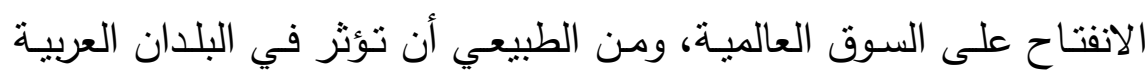

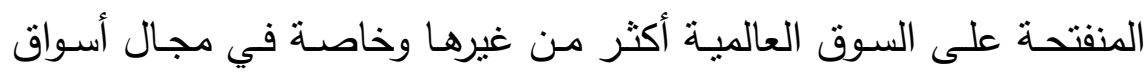

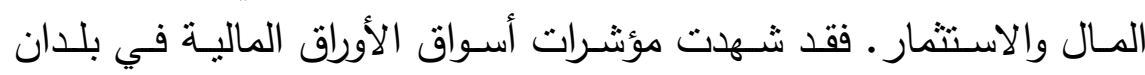

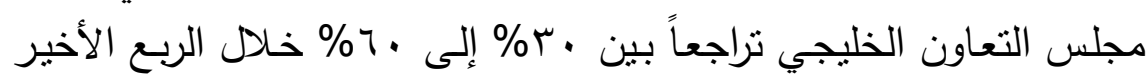




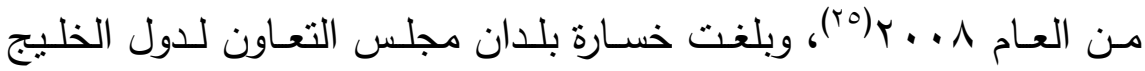
العربي 450 مليار دولار أو ما يعادل مجموع ايراداتها من النفط لسنة كاملة،

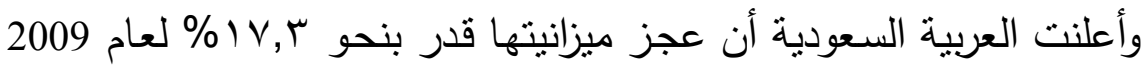
مقابل فائض قدره 160 مليار دولار للعام الذي سبقه(بr(ب).

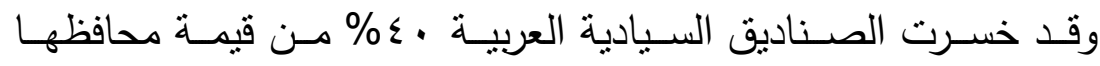

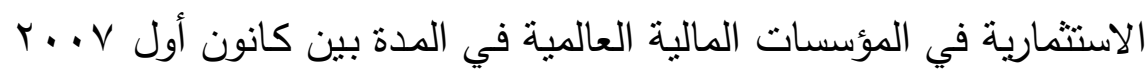

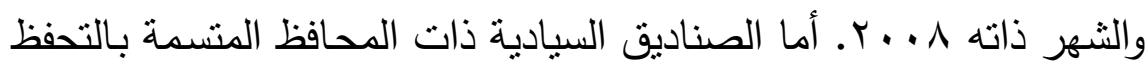

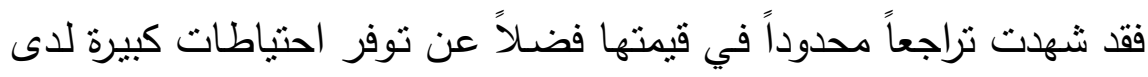
معظمها. وكذللك الحسال لبلدان عربيـة أخرى مثنل مصـر والكويـت ولبنـان وتونس والمغرب مع أتسام مؤشراتها بمرونات نسبية مختلفة. ولكون القطاع المصرفي العربي ذا اندماج محدود في الأسواق العالمية ولتمتع نظمه المالية بالتشديد في مجالات الاقراض ونسب الاحتياطي القانوني المرتفعة فلم يتأثز كثيرا.

ولم تلجـأ البلدان العربية إلى التموبل الخـارجي كمـا حصل في البلدان

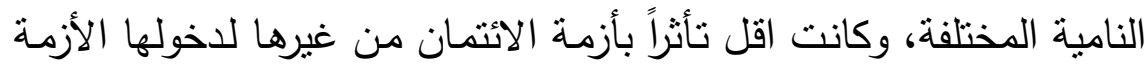
بموازين مدفوعات جيدة وامتلاكها الموارد المالية البديلة لتمويل العجز الكبير بلان الكيل

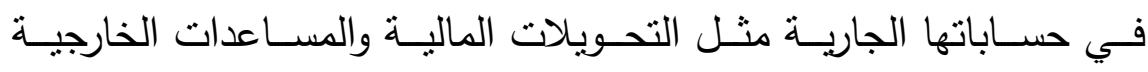
والاستثمارات الأجنبية المباشرة فأين يكمن التأثنر السلبي للازمة المالية؟ في

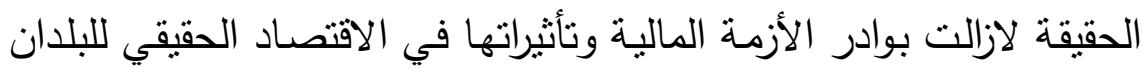

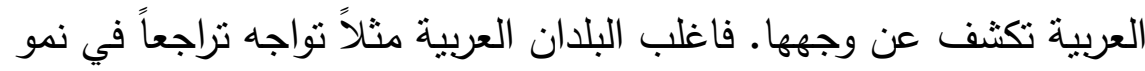

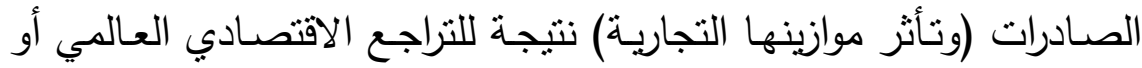

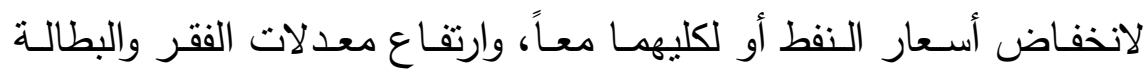
المشار إلبها آنفاً. 


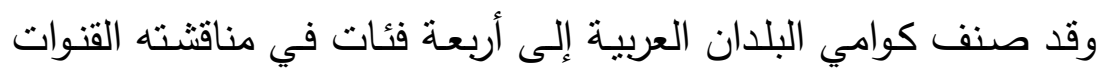

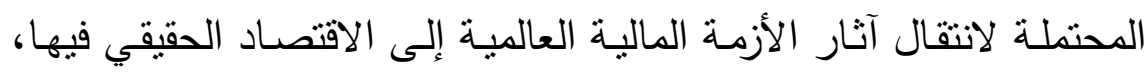
وهي (TV) الفئة الأولى، وتتثمل بلدان مجلس التعاون الخليجي المصدرة للنفط وهي

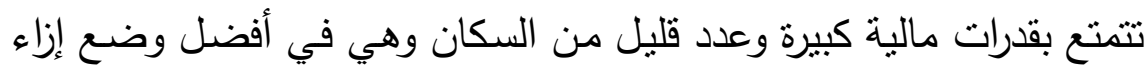

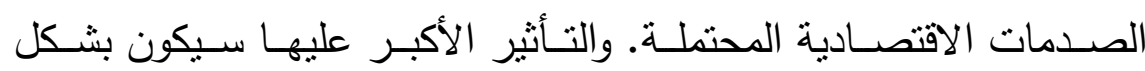

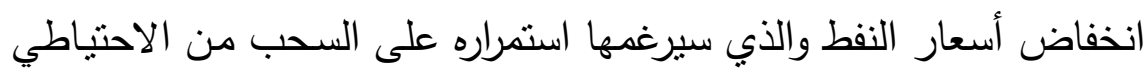

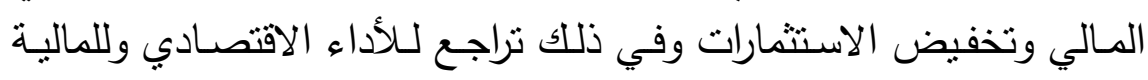
العامة ولتتغيل العمالة الوافدة على الأمد البعيد.

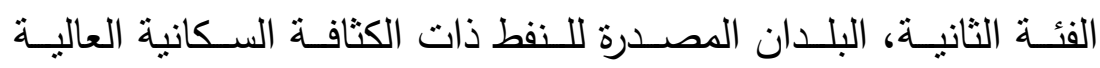

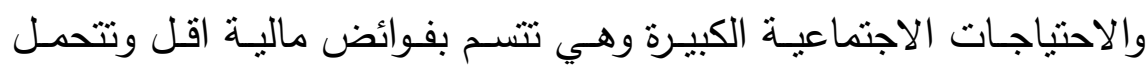

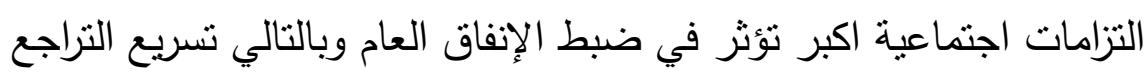

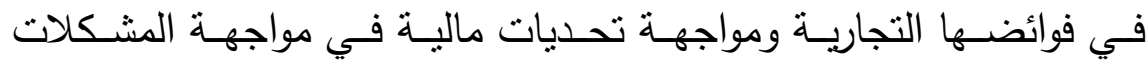

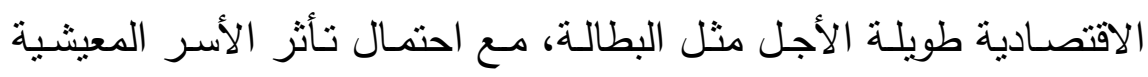

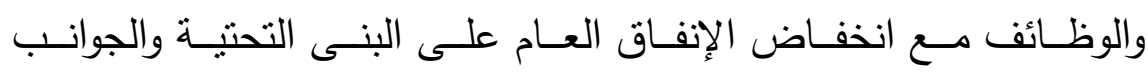
الاجتماعية.

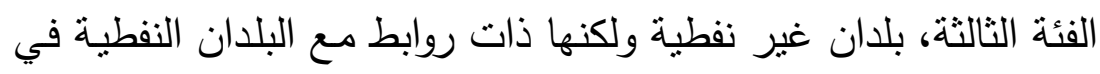

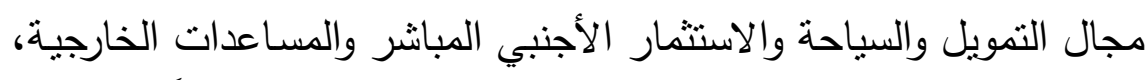

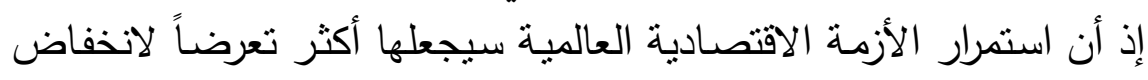

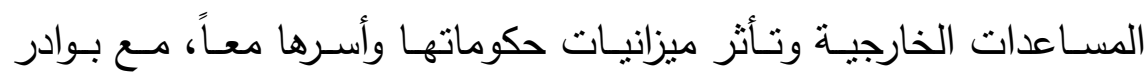

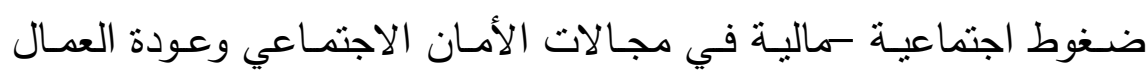
المهاجرين.

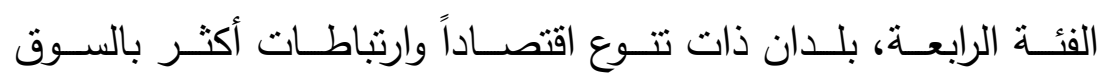

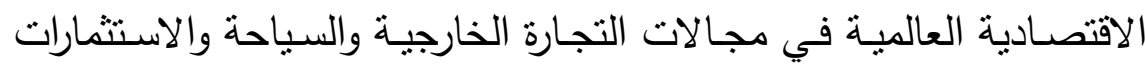


الأوربية فيها (مثل لبنان وتونس والأردن)، وستظهر هذه التأثيرات بشكل

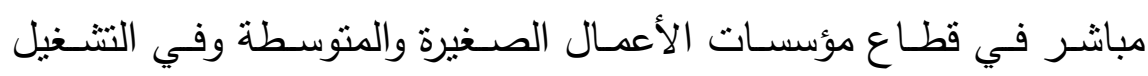

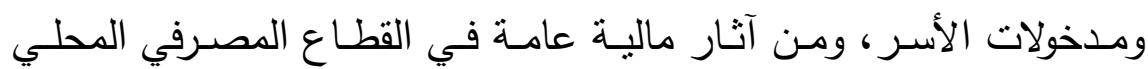

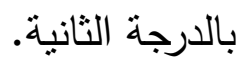

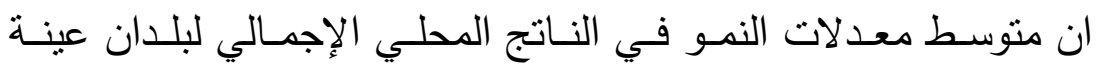

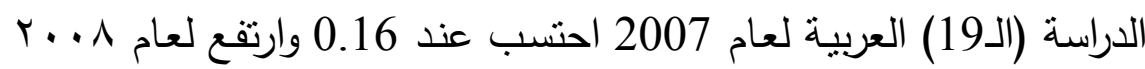

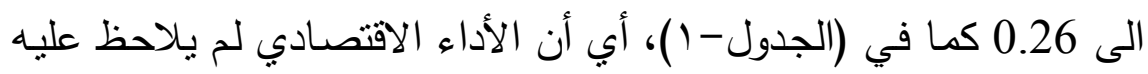

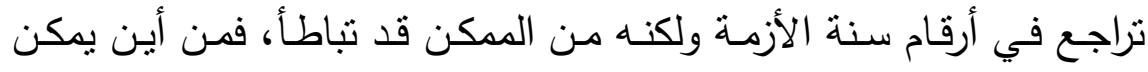

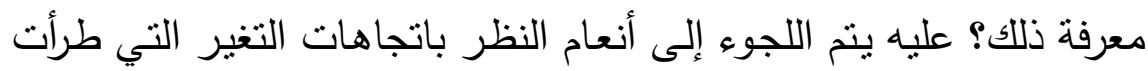

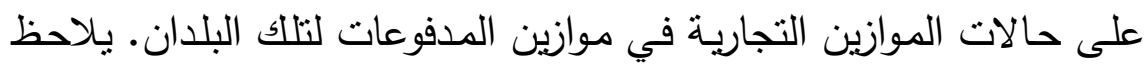

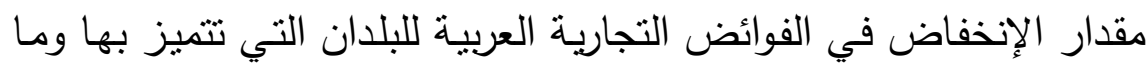

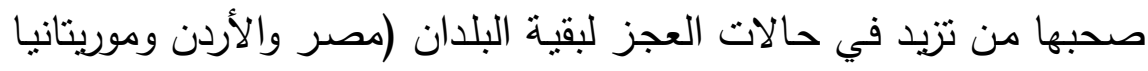

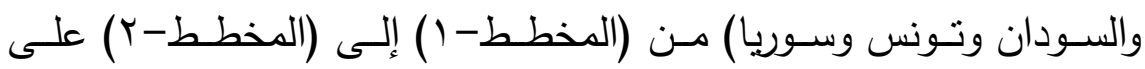

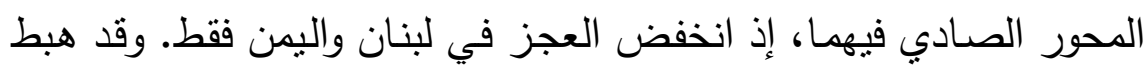

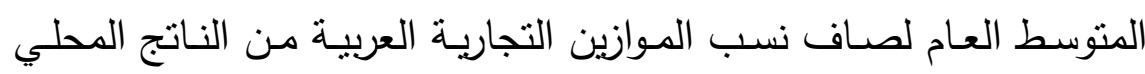

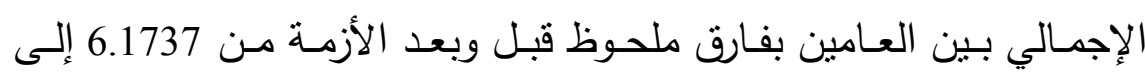


د. نوفل فاسم علي الثهوان

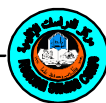

\section{المخطط- 1: أوضاع الموازين التجارية العربية لعام V. P.}

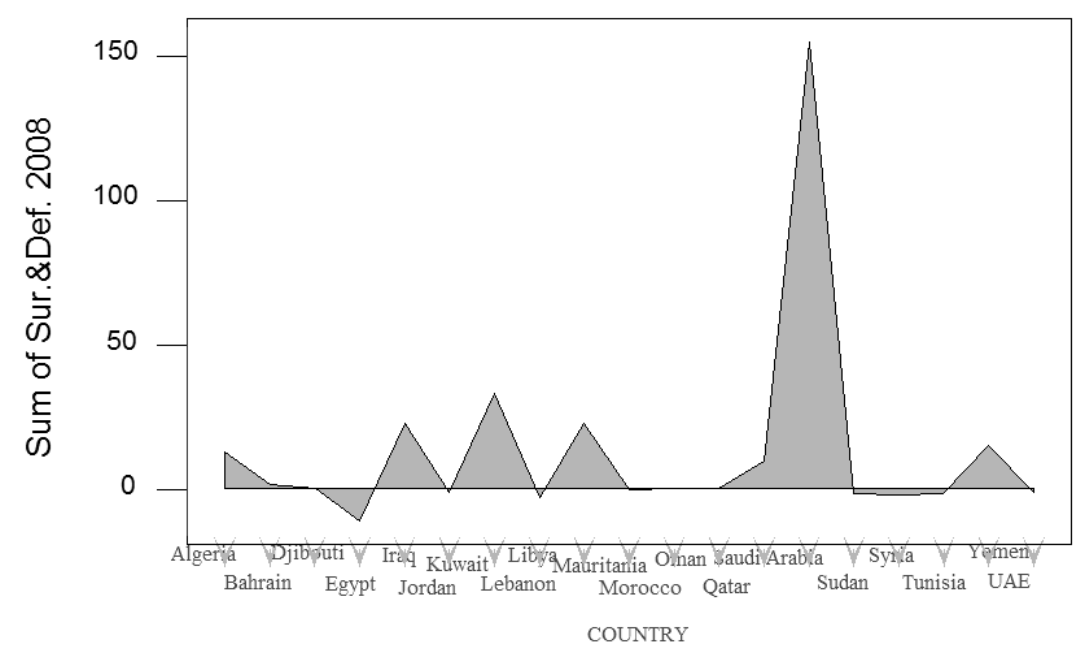

المخطط-Y : أوضاع الموازين التجارية العربية لعام ^ ...

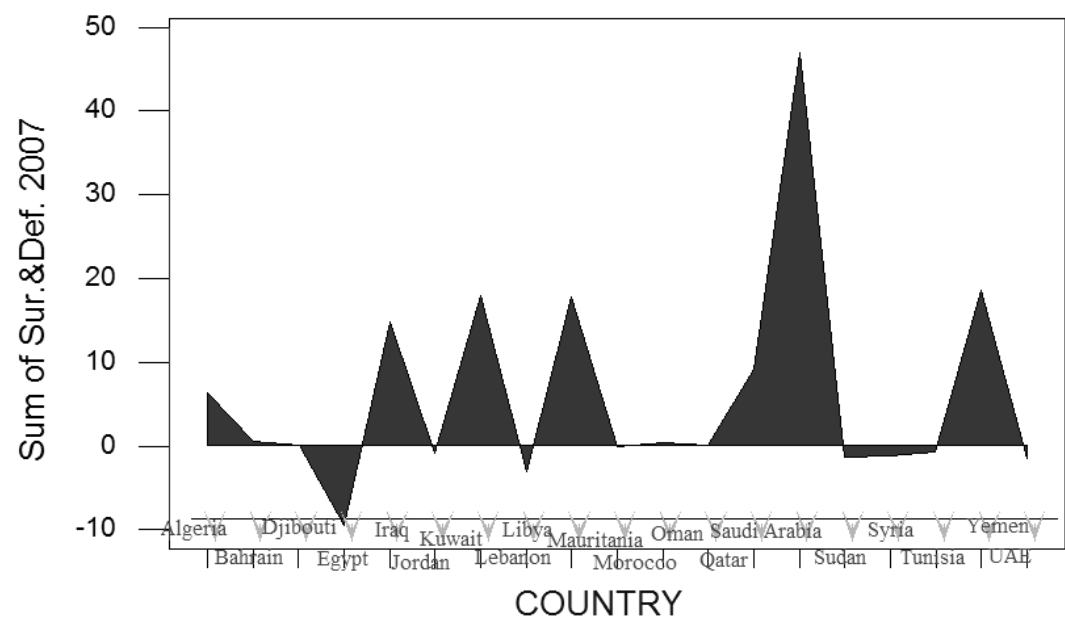

$$
\text { المصدر: بيانات (الجدول - ب) - (ب). }
$$




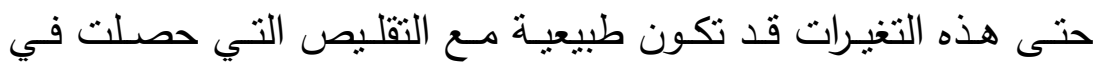
الموازنات الحكومية العامة للبلدان العربية، ولكن اتجاهات التهات التغير في قيمة التهات

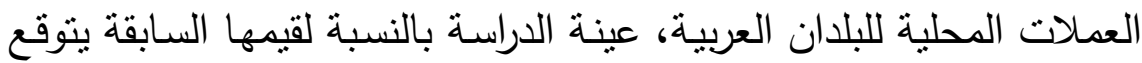

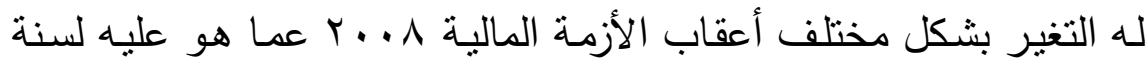

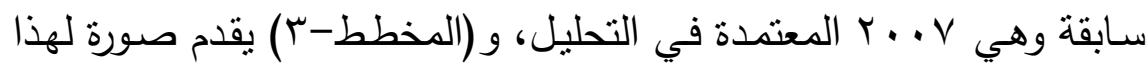

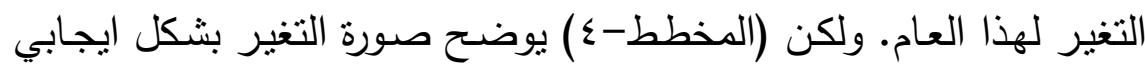

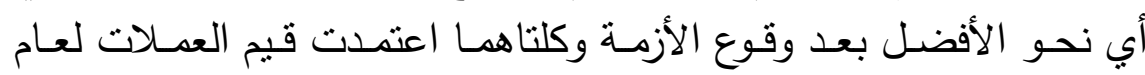
r. . .

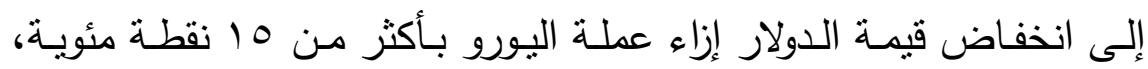

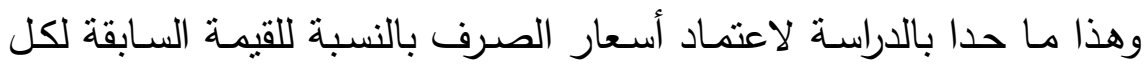
عملة وليس بالنسبة للاولار مثنا أو لغيره.

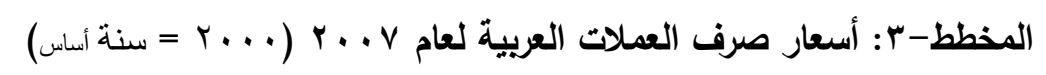

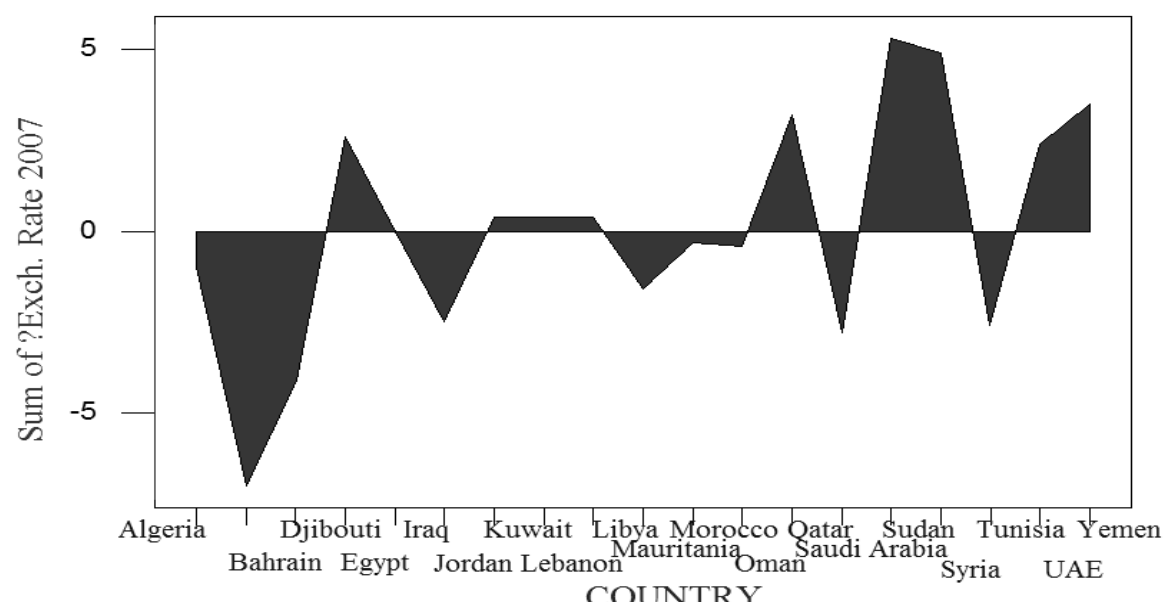
COUNTRY 

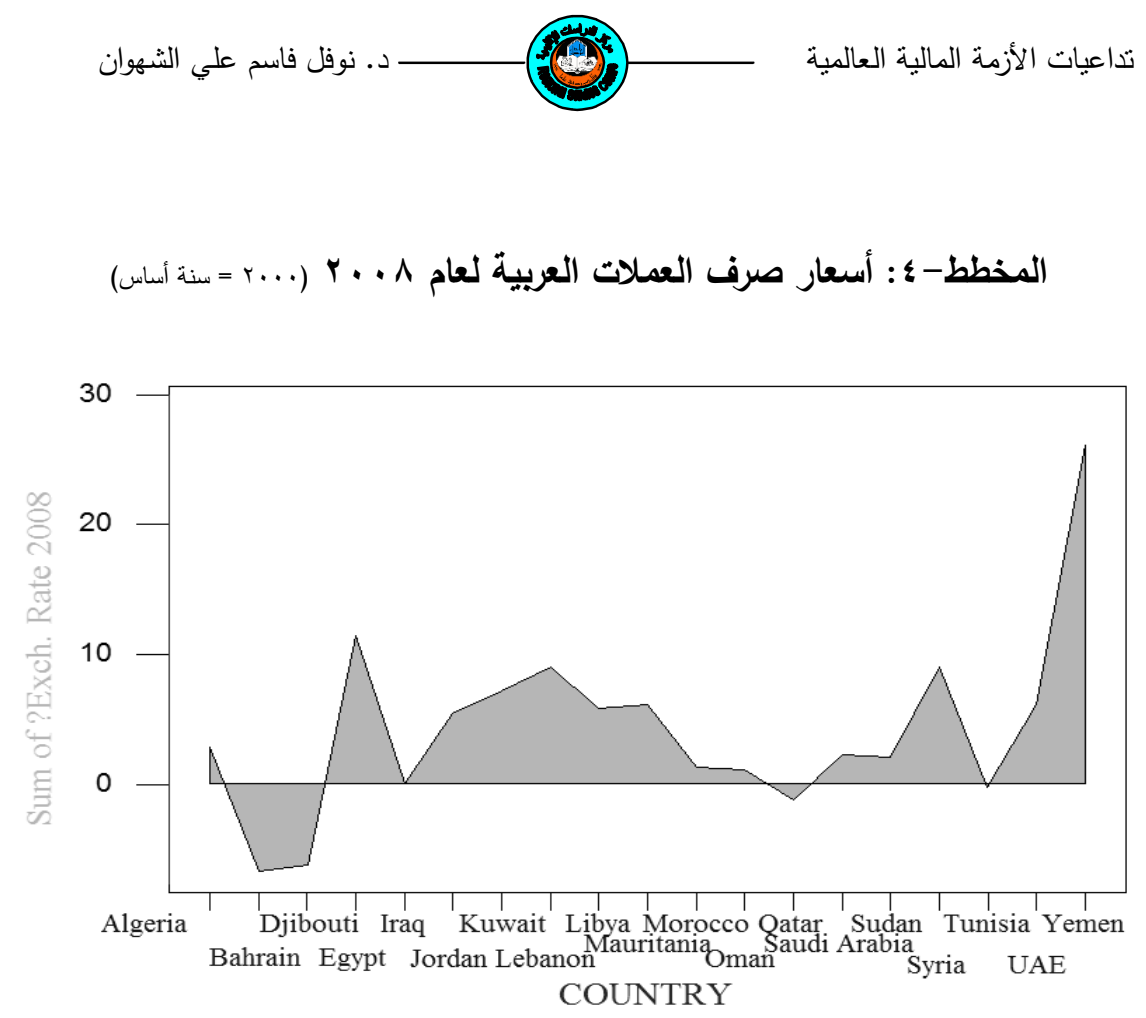

وفي ضوء هذا التغير تبقى الحاجـة لمعرفة اتجاهات تأثثره في الأداء

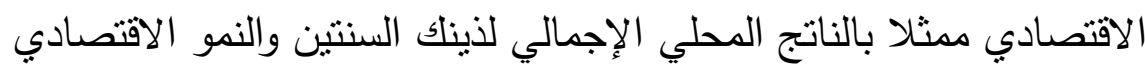

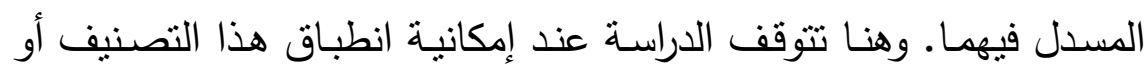

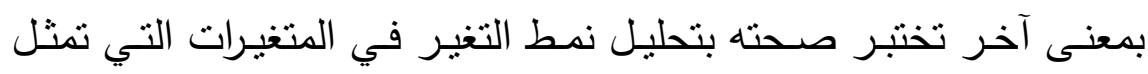

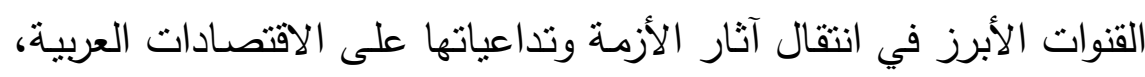

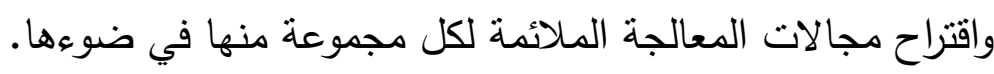

ع. تقدير الآثار غير المباشرة للأزمة المالية العالمية

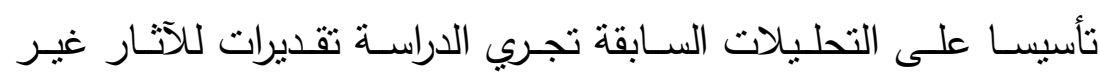

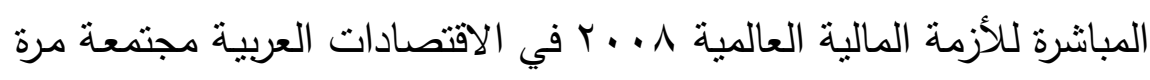

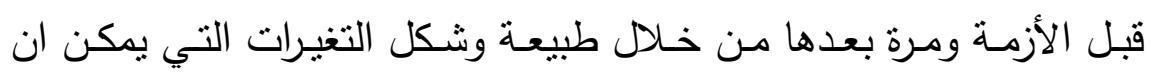




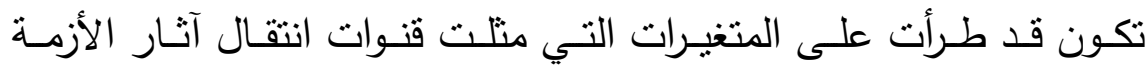

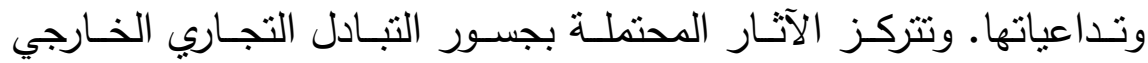

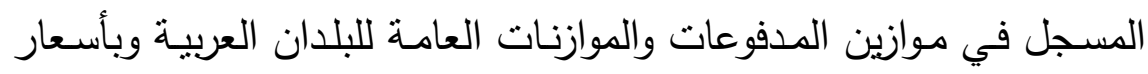

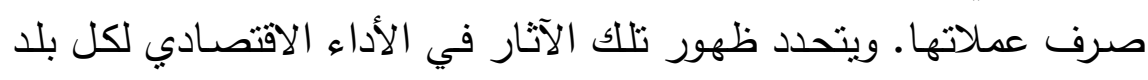

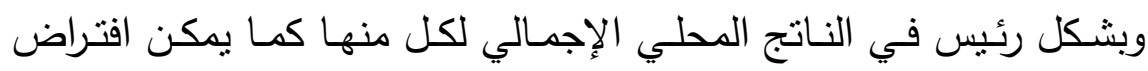

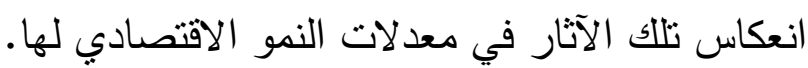

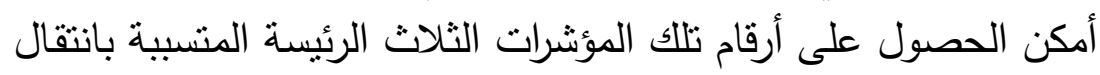

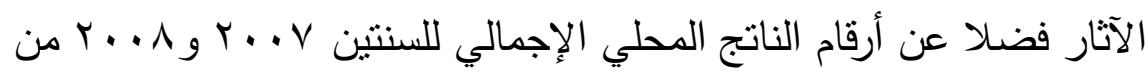

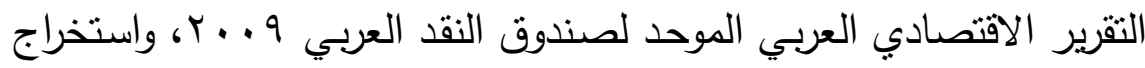

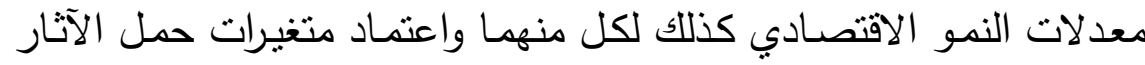

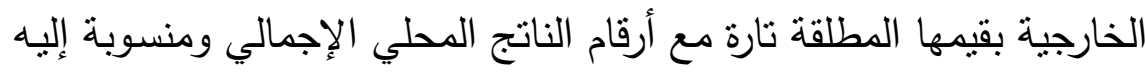

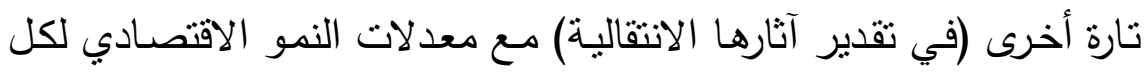

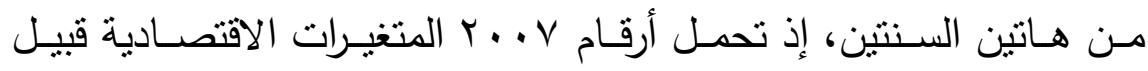

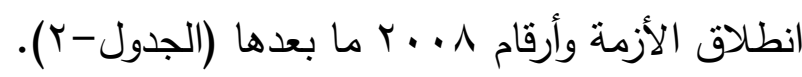




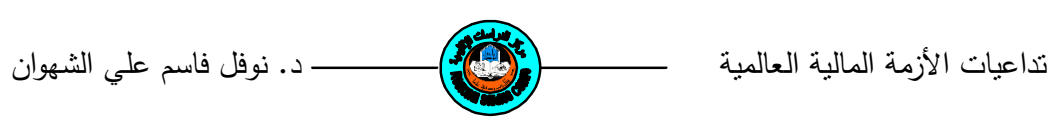

شـملت عينـة التقدير مجمل البلدان العربيـة (باستثناء الصـومال وجزر

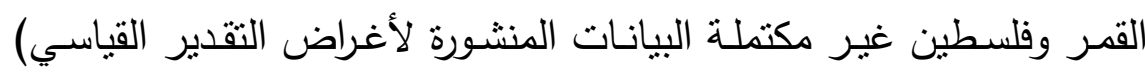


واعتمدت أرقام النـاتج المحلـي الإجمالي بأسـعار السـوق الجاريـة بالدولار

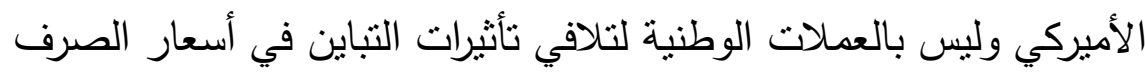

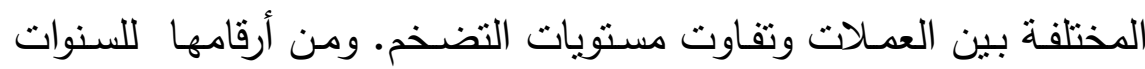

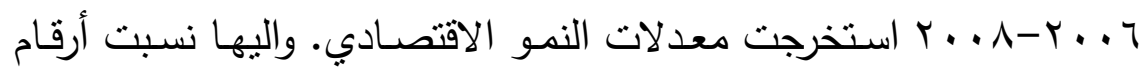

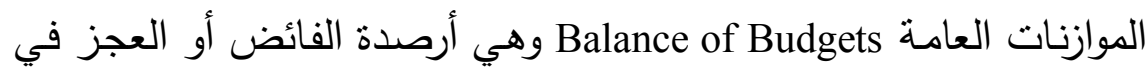

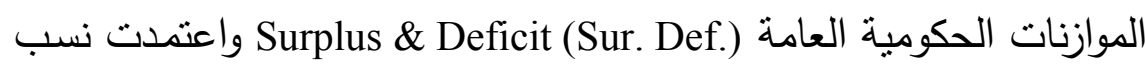
الموازين التجارية Trade Balance (Tr. Ba.) للاول العربية (الجزء الأهم في موازين المدفوعات (Balance of Payments) إلى الناتج المحلي الإجمالي (لإني وتغيرات أسعار الصرف (Bxch. Rate) لسنتي التقدير لأسعار العماتلات

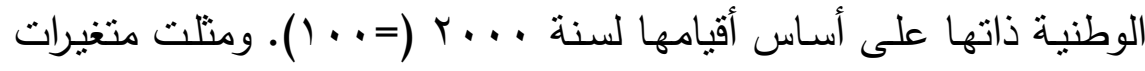

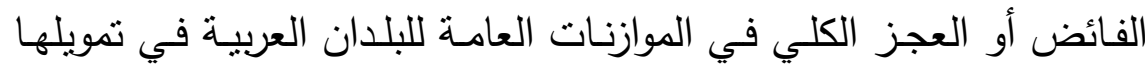

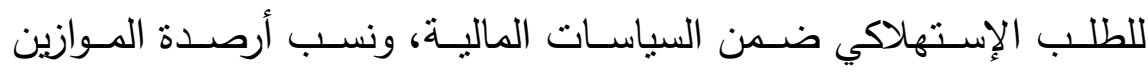

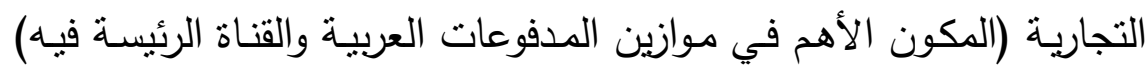

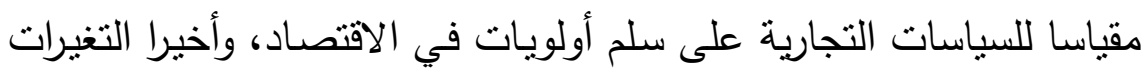

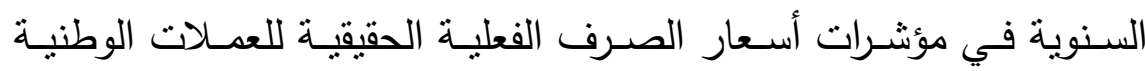
باعتماد سنة الأساس الموحدة.

أولاً: الأزمة المالية والموازنات العامة والأداء الاقتصادي

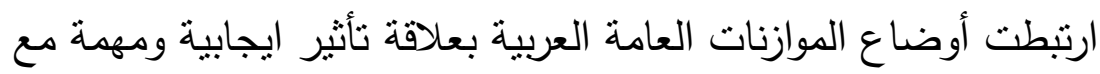

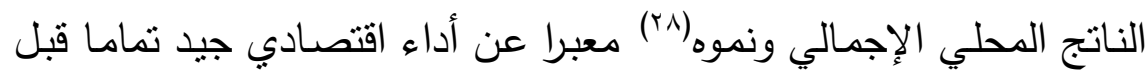

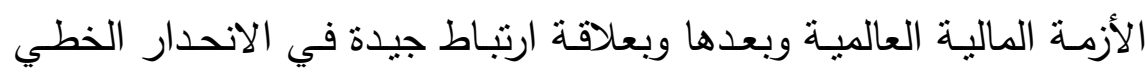

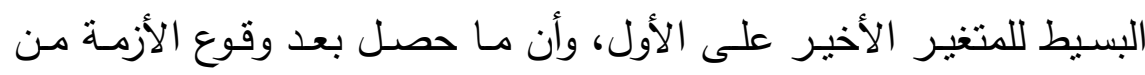
علاقات مقدرة يتلخص بالآتي:

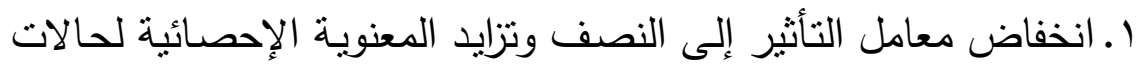

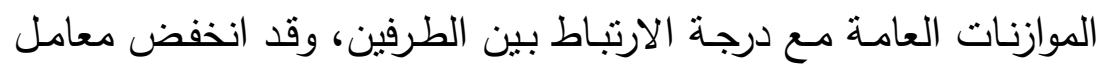




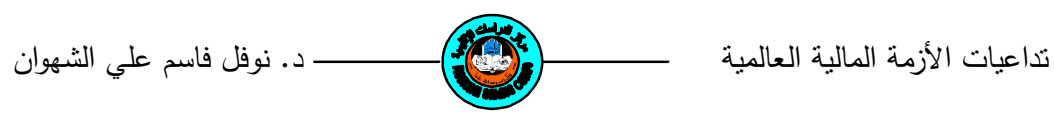

الثأثنر من (5.72) إلى (2.63) لعينة البلدان العربية وارتفعت المعنوية

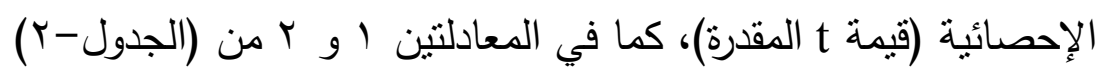

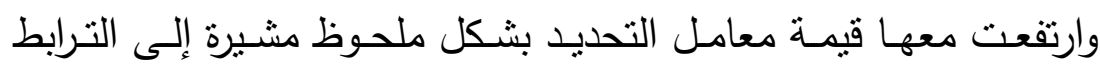
وأهميته رغم انخفاض مقدار التأثثر المتزامن مع تداعيات الأزمـة المالية

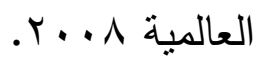

r.عمدت الدراسة إلى تقدير أثر هذا المتغير في النمو الاقتصادي لهاتين

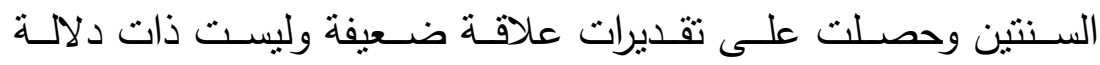

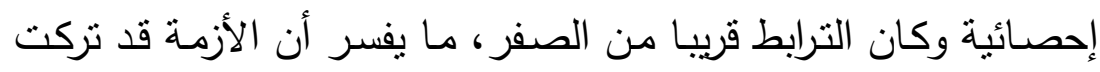

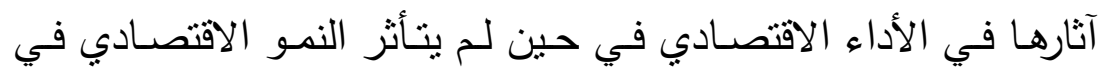
الأجل القصير مع التغيرات الحاصلة في الموازين المالية العامة للبلدان الإني العربية بعد وقوع الأزمة.

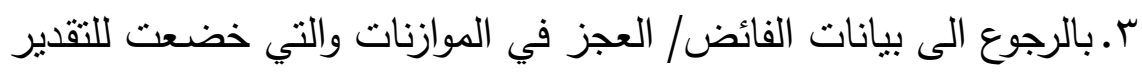

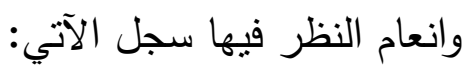

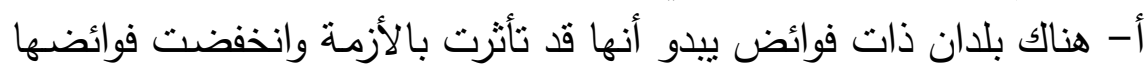

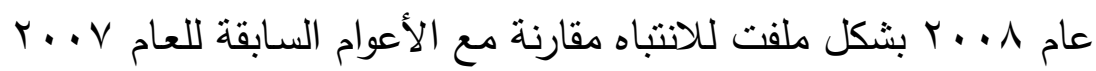
وذللك في كل من الإمارات العربية المتحدة وقطر وليبيا.

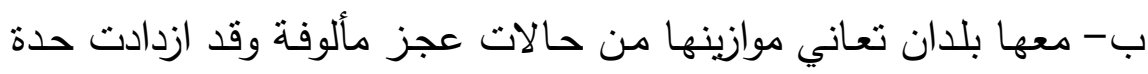

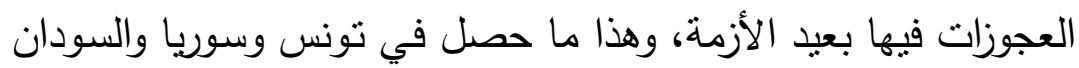

$$
\text { وموريتانيا. }
$$

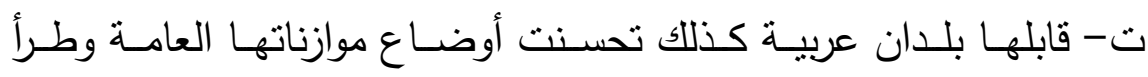

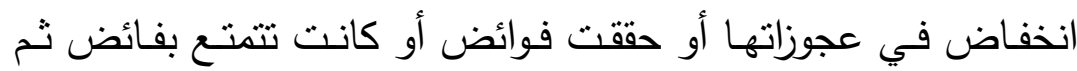
ارتفع بعد الأزمة كم حصل في الأردن ولبنان واليمن على الترتيب.

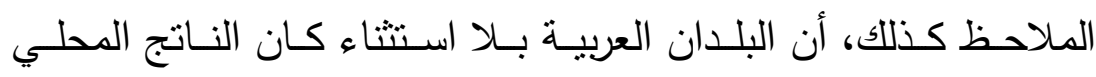

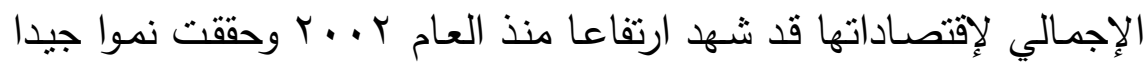


اقتصاديا لغاية العام ^ . . ب ومع ذللك كانت حالات العجز المسجلة للبعض

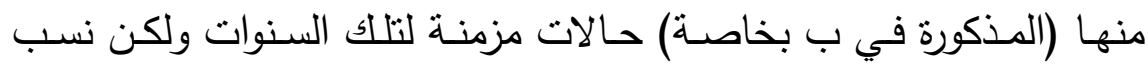
العجز المسجلة وحتى الفوائض المتحققة بعد الأزمة غير مسبوقة الأرقام ما

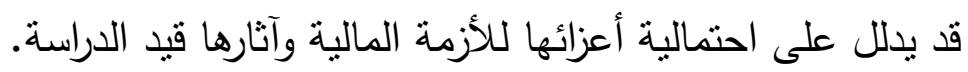
بعبارة أخرى، تأثز البلدان العربيـة النفطيـة منها وكذلك الأكثر انفتاحسا

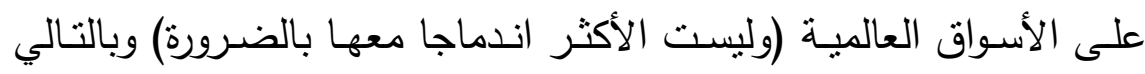

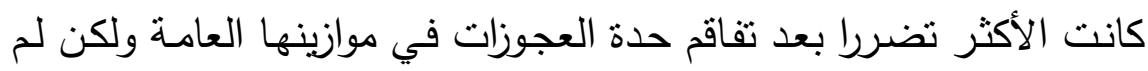

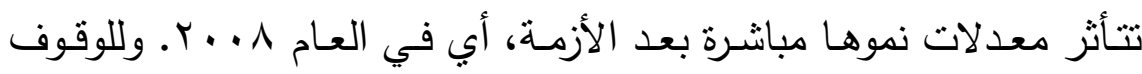

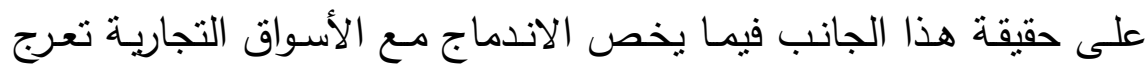
التحليات القادمة على تقديراتها مع الأداء الاقتصادي.

ثانياً: الأزمة المالية والموازين التجارية والأداء الاقتصادي تعد الموازين التجاريـة المكوِّن الأبرز في موازين المدفوعات والأكثر نأثراً

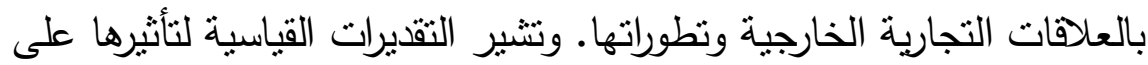
الناتج المحلي الإجمالي للبلدان العربية قبل الأزمة وبعدها إلى استمرار درجة

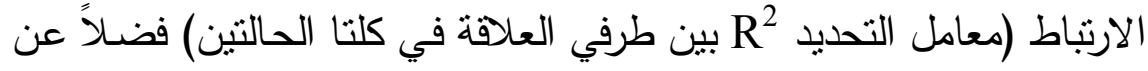
أهمية التقديرات (معاملات t المقدرة) لهما (المعادلتين 3 و 4 من الجدول -بري). واهم ما بلاحظ في هاتين المعادلتين هو انخفاض قيمة معامل التأثنير من (2.14) إلى (1.90)، وما يشير إلبه هذا الانخفاض هن نراجع الآثار الايجابية للموازين التجارية.

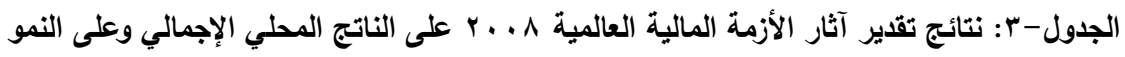
الاقتصادي للإقتصادات العربية عبر القتوات الانتقالية الثثلاث: الموازين التجارية (Sur. or Def.

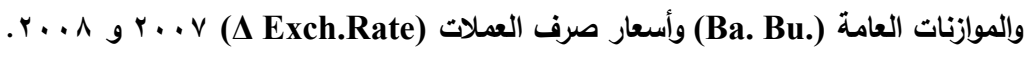




\begin{tabular}{|c|c|c|c|c|c|c|c|c|c|}
\hline \multicolumn{5}{|c|}{ Dependent= GDP } & \multicolumn{5}{|c|}{ Dependent= GDP Grawth } \\
\hline Sec. & Variable & $\alpha$ & $\boldsymbol{\beta}$ & $\begin{array}{l}\mathbf{R}^{2} \\
\%\end{array}$ & Sec. & Variable & $\alpha$ & B & $\begin{array}{l}\mathrm{R}^{2} \\
\%\end{array}$ \\
\hline 1. & $\begin{array}{c}\text { Sur. Def. } \\
2007\end{array}$ & $\begin{array}{c}44.8 \\
(3.33)\end{array}$ & $\begin{array}{c}5.72 \\
(5.89)\end{array}$ & 67 & 7. & $\begin{array}{c}\text { (Sur. Def. } \\
\text { \% GDP) } \\
2007\end{array}$ & $\begin{array}{l}0.156 \\
(9.91)\end{array}$ & $\begin{array}{l}0.154 \\
(1.04)\end{array}$ & 6.0 \\
\hline 2. & $\begin{array}{c}\text { Sur. Def. } \\
2008\end{array}$ & $\begin{array}{c}65.0 \\
(4.49)\end{array}$ & $\begin{array}{c}2.63 \\
(6.81)\end{array}$ & 73 & 8. & $\begin{array}{c}\text { (Sur. Def. } \\
\text { \% GDP) } \\
2008\end{array}$ & $\begin{array}{l}0.248 \\
(8.93)\end{array}$ & $\begin{array}{l}0.242 \\
(1.16)\end{array}$ & 1.9 \\
\hline 3. & $\begin{array}{c}\text { Tr. Ba. } \\
2007\end{array}$ & $\begin{array}{c}42.2 \\
(3.85)\end{array}$ & $\begin{array}{c}2.14 \\
(7.80)\end{array}$ & 78.2 & 9. & $\begin{array}{c}\text { (Tr. Ba. } \\
\text { \% GDP) } \\
2007\end{array}$ & $\begin{array}{l}0.156 \\
(9.63)\end{array}$ & $\begin{array}{l}0.051 \\
(0.86)\end{array}$ & 4.2 \\
\hline 4. & $\begin{array}{c}\text { Tr. Ba. } \\
2008\end{array}$ & $\begin{array}{c}56.0 \\
(4.18)\end{array}$ & $\begin{array}{c}1.90 \\
(7.82)\end{array}$ & 78.2 & 10. & $\begin{array}{c}\text { (Tr. Ba. } \\
\text { \% GDP) } \\
2007\end{array}$ & $\begin{array}{l}0.245 \\
(9.75)\end{array}$ & $\begin{array}{l}\mathbf{0 . 1 6 9} \\
(2.00)\end{array}$ & 19.1 \\
\hline 5. & $\begin{array}{c}\Delta \text { Exch. } \\
\text { Rate } 2007\end{array}$ & $\begin{array}{c}79.2 \\
(3.74)\end{array}$ & $\begin{array}{c}0.67 \\
(0.10)\end{array}$ & 0.17 & 11. & $\begin{array}{l}\text { (AExch. } \\
\text { Rate \% } \\
\text { GDP) }{ }_{2007}\end{array}$ & $\begin{array}{c}0.161 \\
(11.90 \\
)\end{array}$ & $\begin{array}{c}0.0099 \\
(2.26)\end{array}$ & 23.0 \\
\hline 6. & $\begin{array}{c}\Delta \\
\text { Exch.Rat } \\
\text { e } \\
2008\end{array}$ & $\begin{array}{c}100 \\
(3.26)\end{array}$ & $\begin{array}{c}-0.06 \\
(-0.02)\end{array}$ & 0.03 & 12. & $\begin{array}{c}\text { (AExch. } \\
\text { Rate \% } \\
\text { GDP) }{ }_{2008}\end{array}$ & $\begin{array}{l}0.270 \\
(8.70)\end{array}$ & $\begin{array}{c}- \\
0.0042 \\
(-0.64)\end{array}$ & 2.3 \\
\hline
\end{tabular}

وعلى مستوى البلد الواحد، نشخص البيانات الرسمية حالة سلبية مزمنة لكل من (تونس وجيبوتي ولبنان) منذ عدة سنوات، وجاءت الأزمـة المالية لتزبد من سالبتيها بشكل ملحوظ وخاصة في لبنان التي يضاف إلبها مصر والمغرب والأردن بالمراتب اللاحقة. وفي الوقت الذي تحسنت فيه الموازين

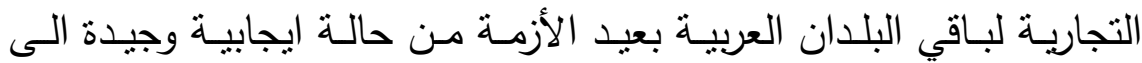

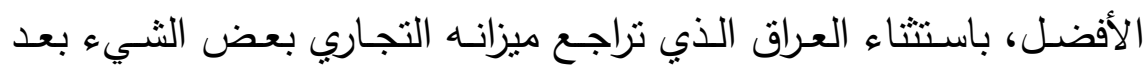

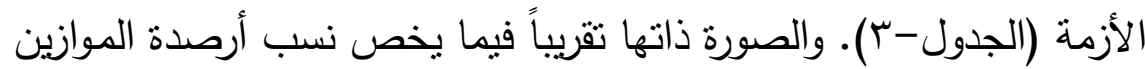
التجارية للدول العربية إلى الناتج المحلي الإجمالي لكل منها لهذه الفترة. وبالانتقال الى النسب المئويـة لأرصدة الموازين التجارية من الناتج المحلي

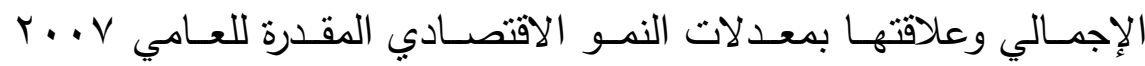

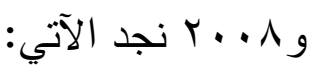


العلاقة بين الطرفين عـام V . . r لـم يكن لها ايـة أهميـة رغم اتجاهها الايجابي ومعامل التحديد 4.2\% في حين تضـاعف حجم علاقـة التأثنير المقدرة لعام ^ . . ب الى أكثر من ثنالثة أضعاف (من 0.05 إلى

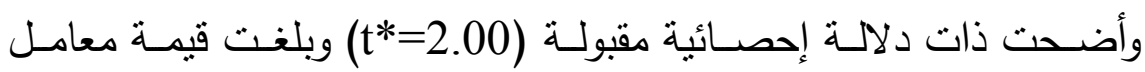
التحديد (19.1\%) في المعادلتين (9 و 10).

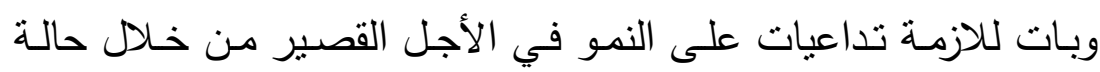

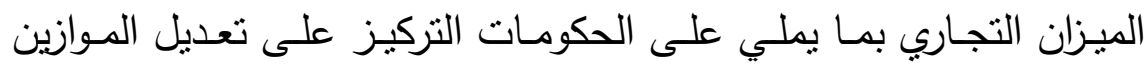

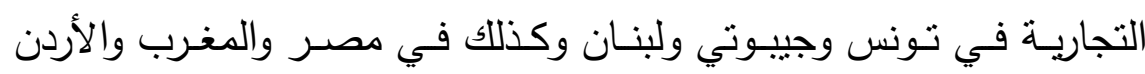

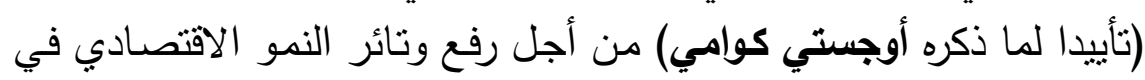

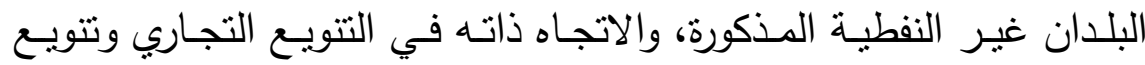

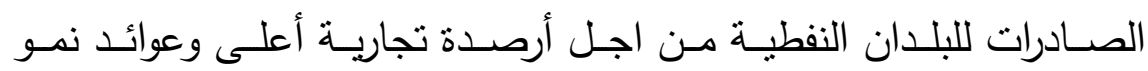

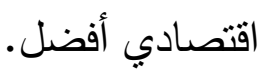

ثالثاً: الأزمة المالية وأسعار الصرف والأداء الاقتصادي لم يكن لأسعار الصرف أهمية كبيرة على الناتج المحلي الإجمالي في

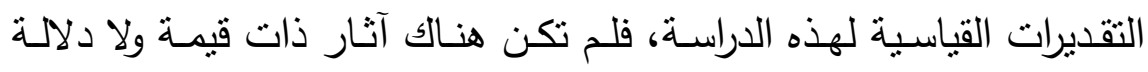
إحصائية عليها كما أن الارتباط بين المتغيرين كان ضعيفا بينهما وأصبح صفر تقريبا بعد الأزمـة، وأهم مـا يلاحظ في هذا السياق هو تحول شكل العلاقة المقدرة من الموجب إلى السالب.

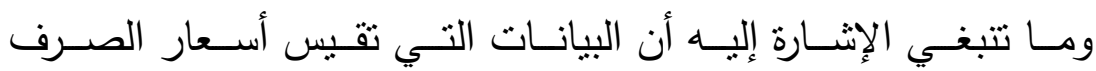
والمستخدمة في التقدير القياسي ليست لأسعار صرف العملات الوطنية إزاء عملة عالمية مثل الدولار الأميركي الأكثر استخداما في الدراسات المختلفة

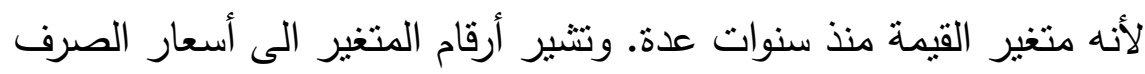

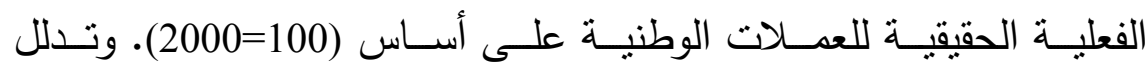

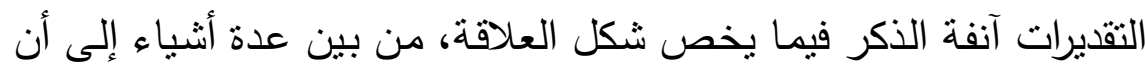


الأزمة قد تجعل من ارتفاع قيمة العملة بعد الأزمة تترك آثنارا معاكسة في قيمة الناتج المحلي الإجمالي. فع النمو الاقتصادي وجدت الدراسة علاقة الإيحابية ذات دلالة احصائية

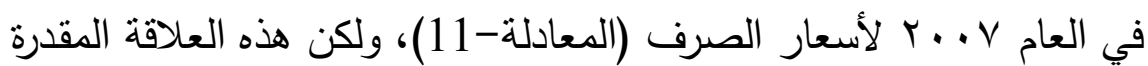

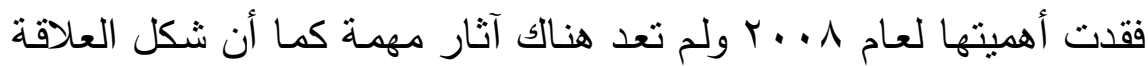

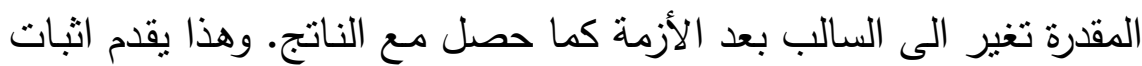

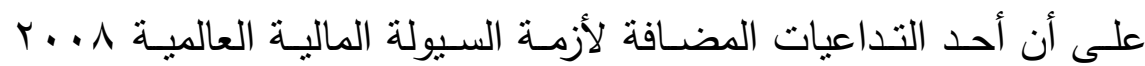

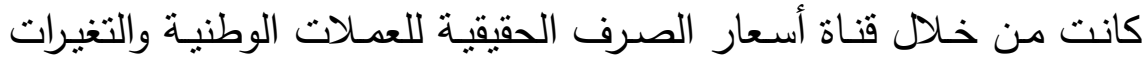
التي طرأت على قيمتها الفعلية.

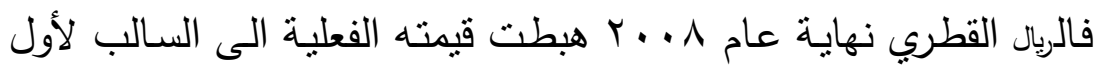

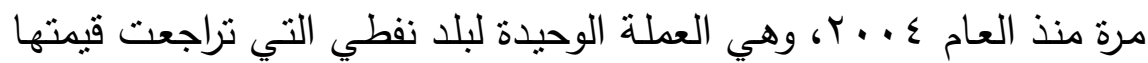

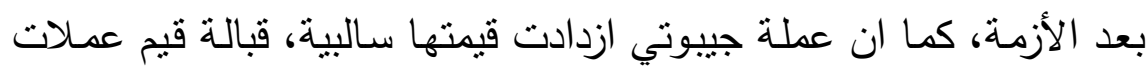

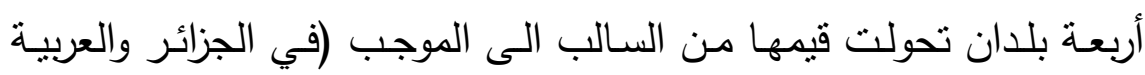

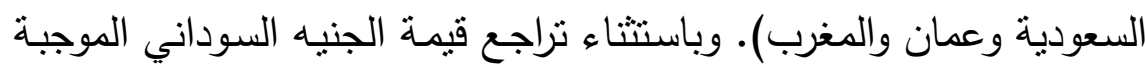

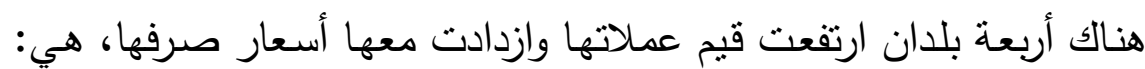
الإمارات العربية المتحدة والكويت وليبيا من البلدان النفطية وكذلك سورية إندانية

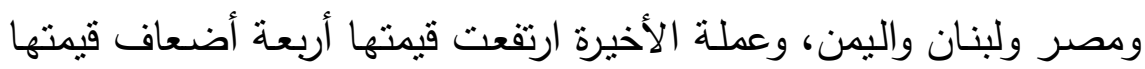

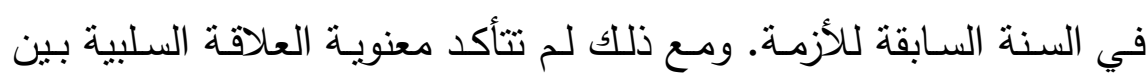

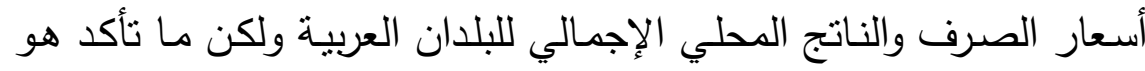

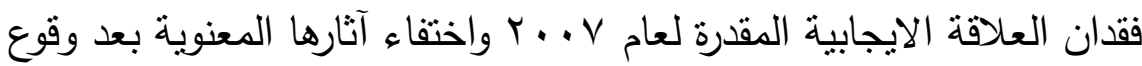

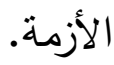
وبتتاول آثار الأزمـة الماليـة على أرقام المتغيرات الثناث قيد الاهتمـام وتقديرها معا تحصل الدراسة على الآتي: 
$\mathrm{GDP}_{2007}=\quad 41.6-2.47 \quad$ Sur.\&Def. ${ }_{2007}+3.02 \quad$ Tr.Ba. ${ }_{2007}+4.82$ $\Delta$ Exch.Rates $_{2007}$

$$
\begin{aligned}
(3.89)(-0.92) \\
\mathrm{R}^{2}=81.8 \%
\end{aligned}
$$

$\mathrm{GDP}_{2008}=50.7-0.00$ Sur.\&Def. ${ }_{2008}+1.91$ Tr.Ba.2008 $+1.18 \Delta$ Exch. Rates $_{2008}$

$$
\begin{aligned}
& (3.03)(-0.00) \\
\mathrm{R}^{2} & =55.7 \%
\end{aligned}
$$

وجد أن معامل الميزان التجاري قبل الأزمة مرتفع ومعنوي إحصائيا تماما

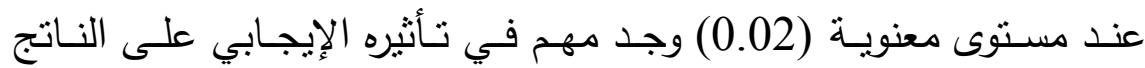

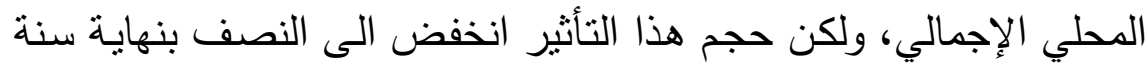

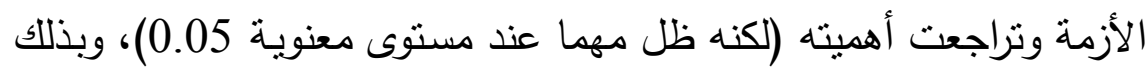

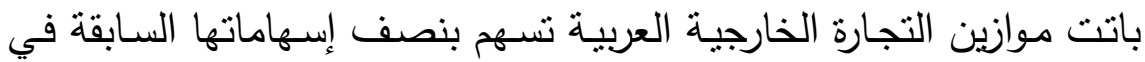

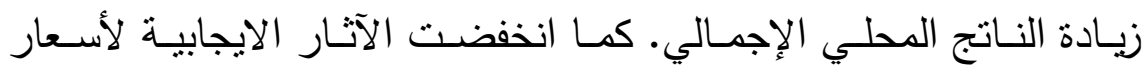

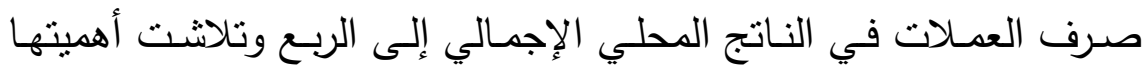

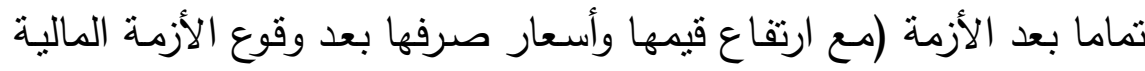
كما لوحظ في المخططين 1 و 2).

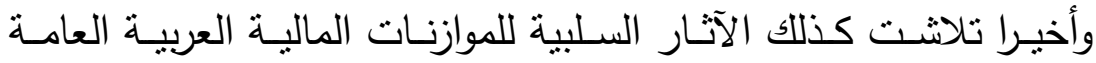

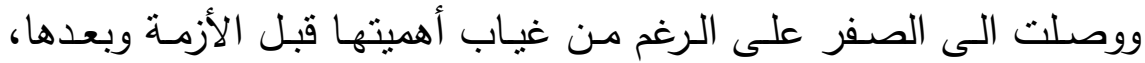

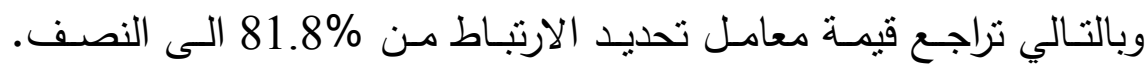

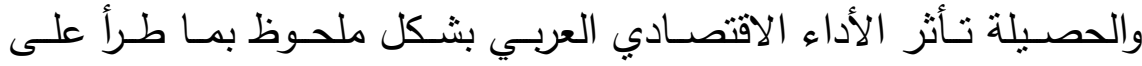

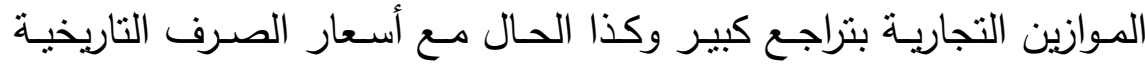

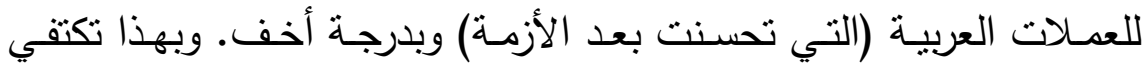


الدراسـة بهذه التقديرات القياسية بصدد الأداء الاقتصـادي للبلدان العربيـة. وبهذا يكون من المناسب مناقثنة مجالات المعالجة في ضوء هذه النتائج.

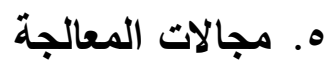

يمكن تلخيص الآثار بثلاثة مجالات رئيسية هي: المجال الأول، عودة

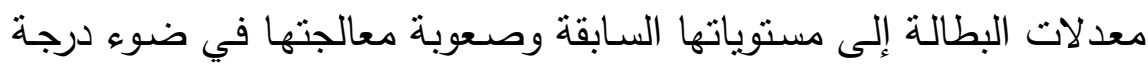

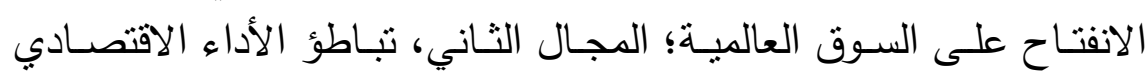

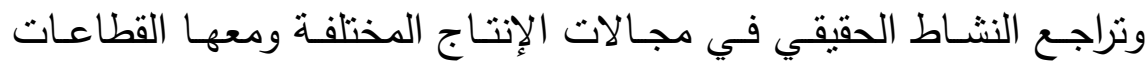

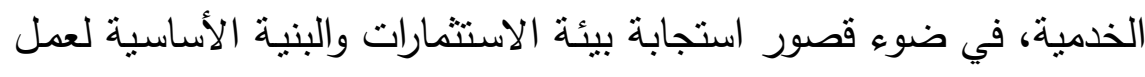

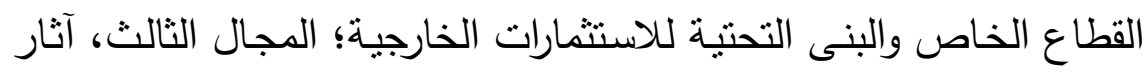

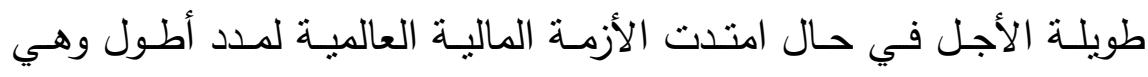

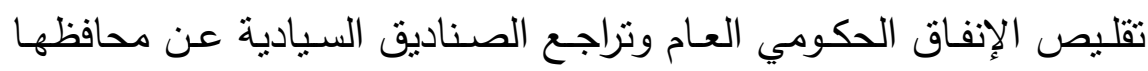
الاستثمارية السابقة وتسجيل حالات عجز في موازين المدفوعات والموازين العين العين التجارية.

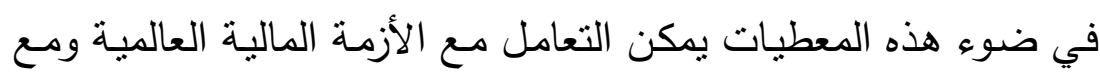

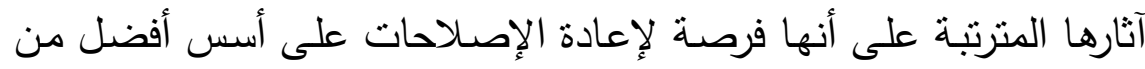

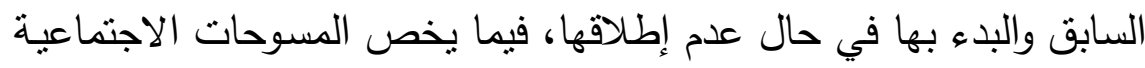

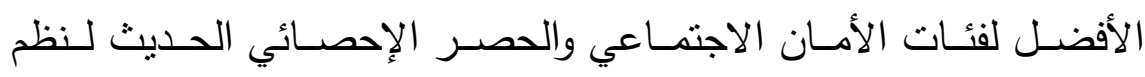

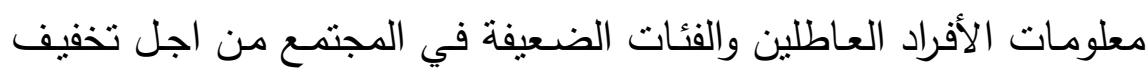
حدة الفقر وتخفيض أعداد الفقراء. وينطوي التعامل الثاني مع الأزمة المالية العالمية ومع آثارها على الثى أنها

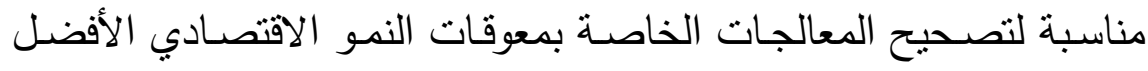

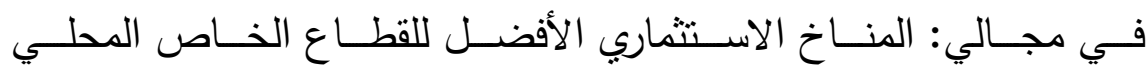

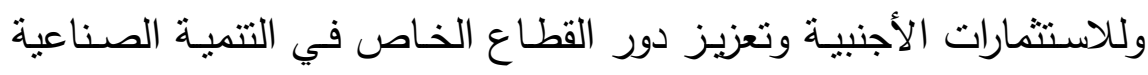


والزراعيـة والخدماتيـة وكذللك في مجـال: الإنفاق العام على البنى التحنيـة

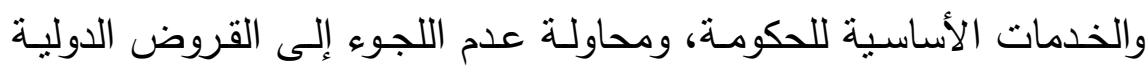

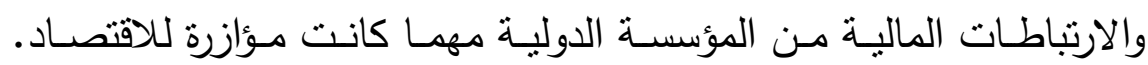

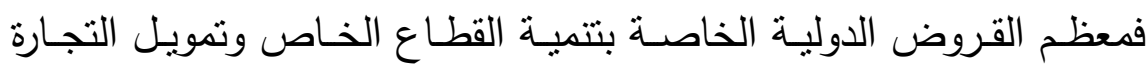

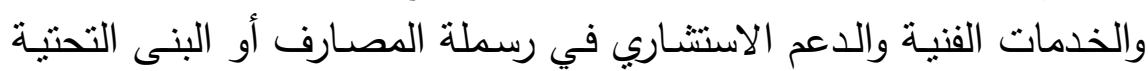
ترتب ديون نزيل كل آثار ايجابية للنمو المحتمل في الأجل الطويل.

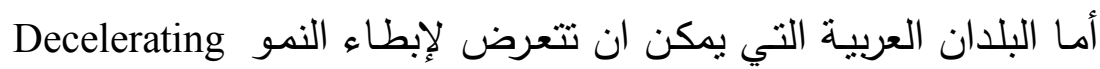

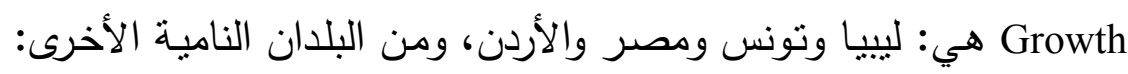

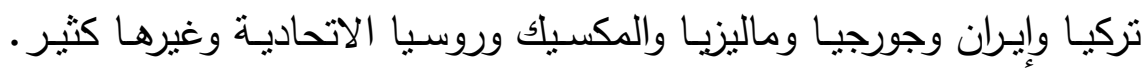

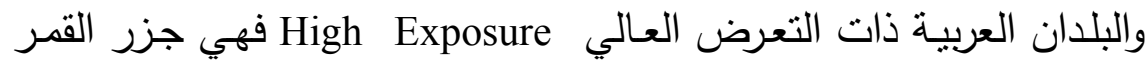
وموريتانيا والسودان وبلدان إقليمية أخرى منل تركمانستان وأوزبكستان وتنتاد

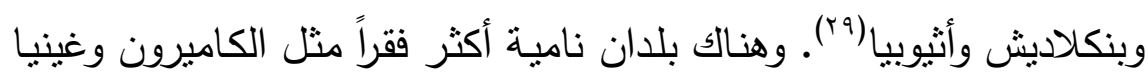

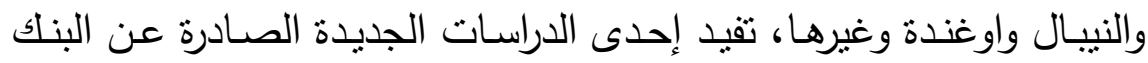

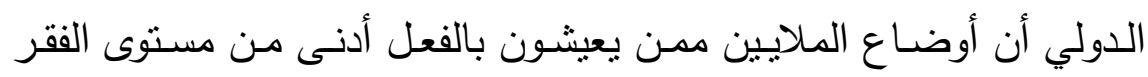

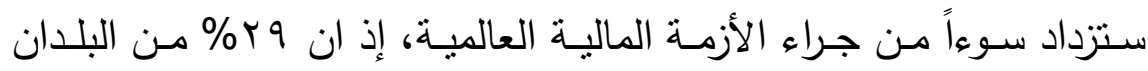

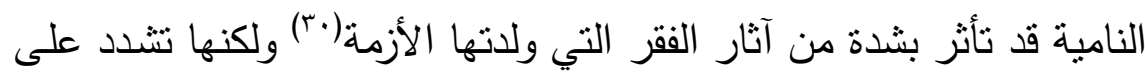

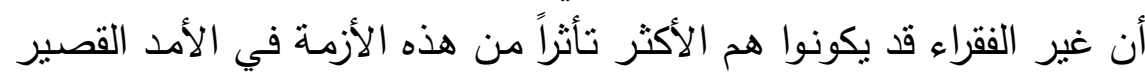
ويحتمل أن تتنقل الآثار السلبية لهذه الأزمة في الأمد المتوسط إلى الألى الأسر الأدر الفقيرة.

فتم تأسيس صندوق دعم المؤسسات لتقديم قروض للفقراء برأسمال . .

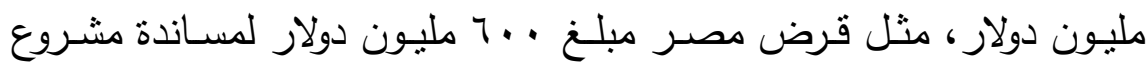

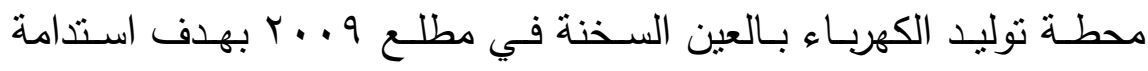

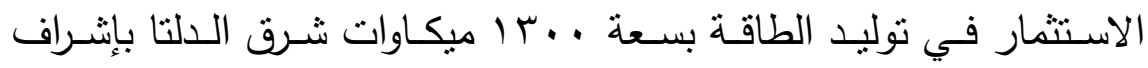

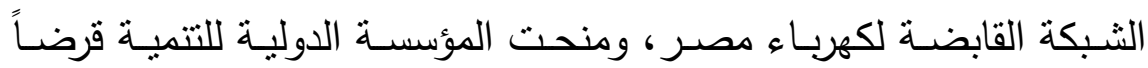


بقيمة •9 مليون دولار لمساندة الحكومة اليمنية لاستكمال استراتيجية قطاع

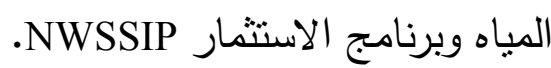

وقد تحلت بلدان الأسواق الصاعدة (مثل البرازيل والهند والصين ومقدونيا

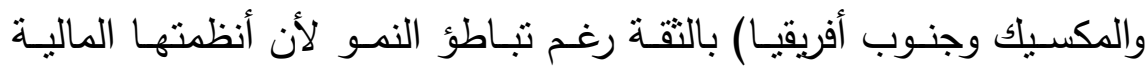

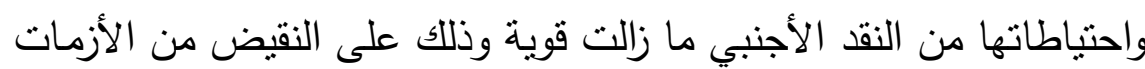

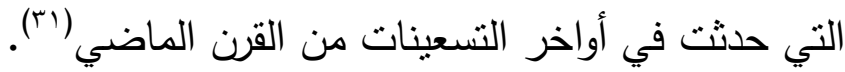

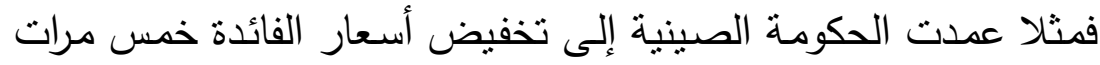

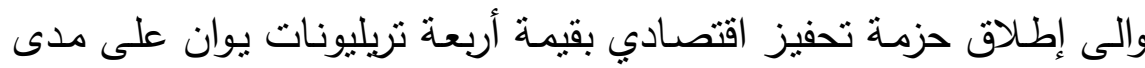

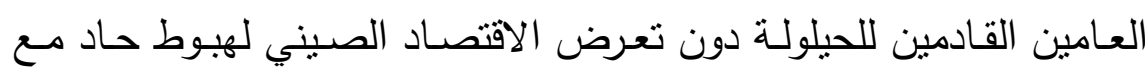

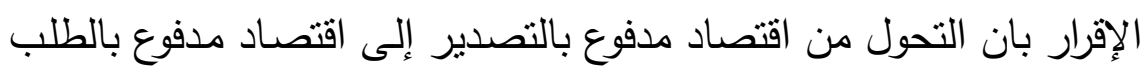

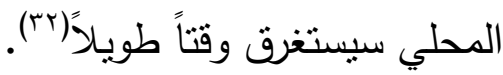

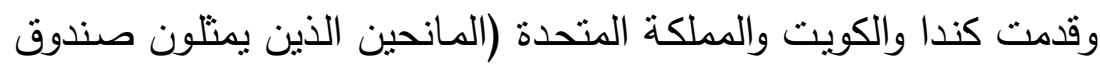

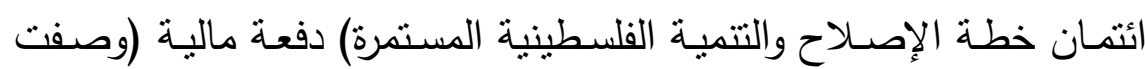

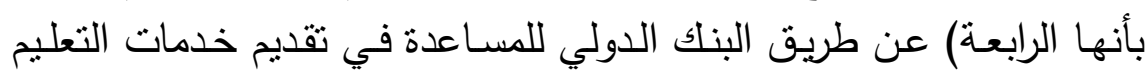

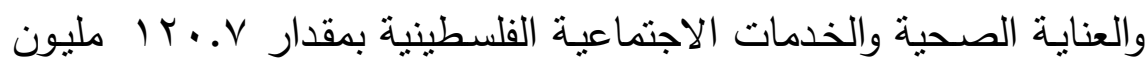

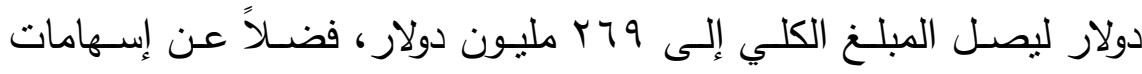

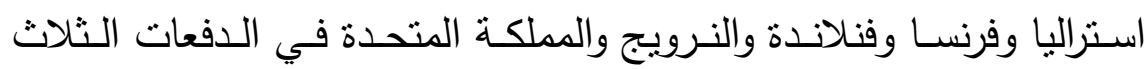

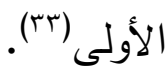
في الواقع ان اقتصـادات البلدان العربية المعروفة ببلدان الثرق الأوسط

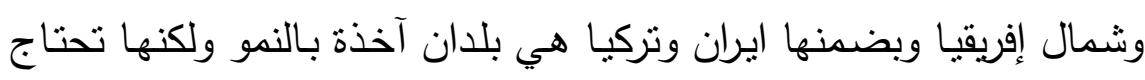

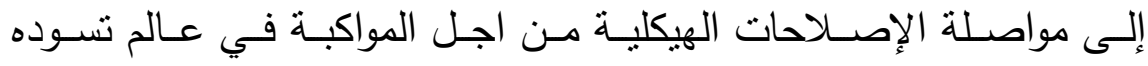

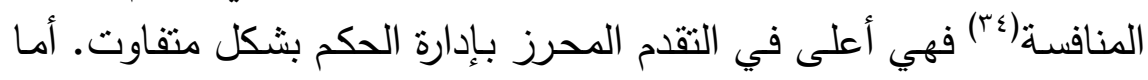

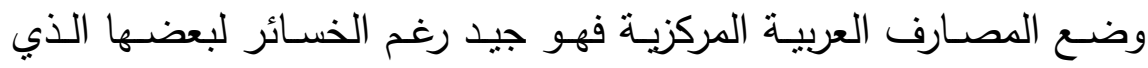
يتعامل بحرية كاملة مع الخارج(ror). 


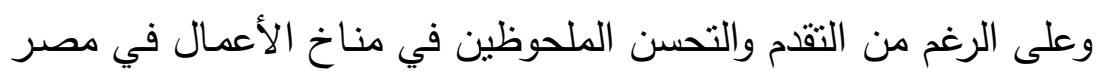

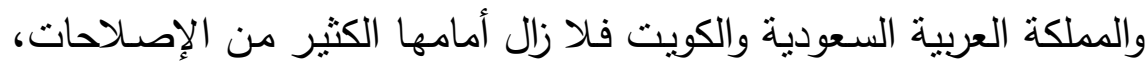

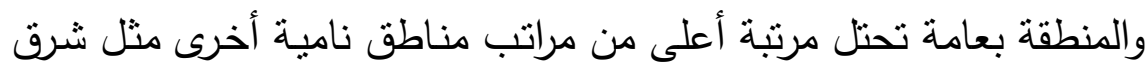

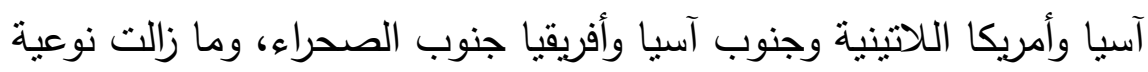

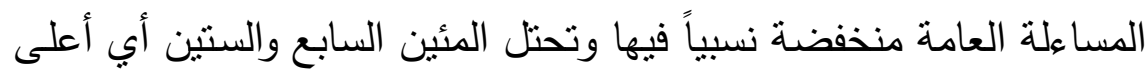

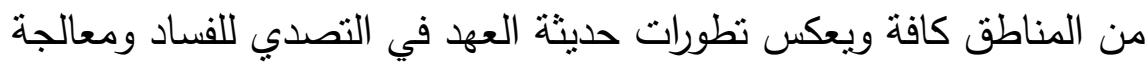

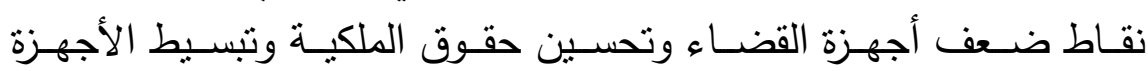
البيروقراطية وخاصة في بلدان مجلس التعاون الخليجي (َّماء).

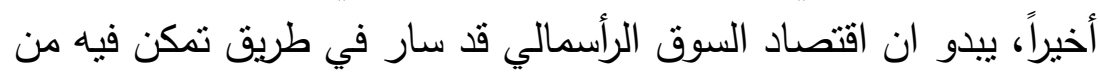

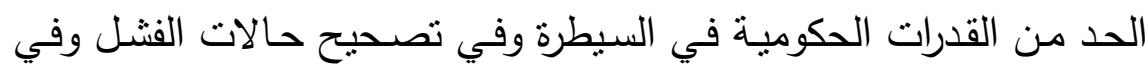

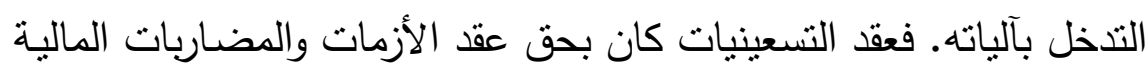

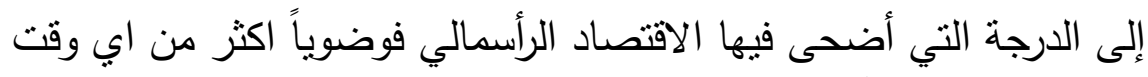

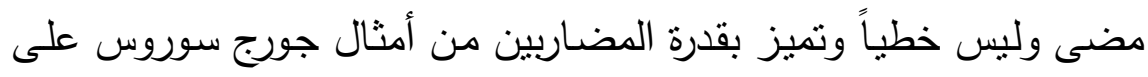

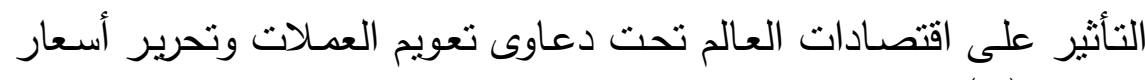

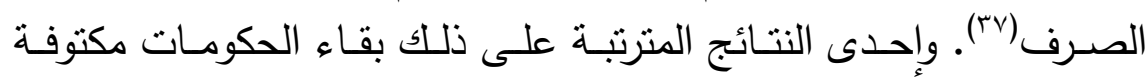

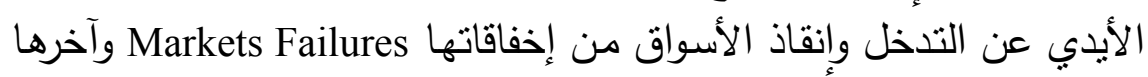

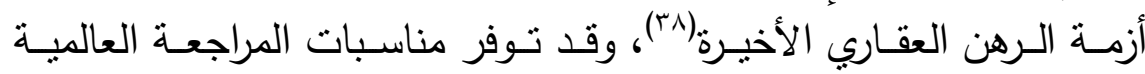

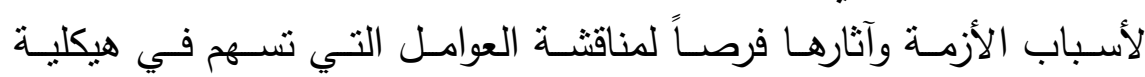

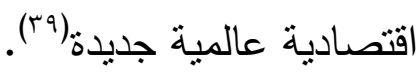

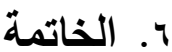

إذا كانت الأزمـة الماليـة جزء مـن ظـاهرة رأسمالية اعتاد عليها النظسام

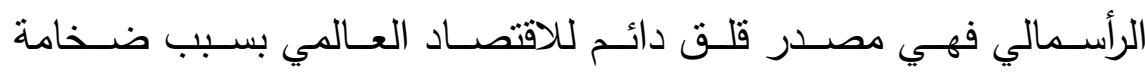


الاقتصـادات الغربية وبخاصـة الاقتصـاد الاميركي الذي يحتل •ـ \% منـه،

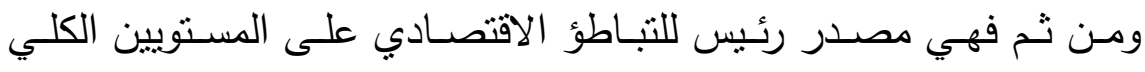
والجزئي لكل من الحكومات والثركات ومنظمات الأعمال في الاقتصادات الاتئ الإن المنفتحة على السوق العالمية.

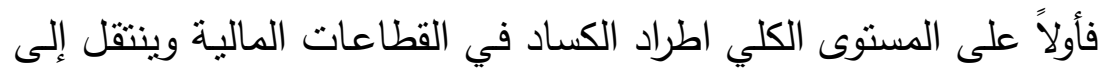

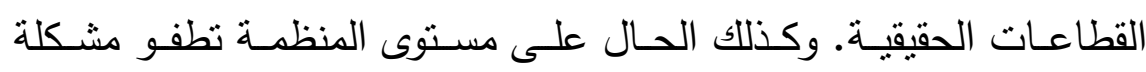

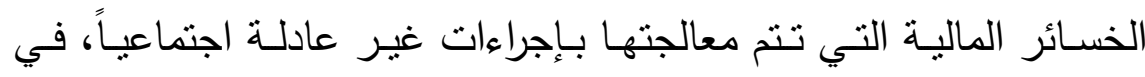

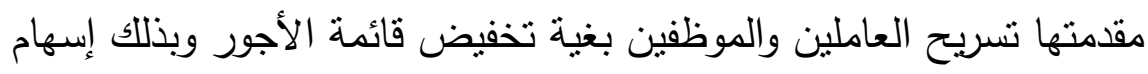

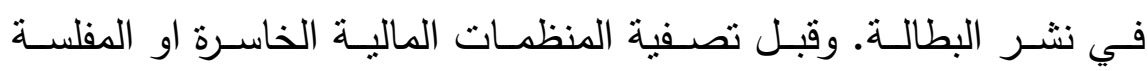

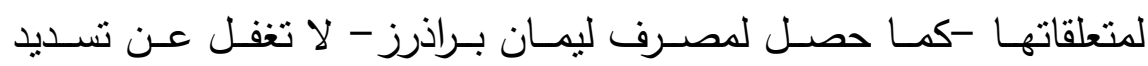

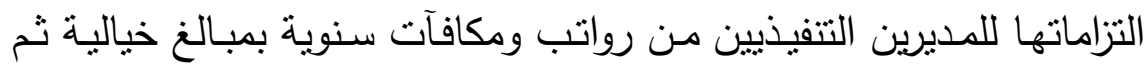

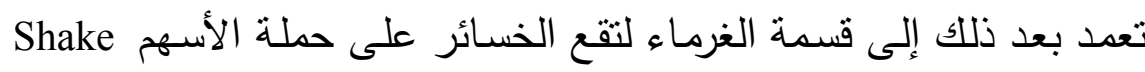
Holders

وعلى المستوى الفردي تتوزع الآثار على المدخرين الذين تنتراكم ادخارا

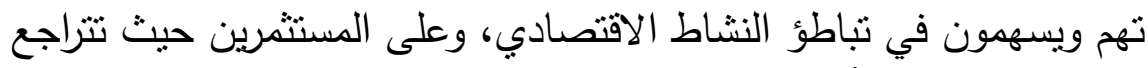

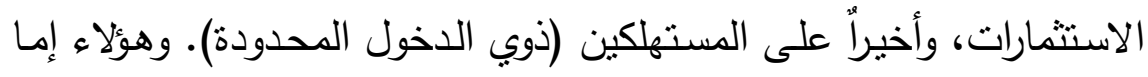

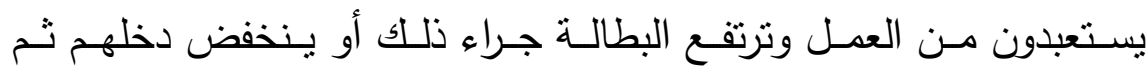

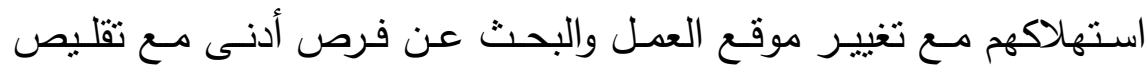

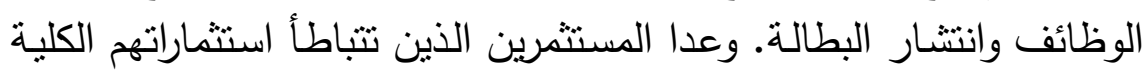

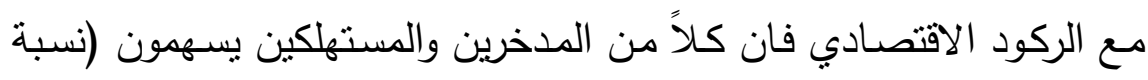

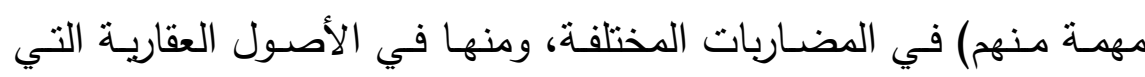

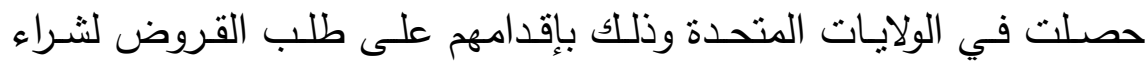

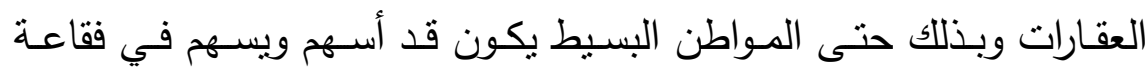

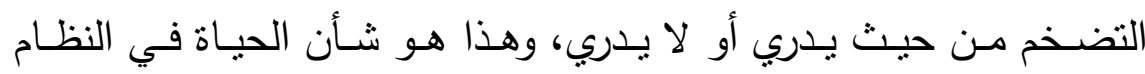


الرأسمالي غير المنضبط وهو يعمل تحت القوانين التـي كفلت لـه حريـة

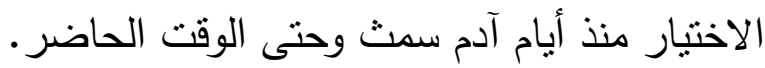

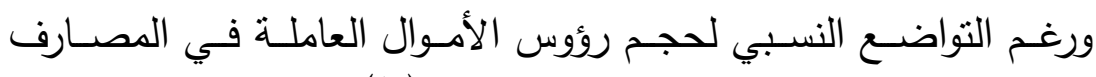

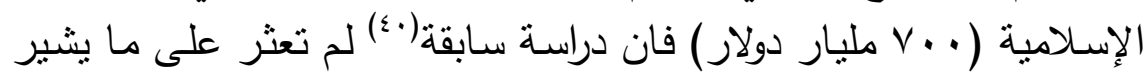

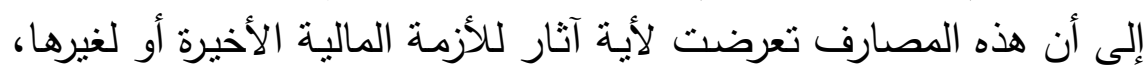

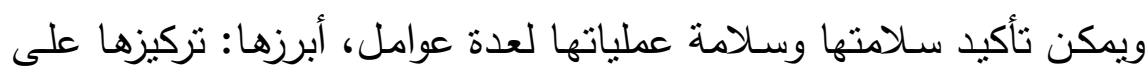

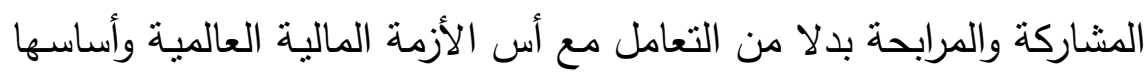

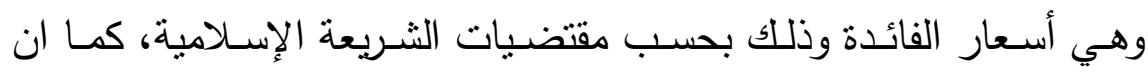

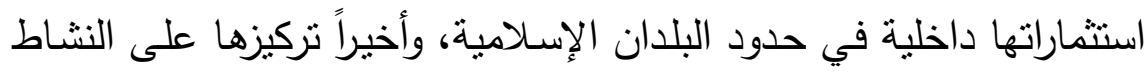

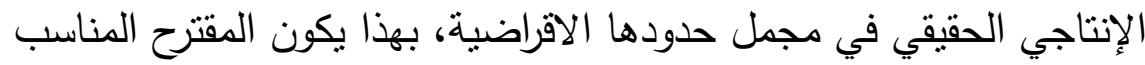

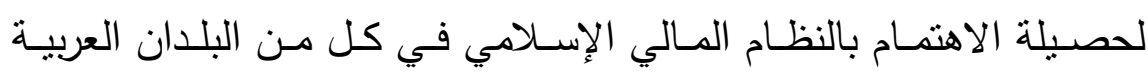

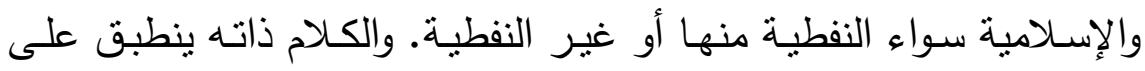

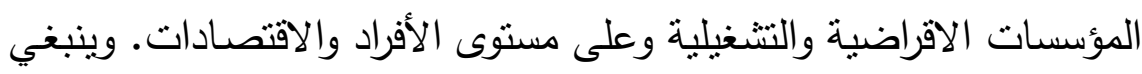

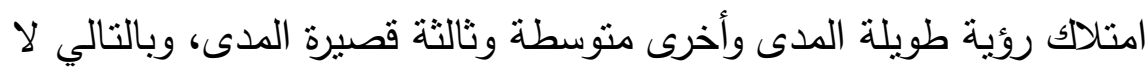

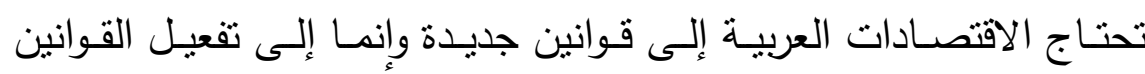

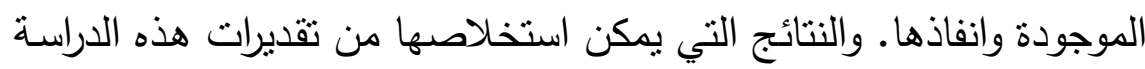

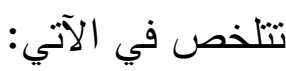
ا. ان أفضـل مـا عمدت اليـه النظم الرأسمالية مـن حلـول للأزمـة الماليـة

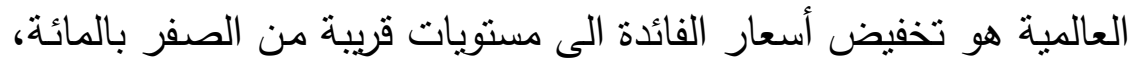

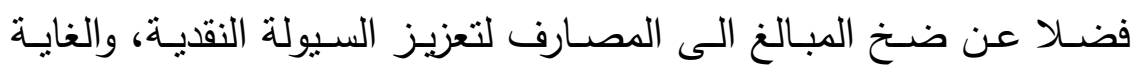

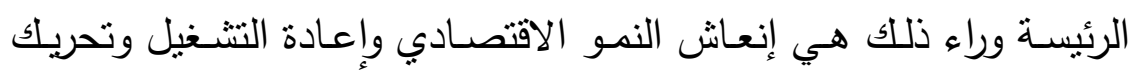

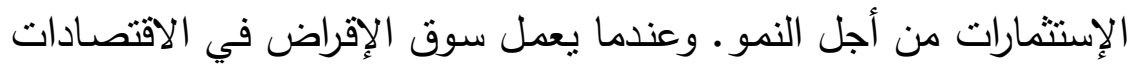

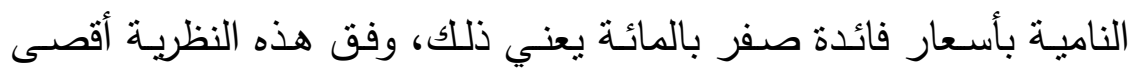

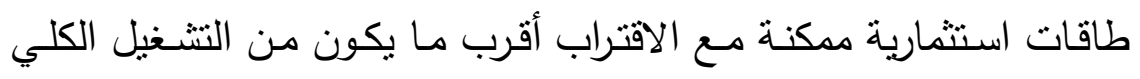




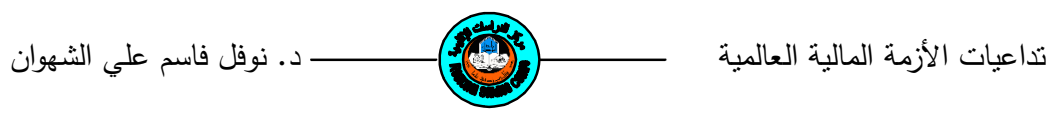

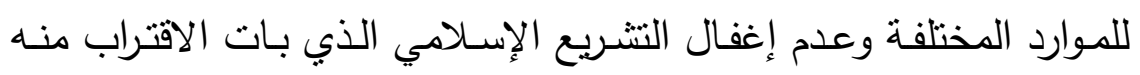
سبيلا في المعالجة لدى الغرب عن قصد أو دون قصد الغدال

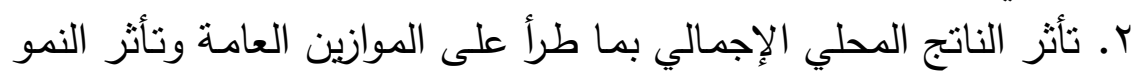
الاقتصادي بما طرأ على الميزان التجاري، وكما يأني:

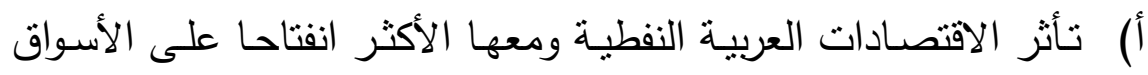
العالمية إذ أنها الأكثر تضررا بعد تفاقم حدة العجوزات في موازناتها العامة (ولم تتأثز معدلات نموها مباشرة بعد الأزمة بذللك).

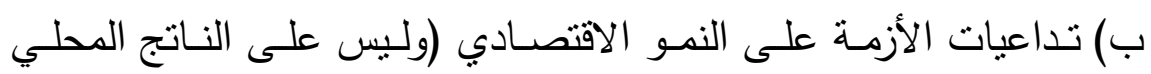

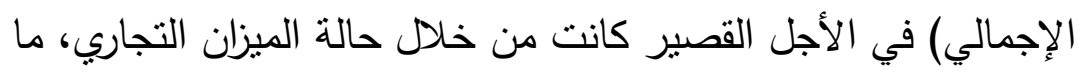

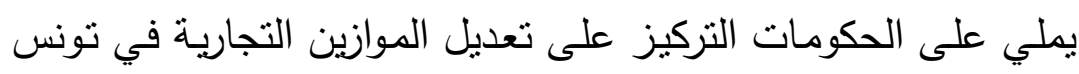
وجيبوتي ولبنان وكذلك في مصر والمغرب والأردن من أجل رفع وتائر النمو الاقتصادي في البلدان غير النفطية المذكورة آنفاً.

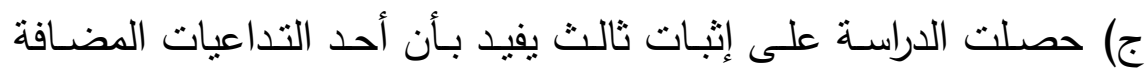

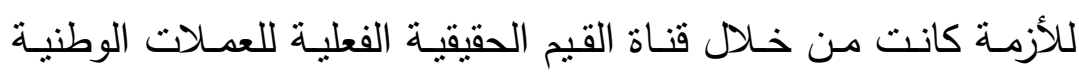
والتغيرات التي طرأت عليها. فتراجع الصـادرات الى الأسـواق العالميـة وخاصة صادرات الخامات النفطية يعود بآثار سلبية في كل من الناتج

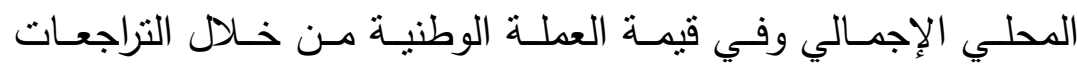

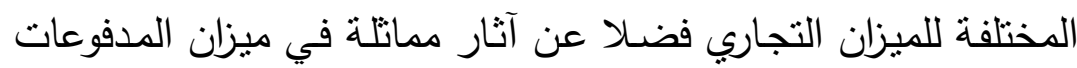

د) ومن خـلال التراجعات التي تطـرأ على الموازنـات العامـة للدولـة تتأثز

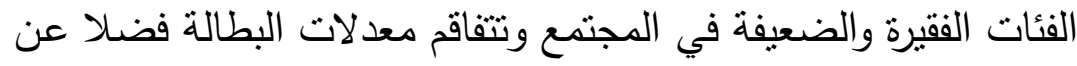

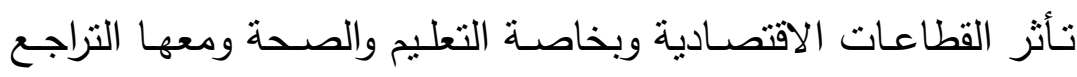
البيئي وفقرات الموازنة الأخرى. 
في ضـوء هذه النتائج توصـلت الدراسـة، في مقدمسة مجـالات المعالجـة

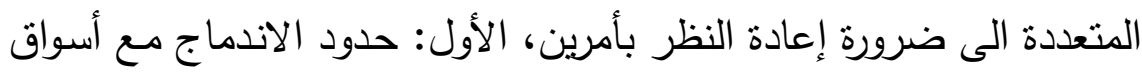

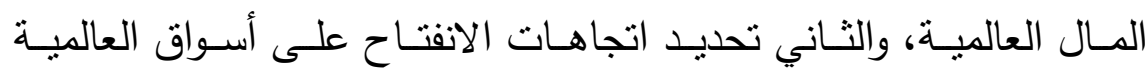

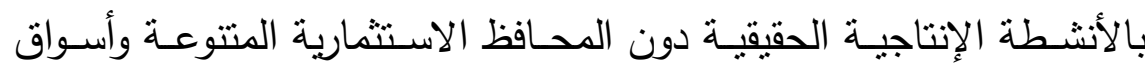

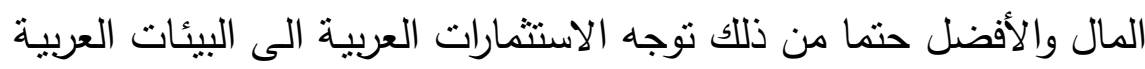

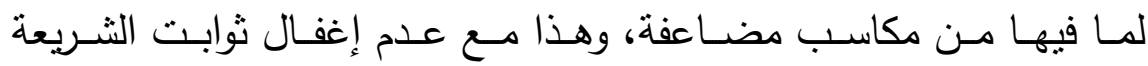

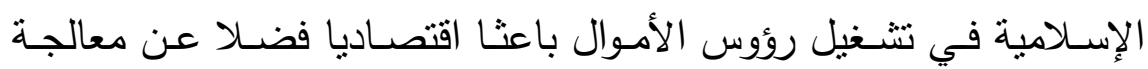

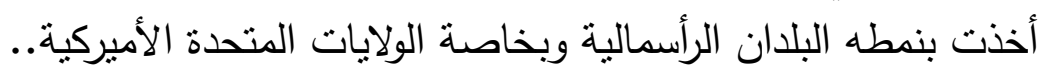




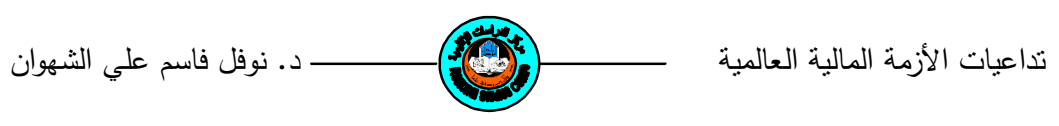

\title{
The Followers Of The Global Finance Crisis 2008 On The Arab Economies And The Remedy Scopes
}

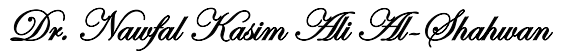 \\ Qlecturer, Eeconomic Pludies ODepartment. The Tenterfor Regional Pludies

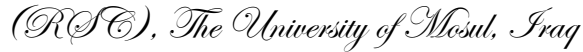

\begin{abstract}
This paper aims at analyzing the followers of the global finance crisis 2008, on the Arab economy's performance and diagnosing the remedy scopes. It estimates the transformed effects throughout the foreign trade relations for the Arab states on their GDPs and Economic Growth, before that crisis and after. There have been an indirect dramatic effects for it by the changes happened on trade balances, public finance budgets, and their currency exchange rates next that crisis. The paper has drawn many conclusions, pointing out two mean suggestions within the foresight driven remedies.
\end{abstract}

Fey words: Global Finance Crisis, Economic performance, The Arab Economies, and foreign trade relations.

الجدول-r ب بيانات البلان العربية المعبرة عن الأداء الاقتصادي ومعها المتغيرات المفترضة لنقل

الآثار الخارجية للأزمة

المالية العالمية

r...

\begin{tabular}{|c|c|c|c|c|c|c|c|c|c|c|c|c|c|}
\hline $\begin{array}{c}\text { Tr.Ba. } \\
\text { \%GDP } \\
\text { 2008 } \\
(12)\end{array}$ & $\begin{array}{c}\text { Tr.Ba. } \\
\text { \%GDP } \\
2007 \\
(11)\end{array}$ & $\begin{array}{c}\Delta \text { Exch. } \\
\text { Rate } \\
2008 \\
(10)\end{array}$ & $\begin{array}{c}\Delta \text { Exch. } \\
\text { Rate } \\
2007 \\
(9)\end{array}$ & $\begin{array}{c}\text { (Sur. Def. } \\
\text { \%GDP) } \\
2008 \\
(8)\end{array}$ & $\begin{array}{c}\text { (Sur.\&Def. } \\
\text { \% GDP) } \\
2007 \\
(7)\end{array}$ & $\begin{array}{c}\text { Sur.\&Def. } \\
\text { 2008 } \\
\text { (Ba.Bu.) } \\
\text { Million } \\
\text { US\$ } \\
\end{array}$ & $\begin{array}{c}\text { Sur.\&Def. } \\
\text { 2007 } \\
\text { (Ba.Bu.) } \\
\text { Million } \\
\text { US\$ } \\
\end{array}$ & $\begin{array}{c}\text { GDPG } \\
2008 \\
\% \\
(4)\end{array}$ & $\begin{array}{c}\text { GDPG } \\
2007 \\
\% \\
(3)\end{array}$ & $\begin{array}{c}\text { GDP } \\
\mathbf{2 0 0 8} \\
\text { Million } \\
\text { US\$ } \\
\text { (2) }\end{array}$ & $\begin{array}{c}\text { GDP } \\
\mathbf{2 0 0 7} \\
\text { Million } \\
\text { US\$ } \\
\text { (1) }\end{array}$ & البلا & \\
\hline 24.2 & 25.5 & 2.8 & -1.0 & 0.076 & 0.048 & 12.949 & 6.383 & 0.269541 & 0.143706 & 170.300 & 134.143 & Algeria & 1 \\
\hline 13.3 & 15.9 & -6.7 & -7.0 & 0.067 & 0.026 & 1.642 & 0.484 & 0.319347 & 0.163702 & 24.338 & 18.447 & Bahrain & r \\
\hline-62.8 & -50.1 & -6.2 & -4.1 & 0.013 & -0.026 & 0.012 & -0.022 & 0.158019 & 0.101299 & 0.982 & 0.848 & Djibouti & $r$ \\
\hline-12.1 & -11.6 & 11.4 & 2.6 & -0.068 & -0.073 & -11.089 & -9.574 & 0.247555 & 0.214094 & 162.640 & 130.367 & Egypt & $\varepsilon$ \\
\hline 20.6 & 31.6 & 0.0 & 0.0 & 0.205 & 0.203 & 22.595 & 14.748 & 0.523370 & 0.321628 & 110.423 & 72.486 & Iraq & 。 \\
\hline-33.8 & -37.9 & 5.5 & -2.5 & -0.046 & -0.051 & -0.977 & -0.866 & 0.248868 & 0.161782 & 21.237 & 17.005 & Jordan & 1 \\
\hline 43.2 & 37.9 & 7.2 & 0.4 & 0.225 & 0.157 & 33.300 & 17.975 & 0.293040 & 0.128372 & 148.163 & 114.585 & Kuwait & $\mathrm{v}$ \\
\hline-37.8 & -31.4 & 9.0 & 0.4 & -0.099 & -0.122 & -2.918 & -3.053 & 0.182718 & 0.116192 & 29.620 & 25.044 & Lebanon & $\wedge$ \\
\hline
\end{tabular}




\begin{tabular}{|c|c|c|c|c|c|c|c|c|c|c|c|c|c|}
\hline 48.5 & 45.6 & 5.8 & 0.4 & 0.296 & 0.278 & 22.683 & 17.769 & 0.201679 & 0.156210 & 76.732 & 63.854 & Libya & 9 \\
\hline 0.7 & 0.8 & 6.1 & -1.6 & -0.065 & -0.017 & -0.234 & -0.049 & 0.282370 & 0.044461 & 3.615 & 2.819 & Mauritania & 1. \\
\hline 28.4 & 24.9 & 1.1 & -0.4 & 0.003 & 0.003 & 0.204 & 0.112 & 0.439636 & 0.131372 & 59.945 & 41.639 & Oman & 11 \\
\hline 27.8 & 31.2 & -1.2 & 3.2 & 0.096 & 0.128 & 9.831 & 9.083 & 0.440056 & 0.251383 & 102.303 & 71.041 & Qatar & ir \\
\hline 5.8 & 2.0 & 2.1 & 5.3 & -0.027 & -0.025 & -1.643 & -1.418 & 0.079908 & 0.244089 & 61.085 & 56.565 & Sudan & 14 \\
\hline-9.8 & -8.1 & -0.2 & -2.6 & -0.036 & -0.019 & -1.485 & -0.684 & 0.146844 & 0.144573 & 40.885 & 35.650 & Tunisia & $1 \varepsilon$ \\
\hline 23.2 & 23.7 & 6.1 & 2.4 & 0.060 & 0.095 & 15.094 & 18.628 & 0.273969 & 0.167825 & 250.517 & 196.643 & UAE & 10 \\
\hline 0.5 & -1.9 & 26.1 & 3.5 & -0.043 & -0.062 & -1.293 & -1.530 & 0.209930 & 0.135100 & 28.708 & 23.727 & Yemen & 17 \\
\hline 45.2 & 39.2 & 2.3 & -2.8 & 0.330 & 0.123 & 154.913 & 47.081 & 0.221244 & 0.077820 & 468.800 & 383.871 & Saudi & IV \\
\hline-3.3 & -1.3 & 9.0 & 4.9 & -0.037 & -0.030 & -1.933 & -1.215 & 0.288648 & 0.221421 & 52.582 & 40.804 & Syria & 14 \\
\hline-22.4 & -18.7 & 1.3 & -0.3 & 0.004 & 0.004 & 0.349 & 0.335 & 0.114805 & 0.144461 & 83.743 & 75.119 & Morocco & 19 \\
\hline
\end{tabular}

الدصدر: الحقول: (1, 2, 5, 6, 9, 1) من الصدرين أدناه والباقي من احتساب الباحث، وكلك الحقلين (11, 12) محتسبة اعتمادا على

$$
\text { ذات المصدرين: }
$$

- صندوق النقد العربي، التقرير الاقتصادي العربي الموحد 2009، موقع الصندوق:

؛http://www.arabmonetaryfund.org/ar/jerep/2009

- صندوق النقد العربي، الإحصائيات المالية الدولية، أيلول 2009 وتقارير المادة الرابعة منها للمشاورات. 


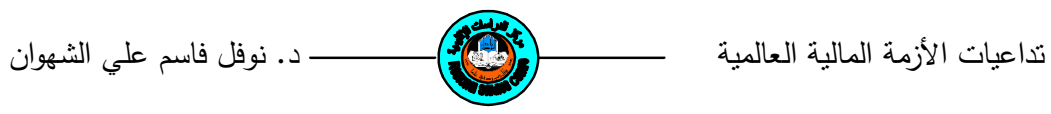

(1) Allen N. Berger, Leora F. Klapper, and Rima Turk-Ariss, "Bank Competition and Financial Stability, Policy Research Working Paper No. 4696, August 2008 .

$$
\text { (r) ( الدكتور حمدي عبد العظيק: (r) }
$$

http://www.aljazeera.net/nr/exeres/cb37aa3a-205f-4f3e-a601-c483206e0016.htm

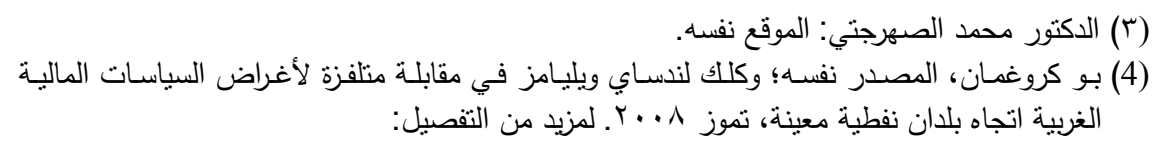

Lindsey Williams, View at a show: Prison Planet TV, Live on: Monday, July 28, 2008, on web: http://fr.youtube.com/watch?v=TKEWiFLxfGA\&feature=related. (5) Allen N. Berger, Leora F. Klapper, and Rima Turk-Ariss, Op. Cit.

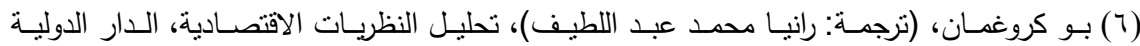

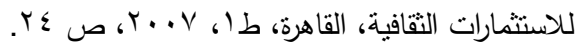

$$
\begin{aligned}
& \text { (v) صندوق النق الدولي، الاقتصاد العالمي على حافة الكساد، محاضرة مسجلة فيديوياً: }
\end{aligned}
$$

http://www.aljazeera.net/NR/exeres/6f2D106D-OA1F-4198-94D6-

B6EE80C0BIBD.HTM

(9) World Bank, The Unfolding Crisis: Implications for Financial Systems and Their Oversight, October 28, 2008.on: http://Worldbank.org/, Link:

FinanceCrisisandDevelopingCounties/November 11,2008

(· (1) للتفضيل حول مضامين الأزمة المالية ومدلولاتها للبلدان النامية، ينظر الوثيقة المرجعية التي أعدها

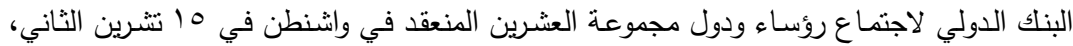

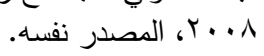

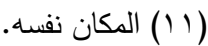

(12) Islamic Foundation Seminar (2008), UK, Asset-Based and Mortgage-Based Financial Products from an Islamic Perspective, Orientation Workshop and Research Seminar on The Islamic Foundation, London, forthcoming.

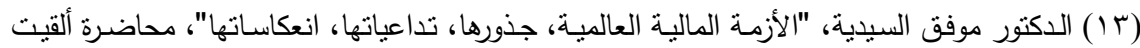

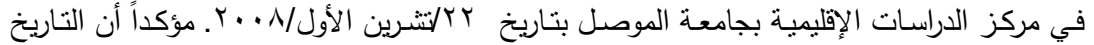

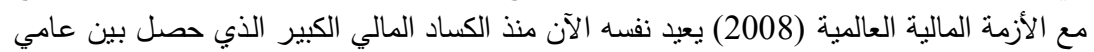

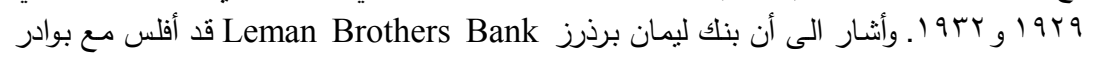

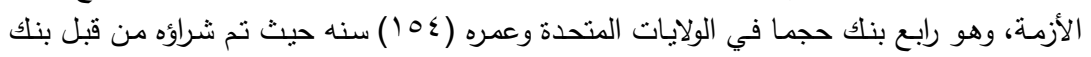

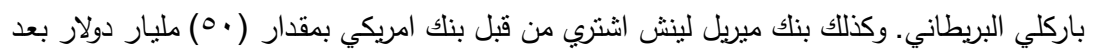

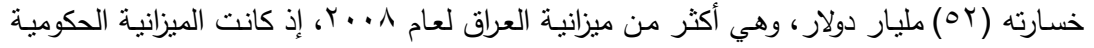




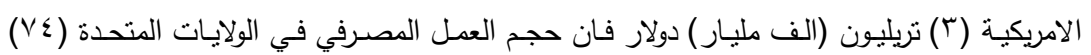

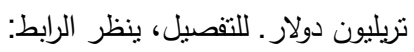

http://regionalstudiescenter.net/site/journals/Observations_files/TheGlobalFinanc ialCrisis2008.htm.

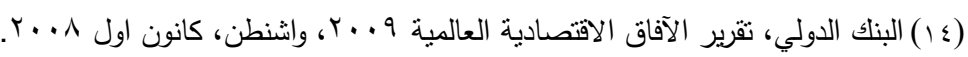

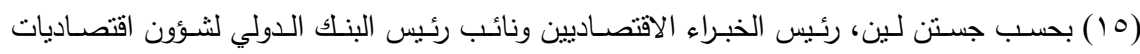

$$
\text { التتمية: المصدر نفسه. }
$$

(7 (1 ) تعمل مؤسسة التمويل الدولية IFC النابعة للبنك الدولي على توقيع مشروعات بحدود مائة مليار

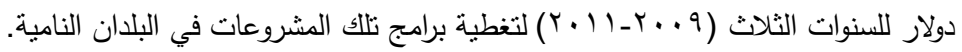

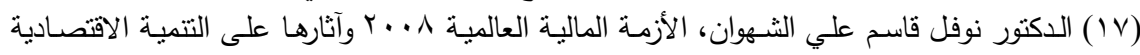

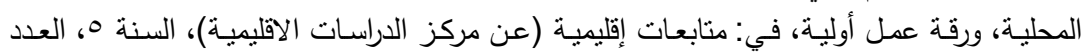

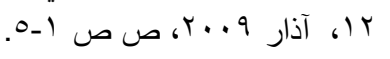

18 http://www.worldbank.ork/global/outlook, on: Feb. 25, 2009.

19 Op. Cit.

(·) جمهورية العراق، وزارة التخطيط والتعاون الإنمائي، دراسـة مقدمة إلى رئاسة مجلس الوزراء حول

$$
\text { الأزمة، برقم العراق }
$$

(Y) البنك الدولي، مجموعة بحوث التتمية، الدروس الدستقاة من بحوث البنك الدولي الخاصة بالأزمات

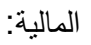

http://econ.worldbang.org/external/default/main?pagepk=6H/65259

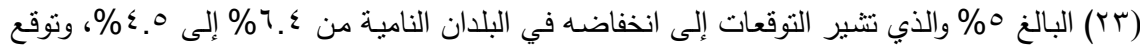

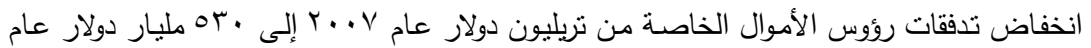

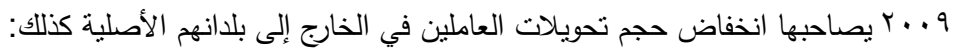

- Follow-Up International Conference on Financing for Development to Review the Implementation of the Monetary Consensus. Doha, Qatar, Nov.29-Dec.2, 2008.

(24) www.worldbank.org/html/extdr/financialcrisis.

$$
\begin{aligned}
& \text { (ro) بحسب اوجستي كوامي القائم بأعمال كبير الخبراء الاقتصاديين (لاى البنك الدولي) في إدارة منطقة }
\end{aligned}
$$

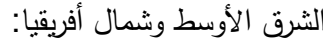

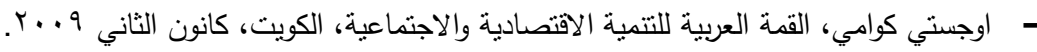

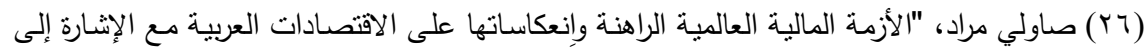

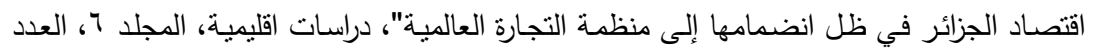

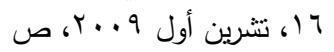




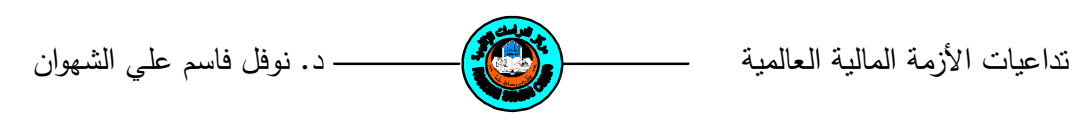

(rV) اوجستي كوامي، الصدر نفسه، واللقاء الذي نثر على موقع البنك الدولي منشور كذلك على موقع

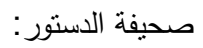

http://addustour.com/ViewTopic.aspx?ac $=\mid$ Economy $\backslash 2009 \backslash 02 \backslash$ Economy issue 50 9 day 28 id $120615 . \mathrm{htm}$

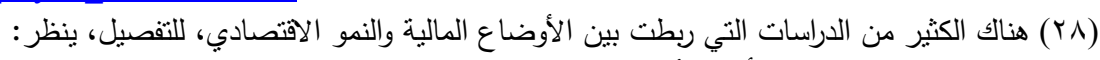

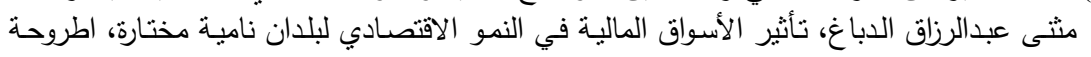

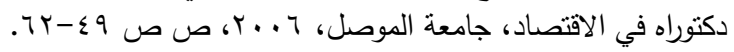

(29) http://go.worldbank.org/9G7Z3UAMUO.

(30) Op. Cit.

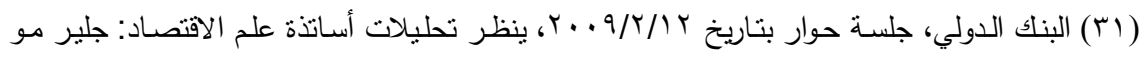

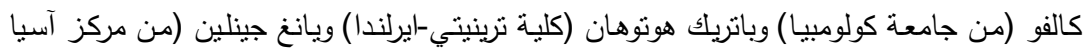

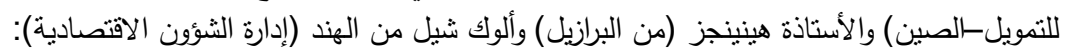

http://go.worldbank.org/GoBONNKLO.

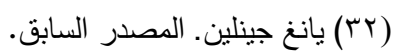

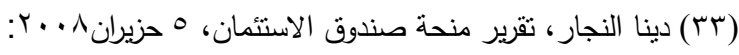

http://go.worldbank.ork/PAILTJP6PO

(؟) عمر كراسابان. مطبوعة الآفاق والتطورات الاقتصادية في منطقة الثرق الأوسط وشمال أفريقيا

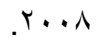

(ب0) عدنان أحمد يوسف، (لقاء مـع رئيس اتحاد المصارف العربية والرئيس التنفيذي لمجموعة البركة

المصرفية)

(דب) كارلوس سلفا (رئيس خبراء الاقتصـاد)، تقرير الآفاق والتطورات الاقتصادية في منطقة الثـرق

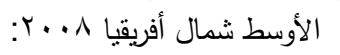

http://go.worldbank.ork/45279X96RO

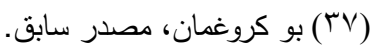

(38) The Financial Crisis and Microfinance: Experience, Insights, and Implications, Virtual Conference on the Financial Crisis, November 18-20, 2008: http://www.cgap.org/p/site/c/template.rc/1.26.3807

(ج" دكتور عمر محمد احمد بن سليمان، الكلمة الافتتاحية للقمة الثانية لمراكز المال العالمية، لندن،

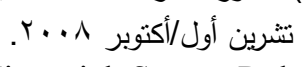

(40) Nawfal K. Ali Al-Shahwan, "Developing The Financial Sector Role In Sustainable Development In Iraq", workin paper presented at the 5th Congress of Scientific Research Outlook in the Arab World: "Scientific Innovation and Sustained Development" 26-30 October 2008, Fez-Morocco. 
دراسات إقليمية (1) 